PNNL-13372

WTP-RPT-003, Rev. 0

(Formerly BNFL-RPT-035)

$\because \mathrm{CEVBEO}$

NOV 162000

OS.TI

\title{
Vitrification and Product Testing of AW-101 and AN-107 Pretreated Waste
}

\author{
G. L. Smith \\ L. R. Greenwood \\ G. F. Piepel \\ M. J. Schweiger \\ H. D. Smith \\ M. W. Urie \\ J.J. Wagner
}

October 2000

Prepared for CH2M Hill Hanford Group, Inc. under Project Number 41503

Pacific Northwest National Laboratory Richland, Washington 99352 


\section{DISCLAIMER}

This report was prepared as an account of work sponsored by an agency of the United States Government. Neither the United States Government nor any agency thereof, nor any of their employees, make any warranty, express or implied, or assumes any legal liability or responsibility for the accuracy, completeness, or usefulness of any information, apparatus, product, or process disclosed, or represents that its use would not infringe privately owned rights. Reference herein to any specific commercial product, process, or service by trade name, trademark, manufacturer, or otherwise does not necessarily constitute or imply its endorsement, recommendation, or favoring by the United States Government or any agency thereof. The views and opinions of authors expressed herein do not necessarily state or reflect those of the United States Government or any agency thereof. 


\section{DISCLAIMER}

Portions of this document may be illegible in electronic image products. Images are produced from the best available original document. 


\section{Summary}

The U.S. Department of Energy (DOE) Office of River Protection (ORP) is acquiring Hanford tank waste treatment services at a demonstration scale. The River Protection Project Waste Treatment Plant (RPP-WTP) team is responsible for producing an immobilized (vitrified) low-activity waste (ILAW) waste form. Pacific Northwest National Laboratory, hereafter referred to as PNNL, has been contracted to produce and test a vitrified ILAW waste form from the Envelope $A$ and $C$ low activity (LAW) samples previously supplied to the RPP-WTP project by DOE.

The primary objective for vitrifying the LAW samples is to generate glass products for subsequent product testing. The work presented in this report is divided into 5 work elements: 1) Glass Fabrication, 2) Chemical Composition, 3) Radiochemical Composition, 4) Crystalline and Noncrystalline Phase Determination, and 5) Release Rate (Modified PCT). These work elements will help demonstrate the RPP-WTP projects ability to satisfy the product requirements concerning, chemical and radionuclide reporting, waste loading, identification and quantification of crystalline and non-crystalline phases, and waste form leachability. VOA, SVOA, dioxins, furans, PCBs, and total cyanide analyses will be reported in as separate document (WTP-RPT-005).

Two pretreated tank supernates, low-activity wastes (241-AW-101 and 241-AN-107) along with a process simulant (termed the Process Blank) were prepared as melter feeds for vitrification. The analyzed compositions of the pretreated AW-101 and AN-107 wastes were used by Catholic University of America's (CUA) Vitreous State Laboratory (VSL) to calculate the target glass composition.

The two supernate tank samples, i.e. 241-AW-101 and 241-AN-107, hereafter referred to as AW-101 and AN-107, were processed through pretreatment chemical separation processes, and the decontaminated supernates were converted to low-activity waste (LAW) glass. The AW-101 supernate sample was processed through the following unit operations to simulate the RPP-WTP project flowsheet: 1) dilution of the feed; 2) ultrafiltration to remove entrained solids; 3 ) removal of ${ }^{137} \mathrm{Cs}$ by ion exchange; and 4) removal of ${ }^{99} \mathrm{Tc}$ by ion exchange. The AN-107 supernate sample was processed through the following unit operations to simulate the RPP-WTP project flowsheet: 1) dilution of the feed;2) removal of Sr/TRU by precipitation; 3) ultrafiltration to remove entrained solids and precipitated Sr/TRU; 4) removal of ${ }^{137} \mathrm{Cs}$ by ion exchange; 5 ) removal of ${ }^{99} \mathrm{Tc}$ by ion exchange; and 6) removal of sulfate $\left(\mathrm{SO}_{4}\right)$ by precipitation. Product testing of the LAW waste forms, as prescribed by the RPP-WTP project, was performed by PNNL to support Phase 1B deliverables.

Glass former additives (Kyanite $\left(\mathrm{Al}_{2} \mathrm{SiO}_{5}\right)$; Orthoboric acid, $\left(\mathrm{H}_{3} \mathrm{BO}_{3}\right)$; Wollastonite $(\mathrm{CaSiO})$; Red Iron Oxide Pigment $\left(\mathrm{Fe}_{2} \mathrm{O}_{3}\right)$; Olivine $\left(\mathrm{Mg}_{2} \mathrm{SiO}_{4}\right)$; Silica sand $\left(\mathrm{SiO}_{2}\right)$; Rutile Ore $\left(\mathrm{TiO}_{2}\right)$; Zinc Oxide $(\mathrm{ZnO})$; Zircon sand $\left(\mathrm{ZrSiO}_{4}\right)$; and sugar) were added to each pretreated waste to produce a melter feed. The AW-101 and AN-107 melter feeds were dried, calcined, and melted at $1150^{\circ} \mathrm{C}$ for one hour. Each melt was then poured onto a stainless steel plate, cooled, crushed to a fine powder, mixed, and added back into the crucible, and melted for an additional hour at $1150^{\circ} \mathrm{C}$. The final $\mathrm{AW}-101$ melt pour was excellent, estimated viscosity of about $5 \mathrm{~Pa}$. $s$ based on visual observation coupled with past experience, and bubbles present in the meniscus burst while being poured. The final AN-107 melt pour was excellent as well, with an estimated viscosity of about 8 to $10 \mathrm{~Pa} \cdot \mathrm{s}$, based on visual observation. Some bubbles present in the meniscus were observed during pouring and a slight vapor of volatile components was observed when the lid was removed from the crucible during pouring. The first portion of each pour went into a platinum crucible for the canister centerline cooling test and the remainder of the melt was quenched on a stainless steel plate. 
Vitrification of slurry melter feed in an actual liquid-fed ceramic melter (LFCM) progresses continuously through 3 distinct stages, drying, calcining and melting. Under steady-state operating conditions, the aqueous slumy that is introduced into the high-temperature melter environment spreads out over an existing cold cap where it dries and becomes part of the melter cold-cap structure. This dried material begins working its way down through the cold-cap as it becomes submerged in incoming feed while, at the same time, material, at the molten-glass/cold-cap interface, is dissolving into the glass melt. During this continuous progression through the cold cap, the temperature that the feed is subjected to monotonically increases from the boiling point of water $\left(\sim 100^{\circ} \mathrm{C}\right)$ to molten glass temperatures $(\sim 1100$ ${ }^{\circ} \mathrm{C}$ ). Accompanying this continuous physical and thermal transition, inorganic eutectic salts are slowly converted to their oxide forms (calcined) that are suitable for subsequent incorporation into the melter's molten glass pool.

All of these discrete phases of liquid-fed ceramic melter feed processing have been faithfully reproduced in the crucible studies performed. What may not be truly represented, however, is the complex stages and nature of the cold-cap chemistry that results in the calcination of the feed material. For non-volatile, inorganic feed constituent, the differences between crucible and melter vitrification conditions are inconsequential. For all other feed components, cold-cap chemistry can influence both partitioning behavior and chemical byproduct yields, which, in turn, can and will affect the resultant glass product.

Consequently to properly represent an LFCM glass product, actual physical and chemical processing conditions need to be replicated. But since this requires the development of a representative cold-cap structure, nothing short of a liquid-fed melting process (e.g., scaled melter or possibly a gradient furnace test) is truly adequate. However, relationships drawn between previous crucible and actual melter testing results, i.e. from VSL and GTS Duratek testing, that were conducted using a fixed feed may be useful in extracting reference glass-product quality parameters from extrapolated crucible test data.

The measured composition of the AW-101 and AN-107 glasses are fairly close to their target compositions. Per the RPP-WTP project LAW glass Task Specification, the concentration of the waste sodium oxide shall be greater than $16 \mathrm{wt} \%$. The target concentration of sodium oxide for both glasses is $20 \mathrm{wt} \%$. The measured wt\% sodium oxide content for the AW-101 and AN-107 glasses are 17.7 and 18.3 , respectively. As all of the sodium oxide content for the AW-101 glass originated from the initial tank waste, the AW-101 glass exceeds the Task Specification, sodium oxide concentration level of 16 weight percent easily considering only the measured wt\% sodium oxide content. Based upon past experience, the measured weight percentage for $\mathrm{Na}_{2} \mathrm{O}$ is almost always lower than its true weight percentage, which provides an even larger margin of passing the Task Specification requirement. Note that as discussed in Section 4.1.2, $\mathrm{Na}_{2} \mathrm{O}$ and $\mathrm{SiO}_{2}$ analyzed by ICP-AES are almost always lower than their true weight percentage because of analytical difficulties associated with these elements. However, not all of the sodium oxide content for the AN-107 glass originated from the initial tank waste. As $79.2 \%$ of the sodium oxide content for the AN-107 glass originated from the initial tank waste, for the AN-107 glass to meet the Task Specification, sodium oxide concentration level of 16 weight percent the wt\% sodium oxide content of the glass would need to be $20 \mathrm{wt} \%$ which is the target concentration. Again, based upon past experience, the measured weight percentage for $\mathrm{Na}_{2} \mathrm{O}$ wt\% values are almost always lower than its true weight percentage. For this reason, the target $\mathrm{Na}_{2} \mathrm{O}$ value is used as the true weight percent oxide value for the ILAW glasses. Therefore, the original, as-received AN-107 waste is determined to meet the Task Specification for waste loading of the AN-107 glass. The ORP Contract Specification 2, Immobilized Low-Activity Waste, Section 2.2.2.2, Waste Loading, states: "The loading of waste sodium from Envelope A in the ILAW glass shall be greater than 14 weight percent based on $\mathrm{Na}_{2} \mathrm{O}$. The loading of waste sodium from Envelope $\mathrm{B}$ in the ILAW glass shall be greater than 5.0 weight percent based on $\mathrm{Na}_{2} \mathrm{O}$. The loading of waste sodium from Envelope $\mathrm{C}$ in the ILAW glass shall be 
greater than 10 weight percent based on $\mathrm{Na}_{2} \mathrm{O}$." Therefore, additionally, both the AW-101 (Envelope $\mathrm{A}$ ) and AN-107 (Envelope C) glasses easily meet the ORP contract specifications for waste sodium loading. The percent difference in the measured wt $\%$ oxide values for components in the AW-101 glass as compared to the targeted wt $\%$ oxide values are $0.3 \%$ for alumina, $3 \%$ for boron oxide, $1.5 \%$ for calcium oxide, $8.8 \%$ for iron oxide, $19 \%$ for potassium oxide, $5.4 \%$ for magnesium oxide, $11.7 \%$ for soda, $4.3 \%$ for silica, $13.7 \%$ for titania, $4 \%$ for zinc oxide, and $14.4 \%$ for zirconia. The percent difference in the measured wt\% oxide values for components in the $\mathrm{AN}-107$ glass as compared to the targeted wt\% oxide values are $1.9 \%$ for alumina, $4.3 \%$ for boron oxide, $2 \%$ for calcium oxide, $8.8 \%$ for iron oxide, $4.9 \%$ for magnesium oxide, $8.4 \%$ for soda, $4.4 \%$ for silica, $6.7 \%$ for titania, $2.8 \%$ for zinc oxide, and $9.6 \%$ for zirconia.

The waste loading was calculated from the dilution factor (decrease in concentration) of elements contained in either the waste or the glass forming additives. The results indicate that the waste fraction of each glass is near their target, i.e. $26.15 \%$ for AW-101 (28.64\% based on waste dilution and $26.88 \%$ based on additive dilution) and $21.4 \%$ for AN-107 (26.04 \% based on waste dilution and $20.34 \%$ based on additive dilution). The measured glass to target composition percent difference comparison of the oxides is small and the calculated waste loading values are very close to or exceed the target. Both support the conclusion that the actual waste loading in each glass met and exceeded the target waste loading.

Based on identification and quantification of radionuclides found in the pretreated wastes and a comparison to radionuclides identified as significant in NUREG/BR-0204 and 49CFR 172.101 (Table 2), the radionuclides to be measured in the AW-101 and AN-107 glasses were determined and analytically measured. In addition, to further demonstrate that the glass product, radionuclide compositional limits were met a radionuclide glass compositional estimate based on sample analysis of the pretreated wastes was completed for both the AW-101 and $\mathrm{AN}-107$ glasses as volatilization of radionuclides may occur during vitrification in crucible melts. ${ }^{90} \mathrm{Sr},{ }^{99} \mathrm{Tc},{ }^{137} \mathrm{Cs}$, and transuranic (TRU) radionuclide values were checked to make sure the glass product met or exceeded the contract success criteria. The estimated glass composition concentrations for ${ }^{90} \mathrm{Sr}$ passed the contract success criteria for both glasses. The estimated glass composition concentrations for ${ }^{99} \mathrm{Tc}$ passed the contract criteria for the AW-101 glass. The estimated glass composition concentrations for ${ }^{99} \mathrm{Tc}$ did not pass the contract criteria for the AN-107 glass. However, Blanchard et al. 1999 have previously shown that an Envelope A waste (e.g. AW-101) can be ${ }^{99} \mathrm{Tc}$ ion exchange decontaminated to a level much below the contract ILAW glass limit. This would allow a sufficient amount of ${ }^{99} \mathrm{Tc}$ to be removed from the AW-101 and AN-107 wastes so that the average ${ }^{99} \mathrm{Tc}$ concentration in the ILAW glass produced would meet or exceed the contract specification. The estimated glass composition concentrations for ${ }^{137} \mathrm{Cs}$ passed the contract success criteria for the AW-101 and AN-107 glasses. And finally, the estimated glass composition concentration analysis for the transuranic (TRU) radionuclides shows that both glasses pass the contract success criteria.

Identification and quantification of crystalline and non-crystalline phases were completed by using $x$-ray diffraction (XRD), optical microscopy, and scanning electron microscopy (SEM). Samples of both LAW glasses (AW-101 and AN-107) were given a slow cool down heat treatment which simulated the calculated cooling profile for glass at the centerline of a LAW canister being filled with an $1150^{\circ} \mathrm{C}$ waste glass and allowed to cool to ambient temperature. No crystals were observed in any of the glass samples examined as determined by XRD, optical microscopy, and SEM evaluations.

The ultimate objective for immobilization of the low activity waste is to incorporate and convert the radioactive and hazardous components into a solid glassy waste form that will resist their release to the environment in a Hanford near-surface burial ground. This resistance of the waste form to release deleterious environmental components is defined by measuring its chemical durability, i.e. the resistance 
of the glass to react with the aqueous environment expected in the glass disposal site. However, to mimic the mean temperature, amount and frequency of available ground waster, etc. expected in the near-surface repository would require a great amount of testing time to be able to detect glass

dissolution. Therefore, an accelerated chemical durability test, the Product Consistency Test (PCT), is employed to gauge the ILAW glass chemical durability. The PCT was run at 40 and $90^{\circ} \mathrm{C}$, using glass samples given a slow cool down heat treatment which simulates the cooling profile for glass at the center line of a canister that has been filled with a waste glass and allowed to cool to ambient temperature, to determine the normalized release of sodium, silicon, and boron. The low-activity test reference material (LRM) standard glass was included in these tests to provide a reliable baseline of results by which to judge the quality of the PCT results for the AW-101 and AN-107 glasses. Note: Vapor Hydration Test's (VHT) were not required as part of the ORP, Part B-1 contractual work and therefore were not part of this scope of work. However, VHT testing of ILAW glasses will be required in the future as another measure of chemical durability .

Both the AW-101 and AN-107 glasses and the LRM glass gave a normalized sodium, silicon, and boron release rates of less than $1 \mathrm{~g} / \mathrm{m}^{2}$ for the $90^{\circ} \mathrm{C} \mathrm{PCT}$ test, which is generally considered to indicate a durable glass. In the present study, the normalized sodium, silicon, and boron $90^{\circ} \mathrm{C} \mathrm{PCT}$ release rates for the AW-101, AN-107, and LRM glasses are: 1) $0.6 \mathrm{~g} / \mathrm{m}^{2}, 0.2 \mathrm{~g} / \mathrm{m}^{2}$, and $0.6 \mathrm{~g} / \mathrm{m}^{2}$;2) 0.4 $\mathrm{g} / \mathrm{m}^{2}, 0.2 \mathrm{~g} / \mathrm{m}^{2}$, and $0.4 \mathrm{~g} / \mathrm{m}^{2}$; and 3) $0.5 \mathrm{~g} / \mathrm{m}^{2}, 0.2 \mathrm{~g} / \mathrm{m}^{2}$, and $0.5 \mathrm{~g} / \mathrm{m}^{2}$; , respectively. The normalized sodium, silicon, and boron $40^{\circ} \mathrm{C} \mathrm{PCT}$ release rates for the AW-101, AN-107, and LRM glasses are: 1) $0.09 \mathrm{~g} / \mathrm{m}^{2}, 0.03 \mathrm{~g} / \mathrm{m}^{2}$, and $0.05 \mathrm{~g} / \mathrm{m}^{2}$; 2) $0.07 \mathrm{~g} / \mathrm{m}^{2}, 0.03 \mathrm{~g} / \mathrm{m}^{2}$, and $0.04 \mathrm{~g} / \mathrm{m}^{2}$; and 3) $0.07 \mathrm{~g} / \mathrm{m}^{2}, 0.02 \mathrm{~g} / \mathrm{m}^{2}$, and $0.02 \mathrm{~g} / \mathrm{m}^{2}$; respectively, which again indicates that the ILAW glasses from this study are similar in durability to the LRM reference glass indicating good durability. In addition, the normalized release rates of sodium, silicon, and boron from the AW-101 and AN-107 glasses are less than $2.0 \mathrm{~g} / \mathrm{m}^{2}$, the contract success criteria. 


\section{Terms and Abbreviations}

\begin{tabular}{|c|c|}
\hline AES & Atomic emission spectroscopy \\
\hline ALO & Analytical Laboratory Operations \\
\hline ARG-1 & Analytical Reference Glass-1 \\
\hline ASTM & American Society for Testing and Materials \\
\hline $\mathrm{CCC}$ & canister centerline cooling \\
\hline CFR & Code of Federal Regulations \\
\hline $\mathrm{CMC}$ & Chemical management center \\
\hline Cs IX & cesium ion exchange \\
\hline CUA & Catholic University of America \\
\hline DI & Deionized \\
\hline DIW & deionized water \\
\hline DL & Detection level \\
\hline DOE & U.S. Department of Energy \\
\hline DOE-RL & U.S. Department of Energy-Richland Operations Office \\
\hline EDS & Energy dispersive spectroscopy \\
\hline EPA & Environmental Protection Agency \\
\hline EQL & estimated quantification limit \\
\hline g & gram \\
\hline GEA & Gamma energy analysis \\
\hline HLW & High level waste \\
\hline IC & Ion chromatography \\
\hline ICP-AES & inductively coupled plasma-atomic emission spectroscopy \\
\hline ICP-MS & inductively coupled plasma-mass spectroscopy \\
\hline ICV & initial calibration verification \\
\hline ILAW & immobilized low activity waste \\
\hline $\mathrm{L}$ & Liter \\
\hline LAW & Low activity waste \\
\hline LCS & Laboratory control standard \\
\hline LEPS & low-energy photon spectrometry \\
\hline LRM & Low-activity test reference material \\
\hline MS & Mass spectrometry \\
\hline MSE & Mean squared error \\
\hline
\end{tabular}




$\begin{array}{ll}\text { NIST } & \text { National Institute of Standards and Technology } \\ \text { NM } & \text { not measured } \\ \text { NUREG } & \text { Nuclear Regulation } \\ \text { ORP } & \text { Office of River Protection } \\ \text { PCB } & \text { polychlorinated biphenyls } \\ \text { PCT } & \text { product consistency test } \\ \text { PND } & \text { Pacific Northwest Division } \\ \text { PNNL } & \text { Pacific Northwest National Laboratory } \\ \text { RCRA } & \text { Resource Conservation Recovery Act } \\ \text { RPD } & \text { Relative Percent Difference } \\ \text { RPG } & \text { Radiochemical Processing Group } \\ \text { RPL } & \text { Radiochemical Processing Laboratory } \\ \text { RPP-WTP } & \text { River Protection Project Waste Treatment Plant } \\ \text { SBMS } & \text { Standards Based Management System } \\ \text { SEM } & \text { Scanning Electron Microscopy } \\ \text { SRTC } & \text { Savannah River Technology Center } \\ \text { SVOA } & \text { Semi-volatile organic analysis } \\ \text { TC } & \text { Total carbon } \\ \text { Tc IX } & \text { technetium ion exchange } \\ \text { TCLP } & \text { Toxicity Characteristic Leaching Procedure } \\ \text { TIC } & \text { Total inorganic carbon } \\ \text { TOC } & \text { Total organic carbon } \\ \text { TRU } & \text { Transuranic } \\ \text { Hm } & \text { Micron } \\ \text { UST } & \text { underground storage tank } \\ \text { VOA } & \text { volatile organic analysis } \\ \text { vol\% } & \text { Volume percent } \\ \text { VHT } & \text { Vapor Hydration Test } \\ \text { VSL } & \text { Vitreous State Laboratory } \\ \text { Wro } & \text { Weight percent } \\ & \end{array}$




\section{Contents}

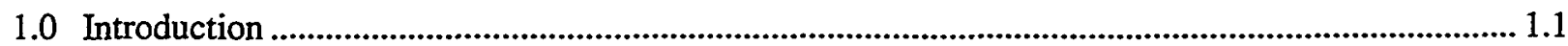

1.1 Quality Assurance .......................................................................................................1

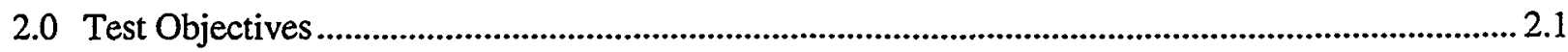

3.0 Experimental Method .................................................................................................................. 3.1

3.1 Glass Fabrication and Analysis .............................................................................................

3.1.1 Glass Fabrication .........................................................................................................

3.1.2 Chemical Composition .................................................................................................. 3.7

3.1.3 Radiochemical Composition ................................................................................................3.7

3.2 Crystalline and Non-Crystalline Phase Determination...............................................................3.8

3.3 Release Rate, Modified Product Consistency Testing ……...................................................10

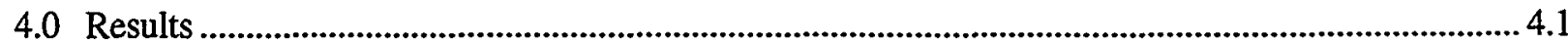

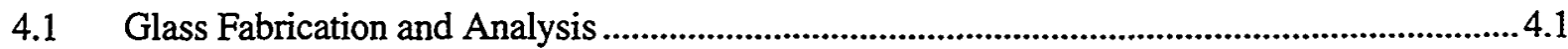

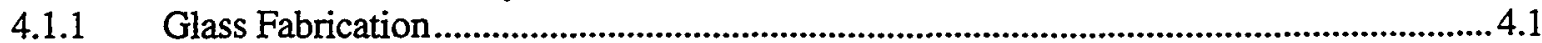

4.1.2 Chemical Composition ......................................................................................................

4.1.3 Radiochemical Composition ...................................................................................4.14

4.2 Crystalline and Non-Crystalline Phase Determination..............................................................18

4.3 Release Rate, Modified Product Consistency Testing …….....................................................4.23

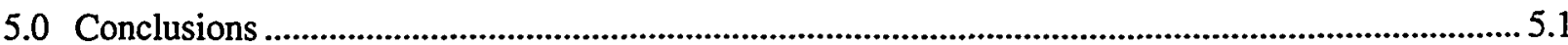

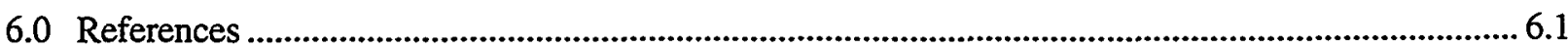

Appendix A: LAW Radioactive Glass Analysis Data.......................................................................... A.1

Appendix B: Crystalline and Non-Crystalline Phase Determination Data................................................1

Appendix C: Release Rate, Modified Product Consistency Test (PCT) Data............................................1 


\section{Figures}

Figure 3.1. Density Measurement of AN-107 Pretreated Waste Prior to Feed Preparation. AW-101 Pretreated Waste is in Plastic 1L Container in Center of Picture.

Figure 4.1. AW-101 Melter Feed After Drying to Temperatures up to $330^{\circ} \mathrm{C}$. .................................... 4.2

Figure 4.2. AW-101 Melter Feed in Platinum Crucible After Calcining................................................ 4.3

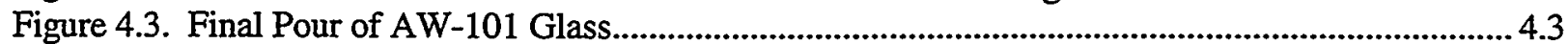

Figure 4.4. AN-107 Feed with Foam Which Crusted on Top of the Dried Feed During the Initial Drying Process. Note the 20-cm Long Stirring Spoon has Foam 80\% Up the Handle....... 4.5

Figure 4.5. AN-107 Feed During Exothermic Reaction. Note the Drainage of Material that Adhered to Beaker Wall and the Cloudy, Frosted Appearance of the Beaker From Condensate During Reaction.

Figure 4.6. The AN-107 Glass in The Process of the Final Pour Onto the Stainless Steel Pour Plate. The $20 \mathrm{ml}$ Crucible for the Canister Centerline Cooling Heat Treatment is Red Hot with Freshly Poured Glass.

Figure 4.7. XRD Diffraction Profiles for Glasses AW-101 and AN-107 Showing General Amorphous Character with Superimposed Peaks Indicating a Contaminating Crystalline Phase Present in the Powder Sample as SEM and Optical Microscopy Results Showed no Crystalline Phases Present in Either Glass.

Figure 4.8. XRD Diffraction Profiles for Glass AW-101 Showing General Amorphous Character with Superimposed Peaks Indicating a Crystalline Phase Present in the XRD Powder Sample Compared with the XRD Peaks Observed for a Section of the Poly Glove Material. The position of the peaks are identical indicating that the material 'dusting' the gloves is the material contaminating the glass powder.

Figure 4.9. XRD Diffraction Profile for the Heat Treated AW-101 Glass Showing General Amorphous Character with out the Superimposed Peaks that Indicated a Crystalline Phase Present in the Initial Glass Powder Sample. The lack of sharp XRD peaks indicates that the glass is completely amorphous consistent with optical and SEM evaluations.

Figure 4.10. Sodium Volatilization Believed to be Due to Electron Beam Heating of the Glass.

The heating intensity of the beam would be inversely proportional to the area being analyzed.

Figure B.1. Radioactive AW-101 Glass Powder X-Ray Diffraction Results for Glass Heated to Simulate the Calculated ILAW Centerline Cooling Curve of a LAW Canister of Glass $2 / 5$ of the Way from the Bottom of the Canister. Note the completely amorphous character of this profile.

Figure B.2. Radioactive AW-101 and AN-107 Glass Powder X-Ray Diffraction Results for Glass Heated to Simulate the Calculated ILAW Centerline Cooling Curve of a LAW Canister of Glass 2/5 of the Way from the Bottom of the Canister. Note the amorphous character of these profiles with crystal XRD peaks superimposed. These peaks were subsequently found to match peaks from powder on the glove worn when these powder mounts were made up. See Figure B-3.

Figure B.3. Radioactive AW-101 Glass Powder X-Ray Diffraction Results for Glass Heated to Simulate the Calculated ILAW Centerline Cooling Curve of a LAW Canister of Glass $2 / 5$ of the Way from the Bottom of the Canister. This initial XRD profile shows crystalline peaks that are identical with the XRD peaks produced by the mineral powder used to dust the gloves.

Figure B.4. Radioactive AW-101 Glass SEM Micrograph from a Glass Sample Heated to Simulate the Calculated ILAW Centerline Cooling Curve of a LAW Canister.

Figure B.5. Radioactive AN-107 Glass SEM Micrograph from a Glass Sample Heated to Simulate the Calculated ILAW Centerline Cooling Curve of a LAW Canister. 


\section{Tables}

Table 3.1. Composition of Envelope A (AW-101) Cs IX Column Feed. 3.4

Table 3.2. Composition of AN-107 (Envelope C) Pretreated Waste (Following Sulfate Removal) from Fiskum et al. 2000 Report

Table 3.3. AW-101 and AN-107 Glass Former Additives.

Table 3.4. Temperature Profile Line Segments Used as Guidelines for Programming the Del Tech Furnace Controller to Generate the Canister Centerline Cooling Profile.

Table 4.1. Chemical Analyses of AW-101 and AN-107 Radioactive Glasses.

Table 4.2. Target Versus Measured Composition of AW-101 and AN-107 Radioactive Glasses.

Table 4.3. Waste Loading/Dilution factors for LAW Waste Glass AW-101

Table 4.4. Waste Loading/Dilution factors for LAW Waste Glass AN-107

Table 4.5. Radiochemical Composition of AW-101 and AN-107 Glasses.

Table 4.6. Contract Success Criteria Determination: Radionuclide Glass Content of the ILAW Glass Product.

Table 4.7. AN-107 Glass 'As Measured' and 'Normalized' Values Compared to the AN-107 Re-normalized Target Values. All Values Have Been Re-normalized to $100 \%$ Using Only the Ten Oxides Listed Below.

Table 4.8. Comparison of $40^{\circ} \mathrm{C} \mathrm{PCT}$ and $90^{\circ} \mathrm{C}$ PCT Results from the Low-Activity Test Reference Material (LRM) Glass Round Robin (Ebert and Wolf. 1999) with the Equivalent Values Found for the $40^{\circ} \mathrm{C}$ and $90^{\circ} \mathrm{C}$ PCT Tests Described in this Report.

Table 4.9. Average 7-Day $40^{\circ} \mathrm{C}$ PCT Normalized Mass Loss Data Radioactive LAW Glasses from this Study.

Table 4.10. Comparison of Average 7-Day $90^{\circ} \mathrm{C}$ PCT Normalized Mass Loss Data Between VSL Non-radioactive Simulant Glasses and Actual Radioactive LAW Glass Counterparts from this Study. LAWA23R and LRM Data is Provided for Comparison Purposes.

Table A.1. Radioactive AW-101 Glass Chemical Composition Data

Table A.2. Radioactive AN-107 Glass Chemical Composition Data.

Table A.3. Non-radioactive Analytical Reference Glass-1 (ARG-1 Glass Chemical Composition Data)..

Table A.4. Radioactive AW-101 and AN-107 Glass Radiochemical Composition Data.

Table A.5. Radioactive AW-101 and AN-107 Glass Radiochemical Composition Data: GEA Detection Limits.

Table A.6. Radioactive AW-101 and AN-107 Glass Radiochemical Composition Data: ICP-MS...... A.7

Table C.1. Product Consistency Testing (PCT) Leachate Analysis Data. ..C.2

Table C.2. Product Consistency Testing (PCT) Leachate Analysis Data. .C.3

Table C.3. Product Consistency Testing (PCT) Leachate Analysis Data. ..C. 4

Table C.4. Product Consistency Testing (PCT) Leachate Analysis Data. .C.5

Table C.5. Product Consistency Testing (PCT) Leachate Analysis Data. .C.6 


\subsection{Introduction}

The U.S. Department of Energy (DOE) Office of River Protection (ORP) is acquiring Hanford tank waste treatment services at a demonstration scale. The River Protection Project Waste Treatment Plant (RPP-WTP) is responsible for producing an immobilized (vitrified) low-activity waste (ILAW) waste form. Pacific Northwest National Laboratory, hereafter referred to as PNNL, has been contracted by the RPP-WTP project to produce and test a vitrified LAW waste form from the Envelope A and C LAW samples previously supplied to the RPP-WTP project by DOE.

The U.S. Department of Energy currently has radioactive waste stored in underground storage tanks (USTs) at the Hanford site in southeastern Washington. One supernatant sample each was taken from two of the USTs. The particular tanks of interest (241-AW-101 and 241-AN-107) are of doubleshell construction and are 1-million gallon in capacity. Most of the radioactivity was removed from the two supernate samples through pretreatment chemical separation processes, and the decontaminated supernates were processed into low-activity waste (LAW) glass. The AW-101 supernate sample was processed through the following unit operations to simulate the RPP-WTP project flowsheet: 1) dilution of the feed (Urie et al. 1999); 2) ultrafiltration to remove entrained solids (Brooks et al. 1999); 3) removal of ${ }^{137} \mathrm{Cs}$ by ion exchange (Kurath et al. 2000a); and 4) removal of ${ }^{99} \mathrm{Tc}$ by ion exchange (Blanchard et al. 1999). The AN-107 supernate sample was processed through the following unit operations to simulate the RPP-WTP project flowsheet: 1) dilution of the feed (Urie et al. 1999); 2) removal of Sr/TRU by precipitation (Hallen et al. 2000); 3) ultrafiltration to remove entrained solids and ST/TRU precipitate (Hallen et al. 2000); 4) removal of ${ }^{137} \mathrm{Cs}$ by ion exchange (Kurath et al. 2000b); 5) removal of ${ }^{99} \mathrm{Tc}$ by ion exchange (Blanchard et al. 2000); and 5) removal of sulfate $\left(\mathrm{SO}_{4}\right)$ by a precipitation process (Fiskum et al. 2000). Product testing of the LAW glass waste forms, as prescribed by the RPP-WTP project, was performed by PNNL to support Phase 1B deliverables.

The primary objective for vitrifying Envelope A (Tank AW-101) and Envelope C (Tank AN-107) pretreated waste samples was to characterize the glass produced from the crucible melts. Testing of the waste glasses produced from actual tank waste will also show compliance with the RPP-WTP contractual requirements such as chemical and radionuclide reporting, product loading, and dangerous waste limitations and organic content in the glasses.

The scope of this work was divided into 8 work elements: 1) Glass Fabrication, 2) Chemical Composition, 3) Radiochemical Composition, 4) Crystalline and Non-crystalline Phase Determination, 5) Release Rate (Modified PCT), 6) Dangerous Waste Limitations - Toxicity Characteristic Leaching Procedure (TCLP), 7) Total volatile organic and semi-volatile organic analyses, and 8) Regulatory Testing. This report will discuss the results for work elements 1 through 5. Results for work elements 6 through 8, i.e. VOA, SVOA, dioxins, furans, PCBs, and total cyanide analyses, will be presented in a later report (WTP-RPT-005).

\subsection{Quality Assurance}

This work was performed in PNNL's Radiochemical Processing Laboratory (RPL), Building 325 and Building 326 in Richland, Washington. To provide the RPP-WTP project with quality products and services, PNNL established and implemented a quality assurance implementation plan for the River Protection Project-Waste Treatment Plant titled "BNFL Phase B-1 Support, Quality Assurance Planning Document," document number BNFL-QAPjP. The work and results reported herein were conducted under the quality requirements of the Standards-Based Management System (SBMS) as delineated in Section 4.2 of BNFL-QAPjP, Rev. 0 and Section 4.4 of BNFL-QAPjP, Rev. 1. Specific SBMS quality assurance elements (subject areas) applied to this work included: Assessment Closure (Corrective Action Management), Calibration, Document Control, Inspections and Acceptance, Internal Operating 
Procedures, Project Management, Property Management, Purchasing Goods and Services, Records Management for Project Files, Resolving Quality Problems, Suspect/Counterfeit Items and Misrepresented Products, Training and Qualification for Staff, and Work Practice. 


\subsection{Test Objectives}

This work addresses RPP-WTP contract requirements to demonstrate the contractors ability to satisfy the immobilized low activity waste (ILAW) product requirements (specification 2 of the RPP-WTP contract) with samples of LAW.

\section{Test Objectives:}

The primary objective for vitrifying the LAW sample is to generate a glass product for subsequent product testing. Testing will seek to demonstrate the RPP-WTP projectsability to satisfy the product requirements concerning:

- Chemical and radionuclide reporting.

- Waste loading.

- Identification and quantification of crystalline and non-crystalline phases.

- Waste form leachability.

- Dangerous Waste Limitations.

\section{Success Criteria:}

The primary success criteria are associated with the product requirements:

- Identification and quantification of those chemical constituents present at concentrations greater than $0.5 \mathrm{wt} \%$.

- Identification and quantification of those radionuclides (current and indexed to December 31, 2002) identified as significant in NUREG/BR-0204 and 49CFR 172.101 (Table 2). ${ }^{99} \mathrm{Tc}$ shall be considered significant at concentrations greater than $0.003 \mathrm{Ci} / \mathrm{m}^{3}$.

- The concentrations of ${ }^{137} \mathrm{Cs},{ }^{90} \mathrm{Sr},{ }^{99} \mathrm{Tc}$ and transuranic (TRU) radionuclides shall be less than $3 \mathrm{Ci} / \mathrm{m}^{3}, 20 \mathrm{Ci} / \mathrm{m}^{3}, 0.1 \mathrm{Ci} / \mathrm{m}^{3}$ and $100 \mathrm{nCi} / \mathrm{g}$, respectively. [Note: The ORP Contract Specification 2, Immobilized Low-Activity Waste, Section 2.2.2.8, Radionuclide Concentration Limitations, states: "The average concentrations shall be calculated by summing the actual inventories of each of the above radionuclides in the packages that have been presented to date for acceptance and dividing by the total volume of waste in these packages. The Contractor shall remove on average a minimum of $80 \%$ of the 99 Tc present in the feed."]

- The concentration of waste sodium oxide shall be greater than $16 \mathrm{wt} \%$. [Note: The ORP Contract Specification 2, Immobilized Low-Activity Waste, Section 2.2.2.2, Waste Loading, states: "The loading of waste sodium from Envelope A in the ILAW glass shall be greater than 14 weight percent based on $\mathrm{Na}_{2} \mathrm{O}$. The loading of waste sodium from Envelope $\mathrm{B}$ in the ILAW glass shall be greater than 5.0 weight percent based on $\mathrm{Na}_{2} \mathrm{O}$. The loading of waste sodium from Envelope $\mathrm{C}$ in the $\Pi \mathrm{L} \mathrm{AW}$ glass shall be greater than 10 weight percent based on $\mathrm{Na}_{2} \mathrm{O}$."]

- Identification and quantification of crystalline and non-crystalline phases.

- The normalized release rates of sodium, silicon and boron multiplied by the percentage of feed ${ }^{99} \mathrm{Tc}$ remaining in the glass or $20 \%$, whichever is greater, shall be less than those measured for glass LAWA23 from RPP-WTP project, Part A measured at the same conditions $\left(40^{\circ} \mathrm{C}\right.$ and $\left.90^{\circ} \mathrm{C}\right)$. 
- The normalized mass loss of sodium, silicon, and boron shall be measured using a seven-day PCT run at $90^{\circ} \mathrm{C}$ as defined in ASTM C1285-98. The test shall be conducted with a glass to water ratio of 1 gram of glass $(-100+200$ mesh) per 10 milliliters of water. The normalized mass loss shall be less than 2.0 grams $/ \mathrm{m}^{2}$. Qualification testing shall include glass samples subjected to representative waste form cooling curves. The PCT shall be conducted on waste form samples that are statistically representative of the production glass. 


\subsection{Experimental Method}

\subsection{Glass Fabrication and Analysis}

Two pretreated tank supernate, low-activity wastes (AW-101 and AN-107) along with a process simulant (termed the Process Blank) were prepared as melter feeds for vitrification. The analyzed compositions of the pretreated AW-101 and AN-107 wastes were used by Catholic University of America's Vitreous State Laboratory to calculate the target glass composition, which was forwarded to PNNL to prepare the batch processing spreadsheets to prepare the waste glass feed.

\subsubsection{Glass Fabrication}

Before vitrification of the pretreated AW-101 and AN-107 waste samples a "process blank" simulant glass product was made mimicking the process used to make the AW-101 and AN-107 glass samples. The "process blank" glass was processed using a simulant AW-101 pretreated waste sample and the same glass former minerals that were used to make the actual radioactive AW-101 waste glass. This glass will be analyzed for volatile and non-volatile organics (VOA and SVOAs), dioxins and furans, polychlorinated biphenyls (PCBs), and total cyanide along with both of the actual radioactive AW-101 and $\mathrm{AN}-107$ waste glasses to ensure the glass processing procedure did not introduce any organic contaminants. The VOA, SVOA, dioxins, furans, PCBs, and total cyanide analyses will be reported in a separate document (WTP-RPT-005).

The pretreated AW-101 and AN-107 waste was blended with glass forming additives. However, prior to melter feed preparation, the densities of the pretreated LAW solutions were checked to determine any weight change between the pretreatment process and the initiation of vitrification processing (see Figure 3.1). The composition of the pretreated AW-101 waste is provided in Table 3.1; the glass target composition is provided in Table 4.2. See Urie et al. 1999a and 1999b for the analyses of AW-101 and AN-107 tank waste prior to pretreatment. The composition of the pretreated AN-107 waste is provided in Table 3.2; the glass target composition is provided in Table 4.2. The glass former minerals used for both LAW glass melts are provided in Table 3.3. Each mineral component was weighed on a balance capable of accurately measuring to $10 \mathrm{mg}$. The mineral additives were weighed and combined as dry powders and mixed in an agate milling chamber for several minutes. The exact amount of the mineral batch needed to combine with the waste was then weighed out from the blended minerals. 


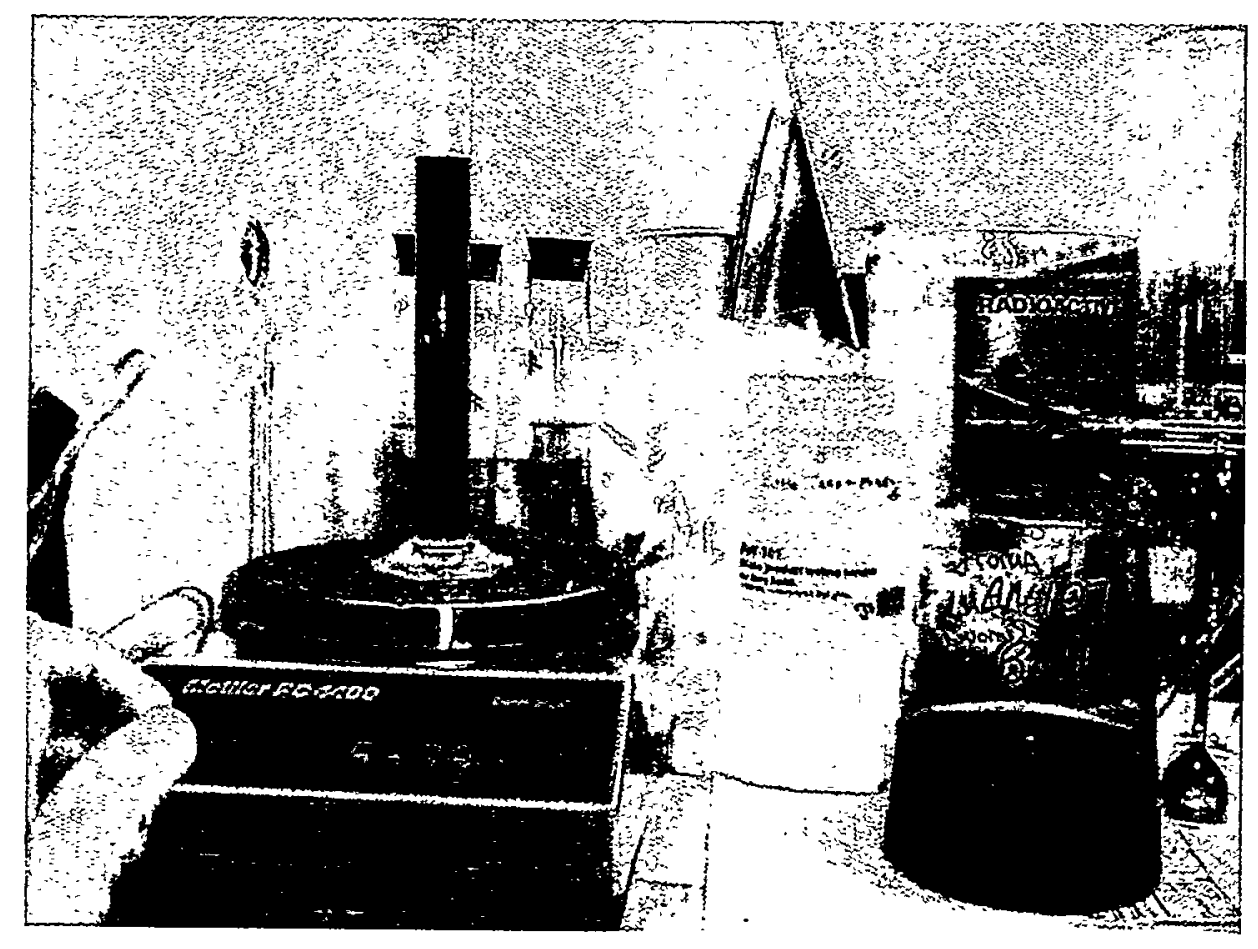

Figure 3.1. Density Measurement of AN-107 Pretreated Waste Prior to Feed Preparation. AW-101 Pretreated Waste is in Plastic 1L Container in Center of Picture.

Combining of the waste and mineral additives together occurred by pouring the liquid LAW slurry in a $2 \mathrm{~L}$ glass beaker containing a magnetic stir bar. The slurry was heated and stirred on a hot plate to evaporate water. While heating and stirring, the mineral additives were slowly added into the vortex of the slurry. Mixing was vigorous so solids from the mineral additives could not settle. The heating / stirring process took three to five hours to thicken the batch to the point the stir bar would no longer rotate. Hand blending was used until the batch was dry; this took an additional two to three hours to complete. Each batch was dried further in an oven by slowly increasing the temperature from approximately 100 to $400^{\circ} \mathrm{C}$ over a 48 to 72 hour period. The dry cake that was produced was hard and brittle. The blended and dried feed was then added to a $500 \mathrm{cc} \mathrm{Pt}-10 \% \mathrm{Rh}$ crucible, placed into a furnace at $600^{\circ} \mathrm{C}$ and calcined. The calcination process began at $600^{\circ} \mathrm{C}$, increased at $25^{\circ} \mathrm{C}$ intervals to $650^{\circ} \mathrm{C}$ where it was held for more than two hours. The crucible was removed, the furnace temperature increased to $1150^{\circ} \mathrm{C}$ and the batch melted approximately 1 hour with lid on. The glass melt was then poured onto a stainless steel plate. The subsequent glass was crushed to a fine powder $(<100 \mu \mathrm{m})$ and mixed to ensure homogeneity using a tungsten carbide disc mill. The crushed glass was placed back into the $\mathrm{Pt}-\mathrm{Rh}$ crucible, covered with a lid, and remelted at $1150^{\circ} \mathrm{C}$ for approximately $60 \mathrm{~min}$. During the final molten glass pour, a portion of the pour went into a small crucible (about $20 \mathrm{~mL}$ ) to be heat treated following the predicted canister centerline cooling (CCC) heat treatment of a LAW canister of glass $2 / 5$ of the way from the bottom of the canister (see Section 3.2 for details). The remaining portion of the glass was quenched on the stainless steel plate, cooled to room temperature, and handled in a manner to keep the glass free of organic contamination. All glass samples were stored in glassware cleaned to EPA standards. Note: There was no CCC heat-treated glass sample for the Process Blank. 
Vitrification of slurry melter feed in an actual liquid-fed ceramic melter (LFCM) progresses continuously through 3 distinct stages, drying, calcining and melting. Under steady-state operating conditions, the aqueous slurry that is introduced into the high-temperature melter environment spreads out over an existing cold cap where it dries and becomes part of the melter cold-cap structure. This dried material begins working it's way down through the cold-cap as it becomes submerged in incoming feed while, at the same time, material, at the molten-glass/cold-cap interface, is dissolving into the glass melt. During this continuous progression through the cold cap, the temperature that the feed is subjected to monotonically increases from the boiling point of water $\left(-100^{\circ} \mathrm{C}\right)$ to molten glass temperatures $(\sim 1150$ $\left.{ }^{\circ} \mathrm{C}\right)$. Accompanying this continuous physical and thermal transition, inorganic eutectic salts are slowly converted to their oxide forms (calcined) that are suitable for subsequent incorporation into the melter's molten glass pool.

All of these discrete phases of liquid-fed ceramic melter feed processing have been faithfully reproduced in the crucible studies performed. What may not be truly represented, however, is the complex stages and nature of the cold-cap chemistry that results in the calcination of the feed material. For non-volatile, inorganic feed constituent, the differences between crucible and melter vitrification conditions are inconsequential. For all other feed components, cold-cap chemistry can influence both partitioning behavior and chemical byproduct yields, which, in turn, can and will affect the resultant glass product.

Consequently to properly represent an LFCM glass product, actual physical and chemical processing conditions need to be replicated. But since this requires the development of a representative cold-cap structure, nothing short of a liquid-fed melting process (e.g., scaled melter or possibly a gradient furnace test) is truly adequate. However, relationships drawn between previous crucible and actual melter testing results, i.e. from VSL and GTS Duratek testing, that were conducted using a fixed feed may be useful in extracting reference glass-product quality parameters from extrapolated crucible test data. 
Table 3.1. Composition of Envelope A (AW-101) Cs IX Column Feed.

\begin{tabular}{|c|c|}
\hline \multicolumn{2}{|r|}{ Cations, $\mathrm{M}$} \\
\hline $\mathrm{Na}^{+}$ & 4.59 \\
\hline $\mathrm{K}^{+}$ & 0.39 \\
\hline $\mathrm{Cs}^{+}$ & $6.14 \mathrm{E}-5$ \\
\hline \multicolumn{2}{|r|}{ Anions, $M$} \\
\hline $\mathrm{AlO}_{2}^{-}(2)$ & 0.411 \\
\hline $\mathrm{Cl}^{-}$ & $0.066(1)$ \\
\hline $\mathrm{CO}_{2}^{-}$ & $0.13(1)$ \\
\hline $\mathrm{CrO}_{4}^{-2}(2)$ & $8.4 \mathrm{E}-4$ \\
\hline $\mathrm{NO}_{2}^{-}$ & $0.97(1)$ \\
\hline $\mathrm{NO}_{3}^{-}$ & $1.43(1)$ \\
\hline $\mathrm{OH}^{-}$ & $3.1(1)$ \\
\hline $\mathrm{PO}_{4}^{-3}(2)$ & 0.007 \\
\hline $\mathrm{SO}_{4}^{-2}$ & $0.019(1)$ \\
\hline Oxalate & $<8.6 \mathrm{E}-3(1)$ \\
\hline \multicolumn{2}{|r|}{ Radionuclides } \\
\hline${ }^{60} \mathrm{Co}(\mu \mathrm{Ci} / \mathrm{mL})$ & $<1 . E-2(1)$ \\
\hline${ }^{90} \mathrm{Sr}(\mu \mathrm{Ci} / \mathrm{mL})$ & $<5 . \mathrm{E}-1(1)$ \\
\hline${ }^{99} \mathrm{Tc}, \mu \mathrm{Ci} / \mathrm{L}(\mathrm{mg} / \mathrm{L})$ & $64.1(3.75)$ \\
\hline${ }^{134} \mathrm{Cs}(\mu \mathrm{Ci} / \mathrm{mL})$ & $3.4 \mathrm{E}-2$ \\
\hline${ }^{137} \mathrm{Cs}(\mu \mathrm{Cj} / \mathrm{mL})$ & 179.6 \\
\hline${ }^{154} \mathrm{Eu}(\mu \mathrm{Ci} / \mathrm{mL})$ & $<4 . \mathrm{E}-2(1)$ \\
\hline${ }^{155} \mathrm{Eu}(\mu \mathrm{Ci} / \mathrm{mL})$ & $<4 . \mathrm{E}-1(1)$ \\
\hline${ }^{238} \mathrm{Pu}(\mu \mathrm{Ci} / \mathrm{mL})$ & $<5 . \mathrm{E}-5(1)$ \\
\hline${ }^{239} \mathrm{Pu}+{ }^{240} \mathrm{Pu}(\mu \mathrm{Ci} / \mathrm{mL})$ & $1.07 \mathrm{E}-4(1)$ \\
\hline${ }^{241} \mathrm{Am}(\mu \mathrm{Ci} / \mathrm{mL})$ & $7.30 \mathrm{E}-5(1)$ \\
\hline${ }^{242} \mathrm{Cm}(\mu \mathrm{Ci} / \mathrm{mL})$ & $<5 . \mathrm{E}-6(1)$ \\
\hline${ }^{243} \mathrm{Cm}+{ }^{244} \mathrm{Cm}(\mu \mathrm{Ci} / \mathrm{mL})$ & $1.71 \mathrm{E}-5(1)$ \\
\hline Total Alpha $(\mu \mathrm{Ci} / \mathrm{mL})$ & $<1 . \mathrm{E}-2(1)$ \\
\hline \multicolumn{2}{|l|}{ Total U $(\mu \mathrm{Ci} / \mathrm{mL})$} \\
\hline \multicolumn{2}{|r|}{ Solution } \\
\hline Solution Density, $\mathrm{g} / \mathrm{mL}$ & 1.228 \\
\hline \multicolumn{2}{|c|}{$\begin{array}{l}\text { (1) These values have been estimated from the diluted feed characterization data reported in PNWD-2463, } \\
\text { BNFL-RPT- } 003 \text {, rev } 0 \text { using a dilution factor of } 0.71 \text { ( } 4.59 \mathrm{M} \text { Na divided by } 6.46 \mathrm{M} \mathrm{Na}) \text {. Unless } \\
\text { otherwise noted the results are based on direct analysis of the feed. } \\
\text { (2) Al, Cr, and P determined by ICP-AES. Anionic form is assumed on the basis of waste chemistry. } \\
\text { Note: Based on availability the waste analysis used for glass formulation was that measured for cesium IX } \\
\text { feed; the waste composition will essentially be the same as the feed to the LAW vit except for possible } \\
\text { evaporation and the removal of most of the Cs and Tc. The concentration of Cs and Tc at } 4.6 \mathrm{M} \text { Na can be } \\
\text { estimated by dividing the cesium concentration by } 6200 \text { and the Tc concentration by } 12.6 \text {. This is the } \\
\text { information used by the Vitreous State Laboratory to generate the AW-101 glass target composition shown in } \\
\text { Table 4.2. }\end{array}$} \\
\hline
\end{tabular}


Table 3.2. Composition of AN-107 (Envelope C) Pretreated Waste (Following Sulfate Removal) from Fiskum et al. 2000 Report.

\begin{tabular}{|c|c|c|c|c|c|}
\hline \multicolumn{6}{|c|}{ Inorganic Analytes: Average Pretreated Waste } \\
\hline Analyte & $\mu \mathrm{g} / \mathrm{mL}$ & Analyte & $\mu \mathrm{g} / \mathrm{mL}$ & Analyte & $\mu \mathrm{g} / \mathrm{mL}$ \\
\hline $\mathrm{Ag}$ & $<0.68$ & $\mathrm{Fe}$ & 2.8 & $\mathrm{Sb}$ & $<13.6$ \\
\hline $\mathrm{Al}$ & 768 & $\mathrm{~K}$ & 751 & $\mathrm{Se}$ & $<6.8$ \\
\hline As & $<6.8$ & $\mathrm{La}$ & $<1.36$ & $\mathrm{Si}$ & $<13.6$ \\
\hline $\mathrm{B}$ & 1.2 & $\mathrm{Li}$ & $<0.82$ & $\mathrm{Sn}$ & $<40.8$ \\
\hline $\mathrm{Ba}$ & 109 & $\mathrm{Mg}$ & $<2.7$ & $\mathrm{Sr}$ & 7.0 \\
\hline $\mathrm{Be}$. & $<0.27$ & $\mathrm{Mn}$ & $<1.36$ & $\mathrm{Te}$ & $<40.8$ \\
\hline $\mathrm{Bi}$ & $<2.7$ & Mo & 13.3 & $\mathrm{Th}$ & $<27$ \\
\hline $\mathrm{Ca}$ & 886 & $\mathrm{Na}$ & 94675 & $\mathrm{Ti}$ & $<0.68$ \\
\hline $\mathrm{Cd}$ & 22.2 & Nd & $<2.7$ & $\mathrm{Tl}$ & $<13.6$ \\
\hline $\mathrm{Ce}$ & $<5.4$ & $\mathrm{Ni}$ & 176 & $\mathrm{U}$ & $2.9^{(a)}$ \\
\hline $\mathrm{Co}$ & 1.7 & $\mathrm{P}$ & 42.5 & $\mathrm{~V}$ & $<1.36$ \\
\hline $\mathrm{Cr}$ & 6.4 & $\mathrm{~Pb}$ & 22.3 & W & 58 \\
\hline $\mathrm{Cu}$ & 10.6 & $\mathrm{Pd}$ & $<20.4$ & $\mathrm{Y}$ & $<1.36$ \\
\hline Dy & $<1.36$ & $\mathrm{Rh}$ & $<8.2$ & $\mathrm{Zn}$ & 4.4 \\
\hline $\mathrm{Eu}$ & $<2.7$ & $\mathrm{Ru}$ & $<29.9$ & $\mathrm{Zr}$ & $<1.36$ \\
\hline \multicolumn{6}{|c|}{ Ion Chromatography \& Oxidation Analytes: Average Pretreated Waste } \\
\hline Analyte & $\mu \mathrm{g} / \mathbf{m L}$ & Analyte & $\mu \mathrm{g} / \mathrm{mL}$ & Analyte & $\mu \mathrm{g} / \mathrm{mL}$ \\
\hline $\mathrm{Br}$ & $<500$ & $\mathrm{C}_{2} \mathrm{O}_{4}$ & $<1000$ & \multirow{5}{*}{$\mathrm{NH}_{3}$} & \multirow{5}{*}{6.5} \\
\hline $\mathrm{Cl}$ & $<500$ & $\mathrm{PO}_{4}$ & $<1000$ & & \\
\hline$F^{(b)}$ & 3000 & $\mathrm{SO}_{4}$ & 970 & & \\
\hline $\mathrm{NO}_{2}$ & 29550 & TIC & 2070 & & \\
\hline $\mathrm{NO}_{3}$ & 173000 & TOC & 13100 & & \\
\hline \multicolumn{6}{|c|}{ Radiochemistry: Average Pretreated Waste } \\
\hline Analyte & $\mu \mathrm{Ci} / \mathrm{mL}$ & & & Analyte & $\mu \mathrm{Ci} / \mathrm{mL}$ \\
\hline Co-60 & $3.96 \mathrm{E}-02$ & & & Se-79 & $<2 \mathrm{e}-6$ \\
\hline $\mathrm{Nb}-95$ & $1.09 E-03$ & & & Sr-90 & $2.43 E-03$ \\
\hline$Y-88$ & $<2.4 \mathrm{e}-4$ & & & Tc-99 & $4.90 \mathrm{E}-02$ \\
\hline Sn-113 & $5.59 \mathrm{E}-05$ & & & Np-237 & $1.22 \mathrm{E}-05$ \\
\hline Sb- 125 & $<8.4 \mathrm{e}-5$ & & & Pu-239 & $3.88 \mathrm{E}-04$ \\
\hline SnSb-126 & $<3.6 \mathrm{e}-5$ & & & \multirow{5}{*}{ Total alpha } & \multirow{5}{*}{$<2 \mathrm{e}-3$} \\
\hline Cs-137 & 7.33E-02 & & & & \\
\hline $\mathrm{Eu}-154$ & $3.10 \mathrm{E}-03$ & & & & \\
\hline Eu-155 & 2.17E-03 & & & & \\
\hline Am-241 & $1.35 \mathrm{E}-03$ & & & & \\
\hline \multirow{3}{*}{\multicolumn{6}{|c|}{$\begin{array}{l}<\mathrm{x} . \mathrm{xx}=\text { indicates that the analyte is below the detection limit, detection limit value is provided for those analytes. } \\
\text { (a) = U determined by kinetic phosphorescence. } \\
\text { (b) = F results are suspect due to peak distortion and retention time shift. } \\
\text { Radioisotope reference date is } 11 / 1 / 99 \text {; data is from Fiskum, et al. } 2000 \text {. }\end{array}$}} \\
\hline & & & & & \\
\hline & & & & & \\
\hline \multicolumn{6}{|c|}{ NOTE: Pretreated waste properties: density $=1.2064 \mathrm{~g} / \mathrm{mL} ;$ volume $=484.4 \mathrm{~mL} ;$ mass $=584.4 \mathrm{~g}$. } \\
\hline
\end{tabular}


Table 3.3. AW-101 and AN-107 Glass Former Additives

\begin{tabular}{|c|c|c|c|c|c|}
\hline $\begin{array}{c}\text { Oxide } \\
\text { Needed }\end{array}$ & Source & $\begin{array}{c}\text { Company } \\
\text { Address \& tel. }\end{array}$ & $\begin{array}{c}\text { Grade } \\
\text { Identification }\end{array}$ & $\begin{array}{c}\text { wt \% of the } \\
\text { oxide }\end{array}$ & $\begin{array}{c}\text { Principal } \\
\text { other oxides } \\
\text { present }\end{array}$ \\
\hline $\mathrm{Al}_{2} \mathrm{O}_{3}$ & $\begin{array}{l}\text { Raw Kyanite } \\
\mathrm{Al}_{2} \mathrm{SiO}_{5}\end{array}$ & $\begin{array}{l}\text { Kyanite Mining Corp. } \\
\text { Dillwyn VA } 23936 \\
\text { tel. (804) } 983-2043\end{array}$ & $\begin{array}{l}\text { Raw Kyanite } \\
325 \mathrm{MESH}\end{array}$ & $54 \% \mathrm{Al}_{2} \mathrm{O}_{3}$ & $\begin{array}{l}43.7 \% \mathrm{SiO}_{2} \\
0.4 \% \mathrm{Fe}_{2} \mathrm{O}_{3}\end{array}$ \\
\hline $\mathrm{B}_{2} \mathrm{O}_{3}$ & $\begin{array}{l}\text { Orthoboric Acid } \\
\mathrm{H}_{3} \mathrm{BO}_{3}\end{array}$ & $\begin{array}{l}\text { US Borax Inc. } \\
26877 \text { Tourney Road } \\
\text { Valencia, CA } 91355 \\
\text { tel. (660) } 287-5400\end{array}$ & $\begin{array}{l}\text { Technical } \\
\text { Granular }\end{array}$ & $56.3 \% \mathrm{~B}_{2} \mathrm{O}_{3}$ & $\begin{array}{l}\text { None above } \\
0.01 \text { wt } \%\end{array}$ \\
\hline $\mathrm{CaO}$ & $\begin{array}{l}\text { Wollastonite } \\
\mathrm{CaSiO}_{3}\end{array}$ & $\begin{array}{l}\text { NYCO Minerals } \\
124 \text { Mountain View Dr. } \\
\text { Willsboro, NY } 12996 \\
\text { tel. (403) 260-9883 }\end{array}$ & $\begin{array}{l}\text { Powder untreated } \\
\text { NYAD\& } 325\end{array}$ & $47.5 \% \mathrm{CaO}$ & $\begin{array}{l}51.0 \% \mathrm{SiO}_{2} \\
0.4 \% \mathrm{Fe}_{2} \mathrm{O}_{3}\end{array}$ \\
\hline $\mathrm{Fe}_{2} \mathrm{O}_{3}$ & $\begin{array}{l}\text { Red Iron Oxide } \\
\text { Pigment } \\
\mathrm{Fe}_{2} \mathrm{O}_{3}\end{array}$ & $\begin{array}{l}\text { The Prince Manufacturing Co. } \\
\text { I Prince Plaza, P.O. Box } 1009 \\
\text { Quincy, II } 62306 \\
\text { tel. (217) 222-8854 }\end{array}$ & $\begin{array}{l}\text { Red Iron Oxide } \\
5001\end{array}$ & $97 \% \mathrm{Fe}_{2} \mathrm{O}_{3}$ & $\begin{array}{l}1.50 \% \mathrm{Al}_{2} \mathrm{O}_{3} \\
1.35 \% \mathrm{SiO}_{2}\end{array}$ \\
\hline $\mathrm{MgO}$ & 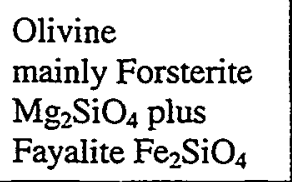 & $\begin{array}{l}\text { UNIMIN Corporation } \\
258 \text { Elm Street } \\
\text { New Canaan, CT } 06840 \\
\text { (203) } 966-8880\end{array}$ & $\begin{array}{l}\text { Olivine } \\
\text { Grade } 180 \\
\text { Green Mountain, } \\
\text { NC }\end{array}$ & $\begin{array}{l}48.01 \mathrm{wt} \% \\
\mathrm{MgO}\end{array}$ & $\begin{array}{l}42.52 \mathrm{wt} \% \mathrm{SiO}_{2} \\
7.68 \mathrm{wt} \% \mathrm{Fe}_{2} \mathrm{O}_{3}\end{array}$ \\
\hline $\mathrm{SiO}_{2}$ & $\begin{array}{l}\text { Ground Silica } \\
\text { Sand } \\
\mathrm{SiO}_{2}\end{array}$ & $\begin{array}{l}\text { US Silica Company } \\
\text { P.O. Box } 187 \\
\text { Berkeley Springs } \\
\text { WV, 25411-0187 } \\
\text { tel. (800) } 243-7500\end{array}$ & SL-CO-SL® 75 & $99.5 \% \mathrm{SiO}_{2}$ & $0.3 \% \mathrm{Al}_{2} \mathrm{O}_{3}$ \\
\hline $\mathrm{ZrO}_{2}$ & $\begin{array}{l}\text { Zircon Sand } \\
\text { Zirconium silicate } \\
\mathrm{ZrSiO}_{4}\end{array}$ & $\begin{array}{l}\text { American Minerals Inc. } \\
901 \text { E. } 8^{\text {th }} \text { Ave., Suite } \# 200 \\
\text { King of Prussia, PA } 19406 \\
\text { tel. }(610) 337-8030\end{array}$ & $\begin{array}{l}\text { FLOUR } 325 \\
\text { MESH }\end{array}$ & $\begin{array}{l}66 \% \mathrm{ZrO}_{2} \\
(+\mathrm{HfO} 2)\end{array}$ & $34 \% \mathrm{SiO}_{2}$ \\
\hline $\mathrm{ZnO}$ & $\begin{array}{l}\text { Zinc Oxide } \\
\mathrm{ZnO}\end{array}$ & $\begin{array}{l}\text { Zinc Corporation of America } \\
300 \text { Frankfort Road } \\
\text { Monaca, PA 15061 } \\
\text { tel. (724) 774-1020 }\end{array}$ & KADOX-920 & $99.8 \% \mathrm{ZnO}$ & $\begin{array}{l}\text { None above } \\
0.01 \mathrm{wt} \%\end{array}$ \\
\hline $\mathrm{TiO}_{2}$ & $\begin{array}{l}\text { Rutile Ore } \\
\mathrm{TiO}_{2}\end{array}$ & $\begin{array}{l}\text { Chemalloy Company } \\
\text { P.O. Box } 350 \\
\text { Bryn Mawr, PA } 19010 \\
\text { tel. (610) } 527-3700 \\
\end{array}$ & $\begin{array}{l}\text { Premium Grade } \\
\text { Rutile Ore } \\
\text { Airfloated }\end{array}$ & $95.4 \% \mathrm{TiO}_{2}$ & $\begin{array}{l}0.91 \% \mathrm{SiO}_{2} \\
0.90 \% \mathrm{ZrO}_{2} \\
0.71 \% \mathrm{Fe}_{2} \mathrm{O}_{3} \\
0.41 \% \mathrm{~V}_{2} \mathrm{O}_{5} \\
\end{array}$ \\
\hline
\end{tabular}




\section{Test Equipment}

Envelope A and B radioactive, blended waste, and additives feed were dried in a Blue-M Stabil-Therm Gravity drying oven, and calcined and melted in a custom-made Del Tech high-temperature furnace equipped with a Eurotherm programmer/controller and the temperature monitored with a calibrated Type $K$ thermocouple and an Omega, Model 660 thermocouple readout. Vitrification was completed in a $450-\mathrm{mL}$ platinum/10\% rhodium crucible.

The Angstrom Disc Mill with a 100-mL tungsten carbide grinding chamber were used to crush and mix the glass, and 3-in.-diameter stainless-steel sieves were used to sieve glass samples.

\subsubsection{Chemical Composition}

Chemical composition of the two LAW glasses (i.e., elements \{excluding oxygen\}) present in concentrations greater than 0.5 percent by weight) were measured in duplicate along with an ARG-1 powdered glass reference standard (Smith 1993) using a sodium peroxide $\left(\mathrm{Na}_{2} \mathrm{O}_{2}\right)$ fusion, according to procedure PNL-ALO-114, and a potassium hydroxide (KOH) fusion, according to procedure PNL-ALO-115. Analytical Reference Glass-1 (ARG-1) is a compositionally well-characterized glass and provides an excellent independent check of the analytical processes and results. The $\mathrm{KOH}$ fusion uses a nickel crucible and the $\mathrm{Na}_{2} \mathrm{O}_{2}$ fusion uses a zirconium crucible. Cation analysis was performed using Inductively Coupled Plasma-Atomic Emission Spectrometry (ICP-AES). An analytical process blank (not to be confused with the AW-101 simulant glass Process Blank) was prepared similarly at the same time as the above samples. Approximately 0.1 grams of sample was processed and diluted to a final volume of about $100 \mathrm{ml}$ (the final solution volume was weighed and density corrected to a volume). All sample material after processing appeared to go into solution (no apparent residue remained in fusion crucibles or as precipitate in final solution). Analytical dilution of 5, 10, and 50-fold were prepared for each fusion preparation and analyzed by ICP-AES. The fusion procedure was modified slightly by including additional hydrochloric acid to assist solubilization of silver, if present. Before ICP-AES analysis a small amount $(0.1 \mathrm{ml})$ of hydrofluoric acid was added to the prepared samples.

A portion of the ALO-114 (sodium peroxide) fusion prepared samples was submitted for radiochemical analysis and Inductively Coupled Plasma-Mass Spectrometry (ICP-MS) analysis (see Section 3.1.3 Radiochemical Composition). No hydrofluoric acid was added to the aliquots submitted for radiochemistry or ICP-MS analysis.

\section{Test Equipment}

Cation analysis of the leachate solutions was completed using a Thermo Jarrell-Ash, Model 61 inductively coupled argon plasma spectrometer according to procedure PNL-ALO-211.

\subsubsection{Radiochemical Composition}

Radiochemical analyses were performed on each ILAW product, i.e. AW-101 and AN-107 glasses. Analyses included ${ }^{137} \mathrm{Cs}$ by gamma emission spectroscopy (GEA), ${ }^{90} \mathrm{Sr},{ }^{99} \mathrm{Tc},{ }^{238} \mathrm{Pu},{ }^{239} \mathrm{Pu},{ }^{240} \mathrm{Pu}$, ${ }^{237} \mathrm{~Np},{ }^{241} \mathrm{Am}$ and ${ }^{244} \mathrm{Cm}$. Concentration values of additional gamma emitters (i.e., $\mathrm{Cr}-51, \mathrm{Fe}-59, \mathrm{Se}-79$, $\mathrm{Nb}-95, \mathrm{Ru}-103, \mathrm{Sn}-113$, and Eu-152) that may be obtained by GEA, depending on concentrations and detection limits, were also looked for but not detected.

Samples of powdered waste glass AW-101 and AN-107 were analyzed for gamma emitters, ${ }^{90} \mathrm{Sr}$, $\mathrm{Pu}$, and $\mathrm{Am} / \mathrm{Cm}$. Duplicate samples of the powdered waste glass were solubilized in the laboratory using a $\mathrm{Na}_{2} \mathrm{O}_{2}-\mathrm{NaOH}$ fusion in a $\mathrm{Zr}$ crucible according to procedure PNL-ALO-114. About $0.1 \mathrm{~g}$ of material 
was fused and then dissolved in acid and brought to a volume of $100 \mathrm{ml}$. This fused material preparation was sampled directly for gamma energy analysis (GEA). A 10-ml aliquot was evaporated to dryness to remove $\mathrm{Cl}^{-}$, then brought back to volume and filtered through a 0.45 -micron filter. This matrix-adjusted material was used for $\mathrm{Pu}, \mathrm{Am}, \mathrm{Cm}$, and $\mathrm{Sr}$ analyses. Where appropriate, relatively large sample sizes were taken for analysis to obtain lower detection limits. Ten $\mathrm{ml}$ aliquots of the fused sample material were directly gamma counted for 14 hours on high-efficiency Ge detectors according to procedure PNLALO-450.

The $\mathrm{Pu}$ and $\mathrm{Am} / \mathrm{Cm}$ separations were performed on a 4-ml fusion aliquot according to procedure PNL-ALO-417. The separated fractions were precipitation plated according to PNL-ALO-496, and the samples were counted by alpha spectrometry according to PNL-ALO-422. Plutonium recovery was traced with ${ }^{242} \mathrm{Pu}$. The curium is known to follow the americium and both these isotopes were traced with ${ }^{243} \mathrm{Am}$.

The Sr separation was performed according to PNL-ALO-476 and radiochemical yields were traced with ${ }^{85} \mathrm{Sr}$. The separated fractions were then beta-counted according to RPG-CMC-408 and gamma counted according to PNL-ALO-450 (for ${ }^{85} \mathrm{Sr}$ determination and ${ }^{137} \mathrm{Cs}$ impurity assessment).

Samples of both AW-101 and AN-107 were analyzed using a radioactively-contained inductively coupled plasma mass spectrometer (ICP-MS) for ${ }^{99} \mathrm{Tc},{ }^{237} \mathrm{~Np},{ }^{239} \mathrm{Pu}$, and ${ }^{240} \mathrm{Pu}$ according to PNL-ALO-280, PNL-ALO-281, and PNL-ALO-282. Dilutions of Isotope Products standards for ${ }^{237} \mathrm{~Np}$ and ${ }^{239} \mathrm{Pu}$ and an Amersham ${ }^{99} \mathrm{Tc}$ standard were used to generate calibration curves. Independent standards of each analyte were used as the initial calibration verification (ICV) standard. The $1 \%$ high-purity nitric acid solution used to dilute the standards and samples was used as a reagent blank.

\section{Test Equipment}

Test equipment conformed to that required to carry out the PNL-ALO and RPG-CMC procedures called out above.

\subsection{Crystalline and Non-Crystalline Phase Determination}

Crystalline and non-crystalline phases were identified and measured using x-ray diffraction (XRD), optical microscopy, and scanning electron microscope (SEM). Twenty grams of heat-treated glass was available. The heat treatment was prescribed by the RPP-WTP project (see below) (Arm, 1999). The cooling curve, supplied by the RPP-WTP project, required to simulate the calculated ILAW centerline cooling curve of a LAW canister of glass $2 / 5$ of the way from the bottom of the canister was approximated by a series of eight (8) linear time-temperature segments. A programmable furnace was used to duplicate the series of eight (8) linear time-temperature segments.

Each heat-treated glass was examined using optical microscopy, both with a metallurgical microscope (magnification from $10 \times$ to $70 x$ ) and a transmitting light microscope (magnification at $100 \times$ to $250 x)$.

Powder XRD was also used to characterize the heat-treated glass samples. The two-theta scan range was from 5 to 75 degrees at a step size of 0.04 degrees with a minimum of 2-second dwell at each step. Both the AW-101 and AN-107 glasses were powdered in a tungsten carbide grinding chamber using a disc mill. An approximately $100 \mathrm{mg}$ sample of each glass was mounted on a plastic XRD sample mount, leveled to X-ray beam height, encapsulated in Mylar film, transported to XRD facility, and analyzed. 
Scanning electron microscopy (SEM) was also used to characterize the heat-treated AW-101 and AN-107 glass samples. Approximately 1 square $\mathrm{cm}$ by $4 \mathrm{~mm}$ thick samples of the LAW glasses were polished and then mounted on aluminum SEM specimen holders for microscopy. Both glass samples were polished to a minimum of 600 grit. Each mount was then coated with a gold film and examined at low magnification (15x and 100x) and higher magnifications such as $500 \times, 1000 \times, 3000 \times, 10,000 \times$, and $20,000 \times$.

\section{Canister Centerline Cooling Heat-treatment}

Samples of both LAW glasses (AW-101 and AN-107) were given a slow cool down heat treatment which simulates the cooling profile for glass at the center line of a canister been filled with a waste glass and allowed to cool to ambient temperature. The immobilized low activity waste (LAW) stainless steel canisters are basically right circular cylinders $2.29 \mathrm{~m}$ in height and $1.22 \mathrm{~m}$ in diameter. Glass canister filling was modeled with a batch target fill rate of $2,080 \mathrm{~kg} / \mathrm{hr}$ ( $50 \mathrm{MT} /$ day) for 45 minutes at a temperature of $1150^{\circ} \mathrm{C}$. Based on the canister configuration and fill rate, the RPP-WTP project provided a model calculation of the cooling curve for the centerline of a canister of glass $2 / 5$ of the way from the bottom of the canister. This model curve was approximated by a series of linear timetemperature segments that a programmable furnace duplicated. Table 3.4 below gives the set of linear time-temperature segments, which were duplicated by the furnace to within $\pm 4-5^{\circ} \mathrm{C}$ at all points along the profile.

Table 3.4. Temperature Profile Line Segments Used as Guidelines for Programming the Del Tech Furnace Controller to Generate the Canister Centerline Cooling Profile.

\begin{tabular}{|c|c|c|}
\hline Hours & Temperature $\left({ }^{\circ} \mathbf{C}\right)$ & dT/dt(deg./hr) \\
\hline $0.06-0.6$ & $1021.26-1000.95$ & -37.60 \\
\hline $0.6-1.80$ & $1000.95-976.94$ & -20.01 \\
\hline $1.80-2.80$ & $976.94-969.68$ & -7.26 \\
\hline $2.80-9.00$ & $969.6-964.16$ & -0.89 \\
\hline $9.00-16.00$ & $964.16-909.73$ & -7.78 \\
\hline $16.00-24.00$ & $909.73-780.63$ & -16.14 \\
\hline $24.00-38.00$ & $780.63-536.13$ & -17.46 \\
\hline $38.00-48.60$ & $536.13-396.59$ & -13.16 \\
\hline
\end{tabular}

The furnace used was the same Del Tech used to melt the glasses originally. The heat treated samples consisted of about 70 grams of glass melt which was poured from the initial melt into a cubic crucible of Pt-Rh foil. These samples were returned to the furnace as soon as it was ready to run the model canister centerline cooling (CCC) profile. After the heat treatment, each sample was sectioned perpendicular to the melt surface. From these sections specimens were produced, which were evaluated by optical microscopy and scanning electron microscopy using an energy dispersive spectroscopy (SEM-EDS) analyzer. 
Testing and Test Sample Evaluation Equipment

Glass samples were cut and polished with a Beuhler diamond saw and polishing equipment. Optical microscopy was completed using an Olympus PMG-3 microscope. An SEM (Model VG Elemental Shielded PQ2) with EDS capabilities was used to look for phase and chemical inhomogeneities. XRD was performed using a model SCINTAG PAD V x-ray diffractometer employing $\mathrm{Cu} \mathrm{K} \forall$ radiation $\left(1.54056 \mathrm{X}\right.$ ) with a scan increment of $0.05^{\circ}$ and a dwell time of 40 to 52 seconds.

\subsection{Release Rate, Modified Product Consistency Testing}

The ultimate objective for immobilization of the low activity waste is to incorporate and convert the radioactive and hazardous components into a solid glassy waste form that will resist their release to the environment in a Hanford near-surface burial ground. This resistance of the waste form to release deleterious environmental components is defined by measuring its chemical durability, i.e. the resistance of the glass to react with the aqueous environment expected in the glass disposal site. However, to mimic the mean temperature, amount and frequency of available ground waster, etc. expected in the near-surface repository would require a great amount of testing time to be able to detect glass dissolution. Therefore, an accelerated chemical durability test, the Product Consistency Test (PCT), is employed to gauge the ILAW glass chemical durability. The PCT was run at 40 and $90^{\circ} \mathrm{C}$, using glass samples given a slow cool down heat treatment which simulates the cooling profile for glass at the center line of a canister being filled with a waste glass and allowed to cool to ambient temperature, to determine the normalized release of sodium, silicon, and boron. The low-activity test reference material (LRM) standard glass was included in these tests to provide a reliable baseline of results by which to judge the quality of the PCT results for the AW-101 and AN-107 glasses.

PCT on the AW-101, AN-107 and glass samples were completed using ASTM C1285-97 "Standard Test Methods for Determining Chemical Durability of Nuclear, Hazardous, and Mixed Waste Glasses: The Product Consistency Test (PCT)." A brief summary of the steps followed is provided here. Crushed glass of a particle size between 75 and $150 \mu \mathrm{m}(-100$ to +200 mesh) was used for testing. The glass was ground in a tungsten carbide grinding chamber and then sieved through 100-and 200-mesh stainless steel sieves. The crushed glass was cleaned by washing in deionized water (DIW) and ethanol using an ultrasonic cleaner. It was then dried and weighed, and approximately $1.5 \mathrm{~g}$ of glass was added to a 22-mL desensitized Type 304L stainless steel container filled with $15 \mathrm{~mL}$ of DIW. The glass was precisely weighed and the leachant volume precisely controlled to achieve a solution volume to glass mass ratio of $10 \mathrm{~mL} / \mathrm{g}$ glass. The ratio of the surface area of the sample to leachant volume is estimated to be $2000 \mathrm{~m}^{-1}$. The container and their contents were held (without agitation) at 40 or $90^{\circ} \mathrm{C}$ for 7 days, for each of the two PCT conducted with each glass sample. The initial and final pH values of the solution were taken. Aliquots of the solution were filtered through a $0.45-\mu \mathrm{m}$ filter and submitted for ICP analysis. Results are reported as normalized elemental mass releases. The low-activity test reference material (LRM) was included in these tests (Ebert and Wolf. 1999). It has been extensively tested for the PCT and gives a reliable baseline of results by which to judge the quality of the PCT that have been run for AW-101 and AN-107.

All tests were run without deviation from the procedure described above except for the temperature profile for the $40^{\circ} \mathrm{C}$ test. During the first 17 hours the temperature drifted upward to about $46^{\circ} \mathrm{C}$ before the operator was able to bring the temperature down to $40^{\circ} \mathrm{C}$ and get the furnace to control at $40^{\circ} \mathrm{C}$ for the remainder of the test. Since the LRM glass was included in the test, its behavior relative to its expected behavior at $40^{\circ} \mathrm{C}$ was compared to see if there was significant deviation due to the initial temperature excursion. 


\section{Test Equipment}

PCT vessels, made of desensitized 304L stainless steel, were cleaned following ASTM C 1285-97, including the lids. DIW was taken from a Barnstead, Nanopure II water purifier. An Orion Research, Model 7201A digital ion analyzer was used to measure the $\mathrm{pH}$. The $\mathrm{pH}$ meter was

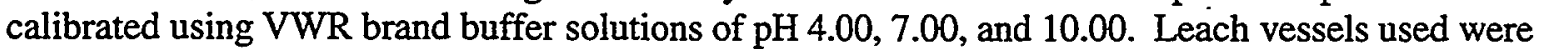
22 -mL screw-cap bombs fabricated from 304L stainless steel. Blue $M$ ovens were used for both 40 and $90^{\circ} \mathrm{C}$ PCT testing.

Analysis of the leachate solutions was completed using a Thermo Jarrell-Ash, Model 61 inductively coupled argon plasma spectrometer according to procedure PNL-ALO-211. 


\subsection{Results}

\subsection{Glass Fabrication and Analysis}

Three glass samples (AW-101, AN-107, and the Process Blank) were successfully processed and melted into a LAW glass form. These glasses were prepared for chemical and radiochemical composition determination.

\subsubsection{Glass Fabrication}

\section{Feed Preparation and Vitrification of the Process Blank Glass}

A surrogate AW-101 simulant LAW solution was made from sodium nitrite and nitrate and sodium and potassium hydroxide. These compounds were dissolved in about $350 \mathrm{~mL}$ of water in a $2 \mathrm{~L}$ glass beaker. The mineral additives $\left(\mathrm{Kyanite}\left(\mathrm{Al}_{2} \mathrm{SiO}_{5}\right)\right.$; orthoboric acid, $\left(\mathrm{H}_{3} \mathrm{BO}_{3}\right)$; Wollastonite $\left(\mathrm{CaSiO}_{3}\right)$; Red Iron Oxide Pigment $\left(\mathrm{Fe}_{2} \mathrm{O}_{3}\right)$; Olivine $\left.\left(\mathrm{Mg}_{2} \mathrm{SiO}\right)_{4}\right)$; Silica sand $\left(\mathrm{SiO}_{2}\right)$; Rutile Ore $\left(\mathrm{TiO}_{2}\right)$; Zinc Oxide ( $\mathrm{ZnO})$; Zircon sand $\left(\mathrm{ZrSiO}_{4}\right)$; and sugar) stirred into the waste solution easily as it was heating to evaporate water. When the feed had caked into a solid material, further drying of the feed took place in an oven over several days starting at about $120^{\circ} \mathrm{C}$ and ending at about $140^{\circ} \mathrm{C}$. Dried clumps were removed from the $2 \mathrm{~L}$ beaker, placed into a $400 \mathrm{~mL}$ beaker put into a furnace, and dried using ramp heating starting at $170^{\circ} \mathrm{C}$ and slowly increased to $370^{\circ} \mathrm{C}$ over 46 hours. The dried batch was a tan color, with light and dark shades.

The dried batch was added to a $500 \mathrm{~cm}^{3}$ platinum $10 \%$ rhodium crucible and calcined for 2.5 hours starting at $600^{\circ} \mathrm{C}$. After several hours at $650^{\circ} \mathrm{C}$ the calcined material was removed from the furnace and cooled. The furnace was heated to $1150^{\circ} \mathrm{C}$ and the calcined batch added back into it. Initial melting was vigorous, with large bubbles ( 3 to $4 \mathrm{~cm}$ diameter) rapidly forming and bursting; volatilization was observed, but foaming was minimal. Crucible was covered with a lid, batch melted for one hour then poured at a viscosity of about $5 \mathrm{~Pa}$. s onto a stainless steel plate. The glass was crushed in a $100 \mathrm{~cm}^{3}$ tungsten carbide grinding chamber, added back into the crucible, and melted for another hour. The glass poured well with no observed volatilization or bubbles and with an apparent viscosity of $5 \mathrm{~Pa} \cdot \mathrm{s}$ based upon past experience. The glass was processed and stored using clean metal and glass tools and containers, with no organic or plastic materials touching the glass.

\section{Feed Preparation and Vitrification of the AW-101 Glass}

A density determination was made of AW-101 pretreated waste just before feed preparation. The density was measured to be $1.23 \mathrm{~g} / \mathrm{cm}^{3}$, which was the same as the measurement made after pretreatment of the waste. This waste had no precipitate present. A portion of the waste, $604.4 \mathrm{~g}$, was measured into a $2 \mathrm{~L}$ glass beaker, stirred and heated for 2.5 hours on a stirrer / hot plate to evaporate water. Glass former additives (Kyanite $\left(\mathrm{Al}_{2} \mathrm{SiO}_{5}\right)$; Orthoboric acid, $\left(\mathrm{H}_{3} \mathrm{BO}_{3}\right)$; Wollastonite $\left(\mathrm{CaSiO}_{3}\right)$; Red Iron Oxide Pigment $\left(\mathrm{Fe}_{2} \mathrm{O}_{3}\right)$; Olivine $\left(\mathrm{Mg}_{2} \mathrm{SiO}_{4}\right)$; Silica sand $\left(\mathrm{SiO}_{2}\right)$; Rutile Ore $\left(\mathrm{TiO}_{2}\right)$; Zinc Oxide $(\mathrm{ZnO})$; Zircon sand $\left(\mathrm{ZrSiO}_{4}\right)$; and sugar) were added about half way through the heating process. Stirring stopped when slurry became too thick for the magnetic stirrer to spin. 
The batch was dried in an oven at $100^{\circ} \mathrm{C}$ over night, but a thin elastic film developed which prevented water from evaporating. The batch was continually heated in the oven at about $140^{\circ} \mathrm{C}$ with occasional hand stirring for six hours. The slurry hardened into a cake, which had to be heated on the hot plate to loosen it from beaker wall. The hard, dry cake was removed from beaker, broken, and placed in a $400 \mathrm{~cm}^{3}$ beaker. The batch was ramp heated to $330^{\circ} \mathrm{C}$ for 32 hours, cooled to $180^{\circ} \mathrm{C}$, and held for about 72 hours. The dried cake was light brown to light tan in color (see Figure 4.1).

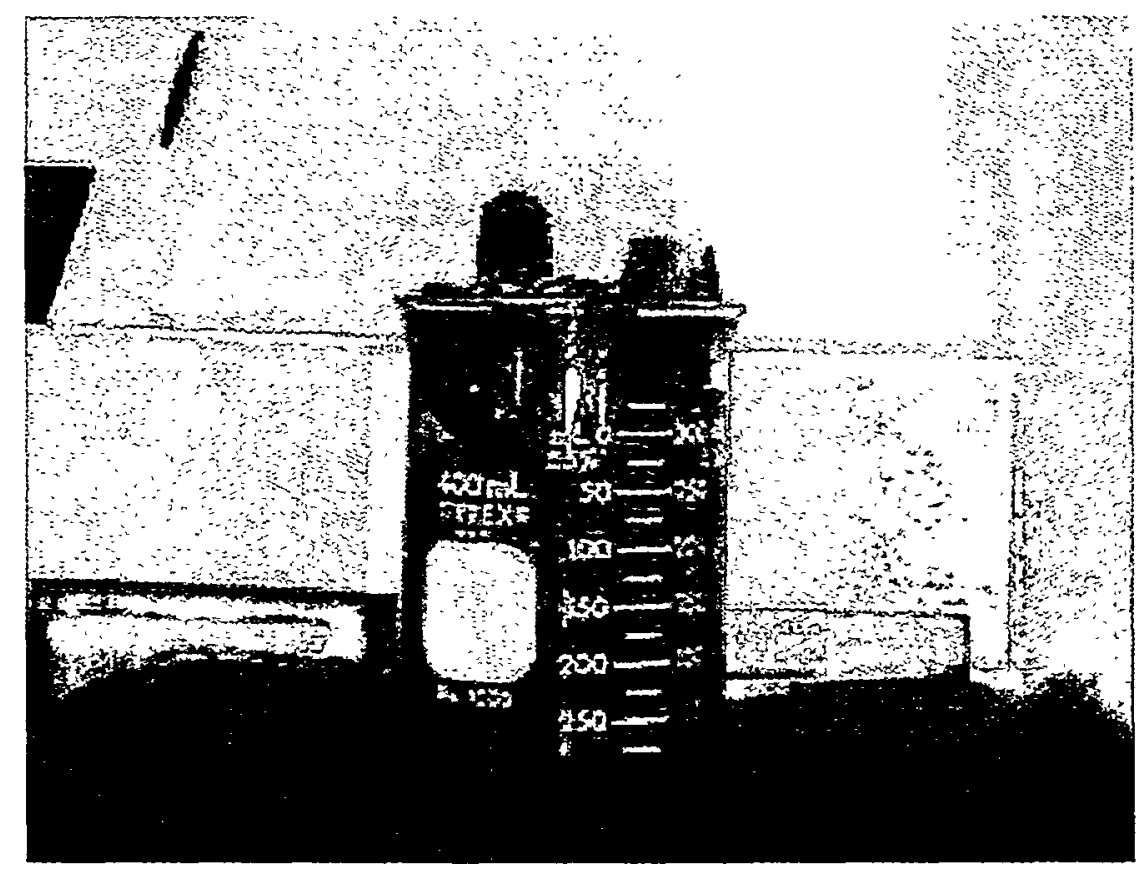

Figure 4.1. AW-101 Melter Feed After Drying to Temperatures up to $330^{\circ} \mathrm{C}$.

The dried batch was placed into a $500 \mathrm{cc}$ platinum $10 \%$ rhodium crucible and calcined for about 2.5 hours starting at $586^{\circ} \mathrm{C}$ and increasing the temperature to $682^{\circ} \mathrm{C}$. At $640^{\circ} \mathrm{C}$ the batch appeared dark gray in color and had become very dry and brittle, easily crumbling when lightly touched with tongs. At $682^{\circ} \mathrm{C}$, the batch began to sinter and foam (see Figure 4.2).

The AW-101 feed was melted at $1150^{\circ} \mathrm{C}$. Initially the feed had a difficult time fusing into a melt; there was foaming, volatile fumes observed, thick elastic skin on melt surface, and lots of bubbles that were having difficulty bursting. Once the feed had melted, the viscosity of the melt was about $5 \mathrm{~Pa} . \mathrm{s}$. After one hour, the melt was poured on a stainless steel plate, cooled, crushed to a fine powder in a 100 $\mathrm{cm}^{3}$ tungsten carbide grinding chamber, added back into the crucible, and melted for an hour. The final melt pour was excellent, with the viscosity of the melt at about $5 \mathrm{~Pa} \cdot \mathrm{s}$, bubbles present in the meniscus burst while being poured, and no volatile fumes were observed. The first portion of the pour went into a $2.54 \mathrm{~cm}^{3}$ box crucible for the canister centerline cooling test and the remainder of the melt was quenched on a stainless steel plate (see Figure 4.3). As seen in Figure 4.3, the box crucible for canister centerline cooling heat treatment is glowing red with hot, freshly poured glass. The slab of glass on the stainless steel pour plate has cooled but not broken from thermal shock because it is still above the glass transition temperature. 


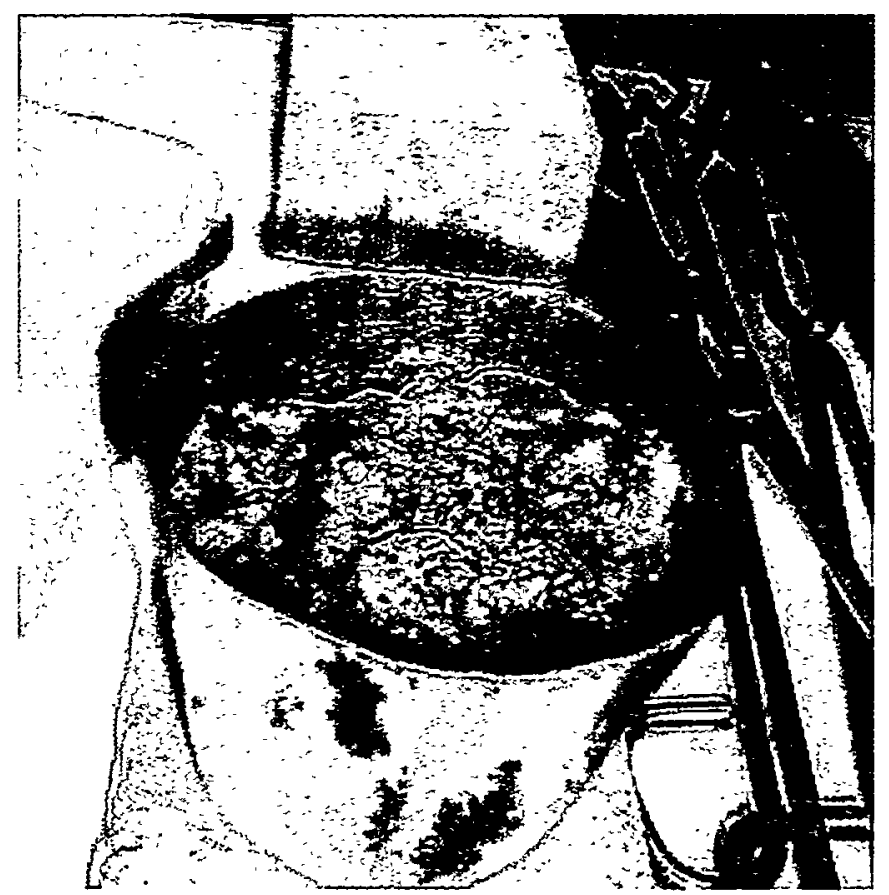

Figure 4.2. AW-101 Melter Feed in Platinum Crucible After Calcining.

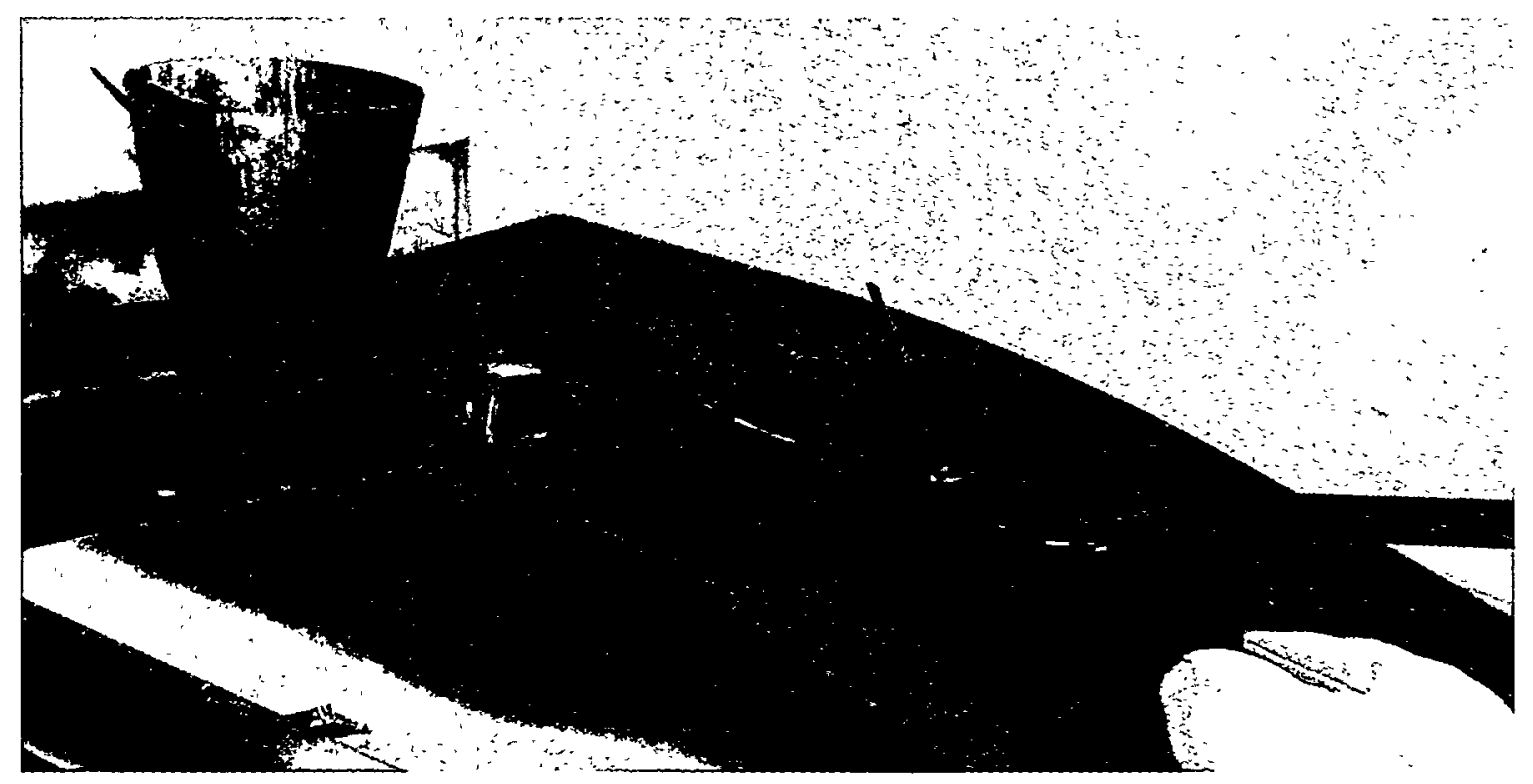

Figure 4.3. Final Pour of AW-101 Glass. 


\section{Feed Preparation and Vitrification of the AN-107 Glass}

Prior to the feed preparation, a density of the AN-107 waste was measured and calculated to be $1.20 \mathrm{~g} / \mathrm{cm}^{3}$, compared to the original density after pretreatment of $1.21 \mathrm{~g} / \mathrm{cm}^{3}$. The entire contents were added from the source container into a $2 \mathrm{~L}$ glass beaker. A thin layer of white precipitate remained on the bottom of the source container (plastic Erlenmeyer flask) and was visually estimated to be $1-2$ vol\%. Characterization of the observed white precipitate was not attempted This layer was carefully scraped with a stir rod and rinsed into beaker (traces of the precipitate remained in the flask). The AN-107 waste was heated and stirred on a hot plate; the heat changed the dark brown waste to an opaque orange-brown color with a suspension of fine solids. When the stir motor was stopped, a $1 \mathrm{~mm}$ layer of white solids collected on the bottom of the beaker.

The waste solution was heated for about one hour, then glass former minerals (Kyanite $\left(\mathrm{Al}_{2} \mathrm{SiO}_{5}\right)$; Orthoboric acid, $\left(\mathrm{H}_{3} \mathrm{BO}_{3}\right)$; Wollastonite $\left(\mathrm{CaSiO}_{3}\right)$; Red Iron Oxide Pigment $\left(\mathrm{Fe}_{2} \mathrm{O}_{3}\right) ;$ Olivine $\left(\mathrm{Mg}_{2} \mathrm{SiO}_{4}\right)$; Silica sand $\left(\mathrm{SiO}_{2}\right)$; Rutile Ore $\left(\mathrm{TiO}_{2}\right)$; Zinc Oxide $(\mathrm{ZnO})$; Zircon sand $\left(\mathrm{ZrSiO}_{4}\right)$; and sugar) were added while stirring. Foaming occurred with each addition of glass former additives. Foaming persisted through the drying cycle until slurry was too thick to stir on the stir plate. The melter feed was placed into the drying oven and heated overnight at about $110^{\circ} \mathrm{C}$. The batch foamed five to eight centimeters above the dried cake during the night (see Figure 4.4). The foam was crushed down onto the hard dry cake. The batch was heated again on a hot plate to dislodge the cake from the beaker. An exothermic reaction (the sugar-nitrate reaction) occurred which caused an incandescent glow, generated heat and smoke, changing the red-dry cake to a very dark brown cake, and coating the beaker walls with particulate (see Figure 4.5). The dried feed was consolidated into a $600 \mathrm{~mL}$ beaker, ramp heated in a Del Tech furnace from 150 to $350^{\circ} \mathrm{C}$, and held overnight at $350^{\circ} \mathrm{C}$. The batch changed color to a light tan and in some areas to a bright reddish-brown. 


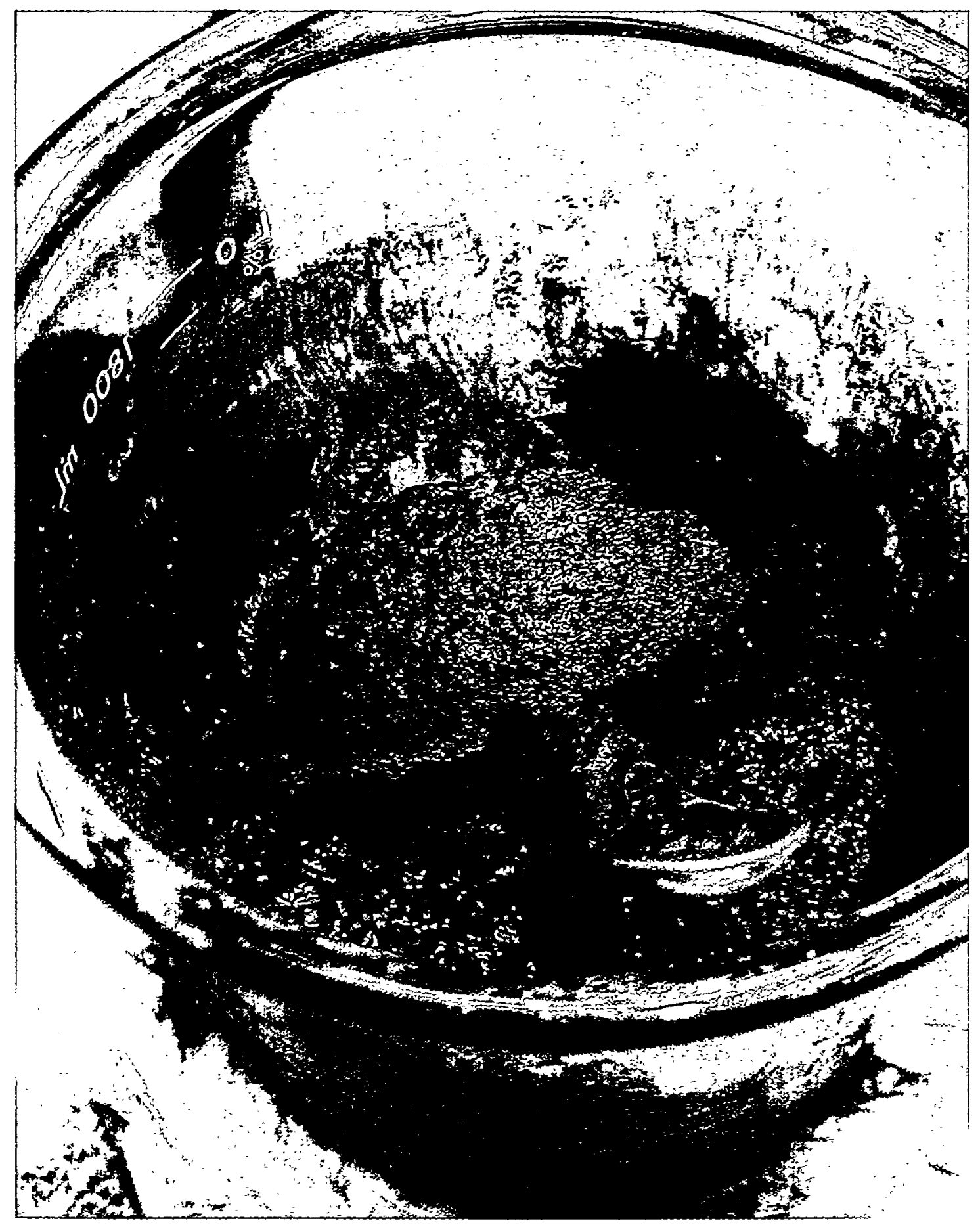

Figure 4.4. AN-107 Feed with Foam Which Crusted on Top of the Dried Feed During the Initial Drying Process. Note the 20-cm Long Stirring Spoon has Foam $80 \%$ Up the Handle. 


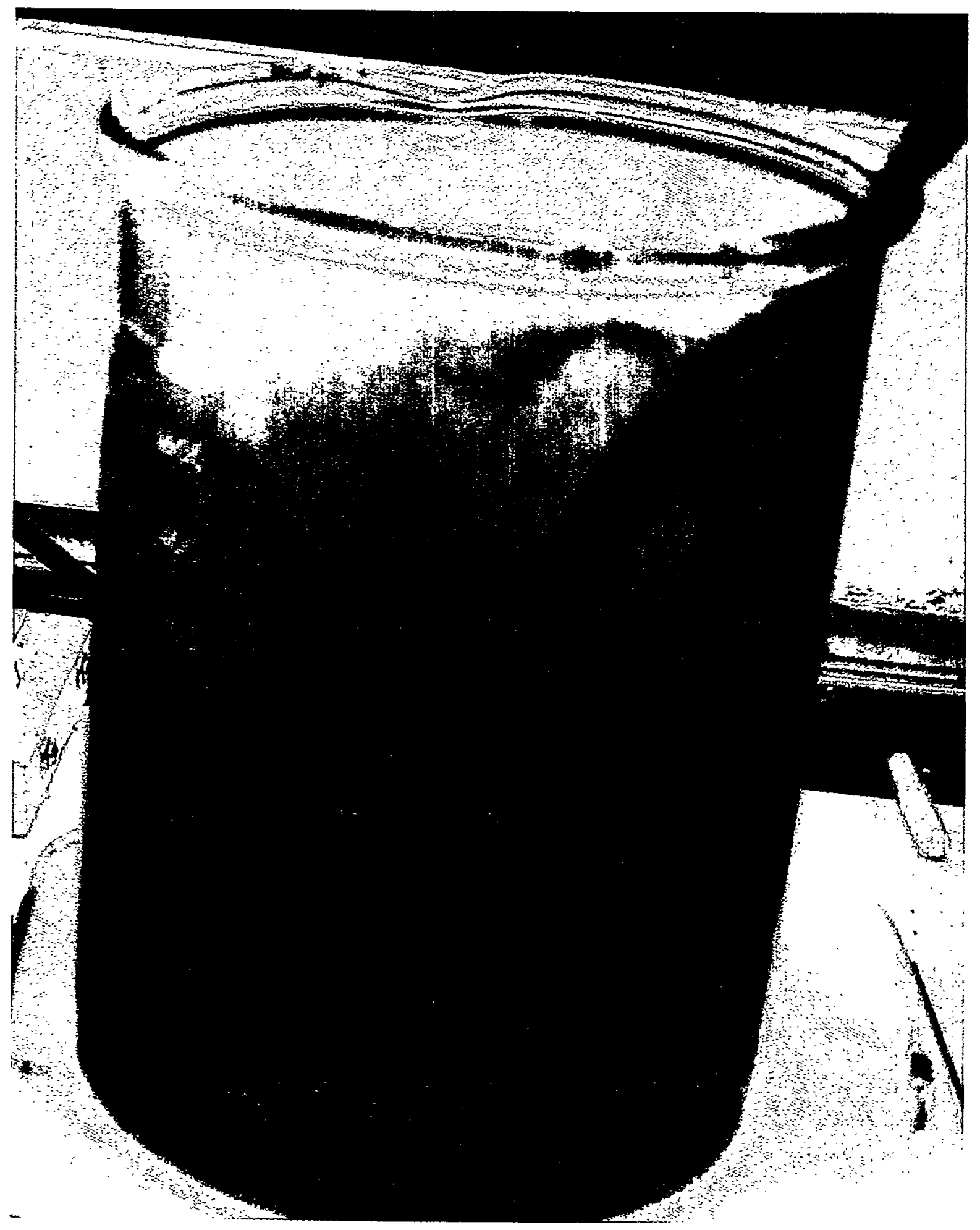

Figure 4.5. AN-107 Feed During Exothermic Reaction. Note the Drainage of Material that Adhered to Beaker Wall and the Cloudy, Frosted Appearance of the Beaker From Condensate During Reaction. 
Due to possible segregation during drying, the batch was crushed to a fine powder and mixed. The powder was added to a $500 \mathrm{~cm}^{3}$ platinum $10 \%$ rhodium crucible and calcined for two hours at $600^{\circ} \mathrm{C}$ and two hours at $650^{\circ} \mathrm{C}$. Batch remained in crucible and was melted at $1150^{\circ} \mathrm{C}$ for one hour, poured on stainless steel plate, cooled, crushed in a $100 \mathrm{~cm}^{3}$ tungsten carbide milling chamber, and remelted at $1150^{\circ} \mathrm{C}$ for an additional hour. The final pour had some bubbles at the meniscus, a slight vapor of volatile components observed when the lid was removed from the crucible, and an estimated viscosity of about 8 to $10 \mathrm{~Pa}$. s, based on visual observation and past experience, during the pour (see Figure 4.6).

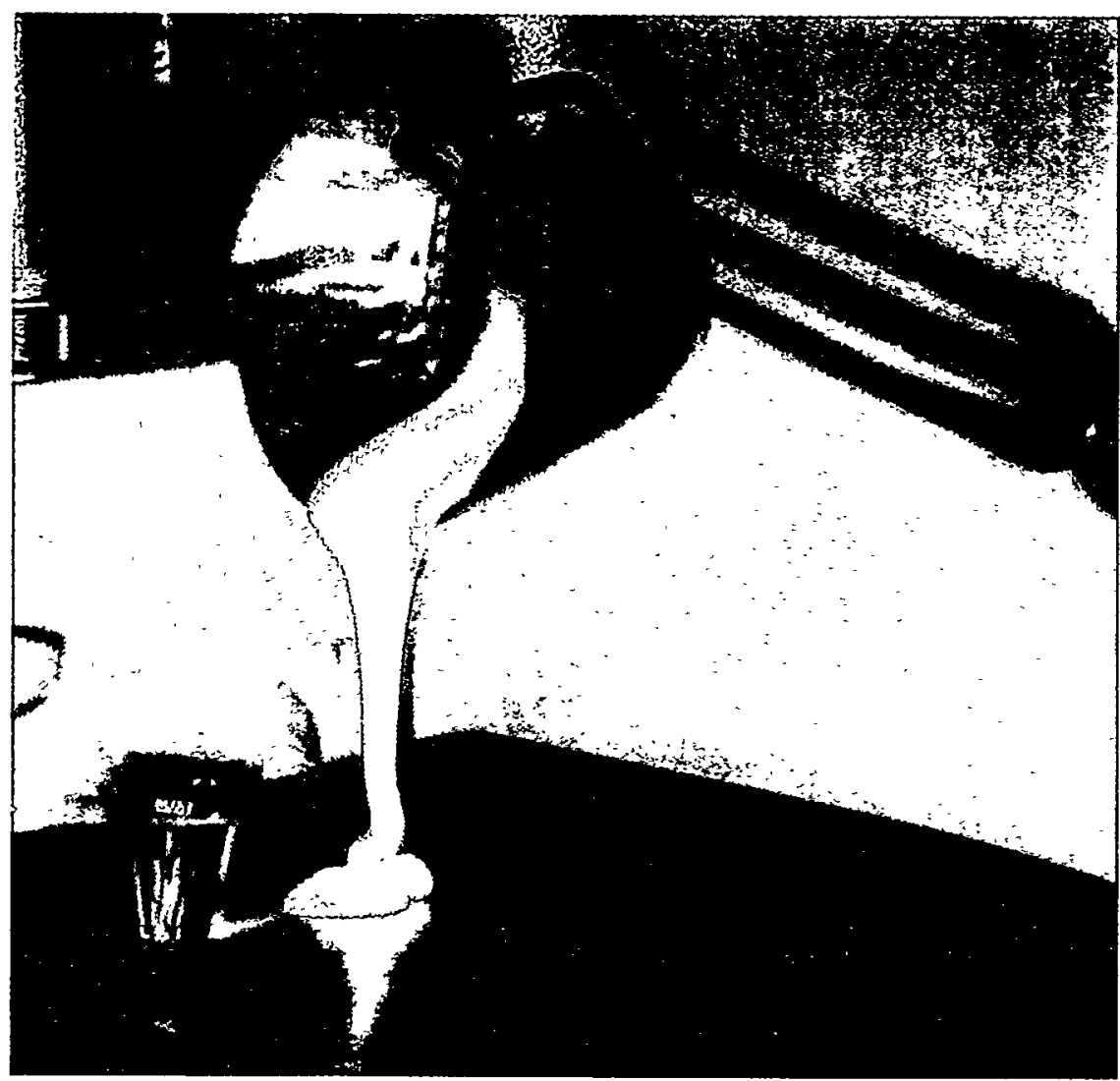

Figure 4.6. The AN-107 Glass in The Process of the Final Pour Onto the Stainless Steel Pour Plate. The $20 \mathrm{ml}$ Crucible for the Canister Centerline Cooling Heat Treatment is Red Hot with Freshly Poured Glass.

\subsubsection{Chemical Composition}

$\mathrm{KOH}$ and $\mathrm{Na}_{2} \mathrm{O}_{2}$ fusion preparations and ICP-AES analyses were performed on each of the radioactive glasses, AW-101 and AN-107, as well as the glass reference standard, ARG-1 (Smith 1993). This process established elemental composition for contract compliance and allowed calculation of modified PCT normalized releases. Table 4.1 provides analyzed chemical compositions in $\mu \mathrm{g}$ element/gram glass and $w t \%$ oxide. The reported wt $\%$ oxide values are analytical 'process blank' corrected. The ARG-1 analysis is found in Appendix A, Table A.3. The table shows that the analytical wt\% values agree with the target values for ARG-1 quite well indicating good analytical results.

Quality control objectives.were met for all analytes whose concentration was equal to or greater than $0.5 \mathrm{wt} \%$ as required. Concentrations of analytes in the ARG-1 laboratory control standard (LCS) that were present at levels greater than the estimated quantification limits (BQL) were within $\pm 10 \%$ of the values listed for the "Consensus Composition Determined by Round Robin 6" (Table 3.1, 
Smith 1993). Except for zinc, all other analytes detected in the LCS were recovered within the acceptance limits of 75 to $125 \%$. Summation of measured wt\% oxides in the LCS was about $98 \%$. The total accountability of mass in the glass by ICP-AES is $94.3 \%$ for Envelope A (AW-101) and 93.9\% for Envelope $\mathrm{C}(\mathrm{AN}-107)$. One reason for the approximately $6 \%$ discrepancy in total wt\% oxides is because certain elements (such as $\mathrm{SO}_{3}$; the halides $\mathrm{Br}, \mathrm{Cl}$, and $\mathrm{F}$; and trace metals) were not included in the analyses. Another reason is the lack of complete recovery of $\mathrm{SiO}_{2}$ and $\mathrm{Na}_{2} \mathrm{O}$ during the preparation of the sample for analysis. It will be shown shortly that when omitted or discrepant components are adjusted, the total wt $\%$ values for $\mathrm{AW}-101$ and $\mathrm{AN}-107$ are quite close to $100 \mathrm{wt} \%$.

ARG-1 glass was used as a reference to evaluate potential biases between measured wt $\%$ oxide in a glass sample and the true wt\% oxide in the glass. Using nominal wt\% oxides and associated standard deviations for ARG-1 from the MCC Round Robin (Smith 1993), a 80\% prediction interval for a single observation was formed for each oxide as discussed in Hahn and Meeker (1991). If the weight percent for a particular oxide in the ARG-1 glass (measured along with AW-101 and AN-107) was found to be outside the prediction interval for that oxide, then the bias for that oxide was deemed to be statistically significant. $\mathrm{CaO}, \mathrm{SrO}$, and $\mathrm{ZrO}_{2}$ were found to have statistically significant biases at the $80 \%$ confidence level. An $80 \%$ confidence level was used because the fact that ARG-1 was only analyzed once with AW-101 and AN-107 makes it statistically difficult to declare as significant biases ARG-1 measured values that are different from nominal values. Although ARG-1 measured versus nominal differences in $\mathrm{Al}_{2} \mathrm{O}_{3}$ and $\mathrm{TiO}_{2}$ were not statistically significant at the $80 \%$ confidence level, values of $\mathrm{Al}_{2} \mathrm{O}_{3}$ and $\mathrm{TiO}_{2}$ in $\mathrm{AW}-101$ and AN-107 were also bias corrected. The measured values of $\mathrm{Al}_{2} \mathrm{O}_{3}$ and $\mathrm{TiO}_{2}$ in $\mathrm{AW}-101$ and $\mathrm{AN}-107$ were consistently and non-negligibly below their target values, which agreed with the relative difference in measured ARG-1 values compared to the nominal values. In summary, bias corrections (on a relative basis) were made to the measured $\mathrm{wt} \%$ oxide values of $\mathrm{CaO}, \mathrm{SrO}, \mathrm{ZrO}_{2}, \mathrm{Al}_{2} \mathrm{O}_{3}$, and $\mathrm{TiO}_{2}$ for both $\mathrm{AW}-101$ and $\mathrm{AN}-107$.

Table 4.2 lists adjusted weight percentages for oxides in AW-101 and AN-107, which were obtained in one of several ways. As discussed in the previous paragraph, bias corrections were applied to the measured values of five oxides $\left(\mathrm{CaO}, \mathrm{SrO}, \mathrm{ZrO}_{2}, \mathrm{Al}_{2} \mathrm{O}_{3}\right.$, and $\left.\mathrm{TiO}_{2}\right)$. For other oxides and elements, target values were used as the adjusted values when the oxide or element was not analyzed, or when the analyzed value was less than the detection limit $(<D L)$. For the remaining components (except for $\mathrm{Na}_{2} \mathrm{O}$ and $\mathrm{SiO}_{2}$, discussed below), the analyzed value was used as the adjusted value (i.e., no adjustment). Based on past experience, the measured weight percentages for $\mathrm{Na}_{2} \mathrm{O}$ and $\mathrm{SiO}_{2}$ are typically lower than their true weight percentages. The reasons for this are different for each element. For silica, the reason is difficulty in getting silica into solution and keeping it there; and the precipitate is not easily observed. Hence the solution analyzed by the ICP is actually low in silica. For sodium oxide possible reasons include matrix effects (i.e., other elements present with sodium in the plasma flame) in the ICP plasma flame, temperature of the flame, and stability of the flame. Matrix effects are important because they are known to affect the easily ionized elements such as the alkalies and typical standards do not duplicate the matrix effect and as a result the sodium response in the sample and standard are different. The sodium emission is sensitive to the temperature of the plasma, so any shifting of the plasma flame relative to the optical detectors can change the sodium signal. Though the effect of these factors can shift the sodium-analyzed value up or down, the shift is generally down. Therefore, the target values for $\mathrm{Na}_{2} \mathrm{O}$ and $\mathrm{SiO}_{2}$ were used as their adjusted values. Notice that this action is supported by the fact that the increase of $\mathrm{Na}_{2} \mathrm{O}$ and $\mathrm{SiO}_{2}$ to their target values increases the oxide total for the adjusted analyses closer to $100 \%$ without overshooting $100 \%$. After all adjustments, the total wt $\%$ values for AW-101 and AN-107 are $99.8546 \%$ and 99.2689 , respectively. 
Table 4.2 compares the measured and the adjusted compositions to target glass compositions and shows that both the AW-101 and AN-107 glasses are fairly close to their target compositions. Because the total wt\% values for the adjusted AW-101 and AN-107 compositions are quite close to $100 \mathrm{wt} \%$, it is appropriate to renormalize the adjusted compositions to total $100 \mathrm{wt} \%$. The renormalized, adjusted compositions of AW-101 and AN-107 are shown in Table 4.2. Renormalization of measured compositions to $100 \mathrm{wt} \%$ can be inappropriate, in that: (1) biases are not properly addressed by the renormalization, and (2) renormalization to $100 \mathrm{wt} \%$ can induce biases in unbiased measured values. However, after appropriate bias corrections or adjustments, if total wt\% values are close enough to $100 \mathrm{wt} \%$ to suggest that all significant biases have likely been addressed, then renormalizing the adjusted compositions to $100 \mathrm{wt} \%$ is appropriate. (In fact, it has been shown in the statistics literature that renormalization in such a case actually reduces the uncertainty in the estimated composition.) 
Table 4.1. Chemical Analyses of AW-101 and AN-107 Radioactive Glasses

\begin{tabular}{|c|c|c|c|c|c|}
\hline Element & $\begin{array}{c}\text { AW-101 } \\
(\mu \mathrm{g} \text { element } / \mathrm{g})\end{array}$ & 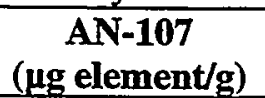 & Oxide & $\begin{array}{c}\text { AW-101 } \\
\text { (wt\% oxide) }\end{array}$ & $\begin{array}{c}\text { AN-107 } \\
\text { (wt\% oxide) }\end{array}$ \\
\hline $\mathrm{Ag}$ & $<130$ & $<130$ & $\mathrm{Ag}_{2} \mathrm{O}$ & 0.00 & 0.00 \\
\hline $\mathrm{Al}$ & 32100 & 32350 & $\mathrm{Al}_{2} \mathrm{O}_{3}$ & 6.06 & 6.11 \\
\hline As & $<1300$ & $<1300$ & $\mathrm{As}_{2} \mathrm{O}_{3}$ & 0.00 & 0.00 \\
\hline $\bar{B}$ & 29250 & 26450 & $\mathrm{~B}_{2} \mathrm{O}_{3}$ & 9.42 & 8.52 \\
\hline $\mathrm{Ba}$ & $<50$ & 240 & $\mathrm{BaO}$ & 0.00 & 0.03 \\
\hline $\mathrm{Be}$ & $<50$ & $<51$ & $\mathrm{BeO}$ & 0.00 & 0.00 \\
\hline$\overline{\mathrm{Bi}}$ & $<500$ & $<510$ & $\mathrm{Bi}_{2} \mathrm{O}_{3}$ & 0.00 & 0.00 \\
\hline $\mathrm{Ca}$ & 14450 & 14100 & $\mathrm{CaO}$ & 2.02 & 1.97 \\
\hline $\mathrm{Cd}$ & $<75$ & $<76$ & $\mathrm{CdO}$ & 0.00 & 0.00 \\
\hline $\mathrm{Ce}$ & $<1000$ & $<1000$ & $\mathrm{CeO}_{2}$ & 0.00 & 0.00 \\
\hline Co & $<250$ & $<250$ & $\mathrm{CO}_{2} \mathrm{O}_{3}$ & 0.00 & 0.00 \\
\hline $\mathrm{Cr}$ & 245 & 235 & $\mathrm{Cr}_{2} \mathrm{O}_{3}$ & 0.04 & 0.03 \\
\hline $\mathrm{Cu}$ & $<130$ & $<130$ & $\mathrm{CuO}$ & 0.00 & 0.00 \\
\hline Dy & $<250$ & $<250$ & $\mathrm{Dy}_{2} \mathrm{O}_{3}$ & 0.00 & 0.00 \\
\hline $\mathrm{Eu}$ & $<500<$ & $<510$ & $\mathrm{Eu}_{2} \mathrm{O}_{3}$ & 0.00 & 0.00 \\
\hline $\mathrm{Fe}$ & 35330 & 44780 & $\mathrm{Fe}_{2} \mathrm{O}_{3}$ & 5.05 & 6.40 \\
\hline $\mathrm{K}$ & 25500 & $<10000$ & $\mathrm{~K}_{2} \mathrm{O}$ & 3.07 & 0.00 \\
\hline $\mathrm{La}$ & $<250$ & $<250$ & $\mathrm{La}_{2} \mathrm{O}_{3}$ & 0.00 & 0.00 \\
\hline $\mathrm{Li}$ & $<150$ & $<150$ & $\mathrm{Li}_{2} \mathrm{O}$ & 0.00 & 0.00 \\
\hline $\mathrm{Mg}$ & 9395 & 12750 & $\mathrm{MgO}$ & 1.56 & 2.11 \\
\hline $\mathrm{Mn}$ & $<250$ & $<250$ & $\mathrm{MnO}_{2}$ & 0.00 & 0.00 \\
\hline Mo & $<250$ & $<250$ & $\mathrm{MoO}_{3}$ & 0.00 & 0.00 \\
\hline $\mathrm{Na}$ & 131000 & 136000 & $\mathrm{Na}_{2} \mathrm{O}$ & 17.66 & 18.33 \\
\hline $\mathrm{Nd}$ & $<500$ & $<510$ & $\mathrm{Nd}_{2} \mathrm{O}_{3}$ & 0.00 & 0.00 \\
\hline $\mathrm{Ni}$ & $<150$ & 430 & $\mathrm{NiO}$ & 0.00 & 0.05 \\
\hline$P$ & 635 & $<510$ & $\mathrm{P}_{2} \mathrm{O}_{5}$ & 0.15 & 0.00 \\
\hline $\mathrm{Pb}$ & $<500$ & $<510$ & $\mathrm{PbO}$ & 0.00 & 0.00 \\
\hline $\mathrm{Pd}$ & $<3800$ & $<3800$ & $\mathrm{PdO}$ & 0.00 & 0.00 \\
\hline $\mathrm{Rh}$ & $<1500$ & $<1500$ & $\mathrm{Rh}_{2} \mathrm{O}_{3}$ & 0.00 & 0.00 \\
\hline $\mathrm{Ru}$ & $<5500$ & $<5600$ & $\mathrm{RuO}_{2}$ & 0.00 & 0.00 \\
\hline $\mathrm{Sb}$ & $<2500$ & $<2500$ & $\mathrm{Sb}_{2} \mathrm{O}_{3}$ & 0.00 & 0.00 \\
\hline $\mathrm{Se}$ & $<1300$ & $<1300$ & $\mathrm{SeO}_{3}$ & 0.00 & 0.00 \\
\hline $\mathrm{Si}$ & 197000 & 200000 & $\mathrm{SiO}_{2}$ & 42.16 & 42.80 \\
\hline Sn & $<7500$ & $<7600$ & $\mathrm{SnO}_{2}$ & 0.00 & 0.00 \\
\hline $\mathrm{Sr}$ & 20 & 35 & $\mathrm{SrO}$ & 0.0024 & 0.0041 \\
\hline $\mathrm{Te}$ & $<7500$ & $<7600$ & $\mathrm{TeO}_{2}$ & 0.00 & 0.00 \\
\hline Th & $<5000$ & $<5100$ & $\mathrm{ThO}_{2}$ & 0.00 & 0.00 \\
\hline $\mathrm{Ti}$ & 10300 & 11200 & $\mathrm{TiO}_{2}$ & 1.72 & 1.87. \\
\hline $\mathrm{Tl}$ & $<2500$ & $<2500$ & $\mathrm{Tl}_{2} \mathrm{O}_{3}$ & 0.00 & 0.00 \\
\hline $\bar{U}$ & $<10000$ & $<10000$ & $\mathrm{UO}_{2}$ & 0.00 & 0.00 \\
\hline $\mathrm{V}$ & $<250$ & $<250$ & $\mathrm{~V}_{2} \mathrm{O}_{3}$ & 0.00 & 0.00 \\
\hline W & $<10000$ & $<10000$ & $\mathrm{WO}_{3}$ & 0.00 & 0.00 \\
\hline $\mathrm{Y}$ & $<250$ & $<250$ & $\mathrm{Y}_{2} \mathrm{O}_{3}$ & 0.00 & 0.00 \\
\hline $\mathrm{Zn}$ & 22750 & 23400 & $\mathrm{ZnO}$ & 2.83 & 2.91 \\
\hline \multirow[t]{2}{*}{$\mathrm{Zr}$} & 18950 & 20150 & $\mathrm{ZrO}_{2}$ & 2.56 & 2.72 \\
\hline & & & Total & 94.3 & 93.85 \\
\hline
\end{tabular}


Table 4.2. Target Versus Measured Composition of AW-101 and AN-107 Radioactive Glasses

\begin{tabular}{|c|c|c|c|c|c|c|c|c|}
\hline \multirow{2}{*}{$\begin{array}{l}\text { Oxide or } \\
\text { Element }\end{array}$} & \multicolumn{4}{|c|}{ AW-101 Radioactive Glass } & \multicolumn{4}{|c|}{ AN-107 Radioactive Glass } \\
\hline & $\begin{array}{l}\text { Target } \\
(\text { wt \%) }\end{array}$ & $\begin{array}{c}\text { Measured } \\
(w t \%)\end{array}$ & $\begin{array}{c}\text { Adjusted }^{(a)} \\
\text { (wt\%) }\end{array}$ & $\begin{array}{c}\text { Normalized } \\
\text { Adjusted }^{(\mathbf{b})} \\
\text { (wt } \%)^{(w 1}\end{array}$ & $\begin{array}{l}\text { Target } \\
\text { (wt\%) }\end{array}$ & $\begin{array}{l}\text { Measured } \\
(w t \%)\end{array}$ & $\begin{array}{c}\text { Adjusted }^{\text {(a) }} \\
\text { (wt\%) }^{\text {and }}\end{array}$ & $\begin{array}{l}\text { Normalized } \\
\text { Adjusted }^{(b)} \\
\text { (wt\%) }\end{array}$ \\
\hline $\mathrm{Al}_{2} \mathrm{O}_{3}$ & 6.08 & 6.06 & $6.2198^{(e)}$ & 6.2289 & 6.2311 & 6.11 & $6.2682^{(e)}$ & 6.3144 \\
\hline $\mathrm{B}_{2} \mathrm{O}_{3}$ & 9.71 & 9.42 & 9.42 & 9.4337 & 8.9433 & 8.52 & 8.52 & 8.5827 \\
\hline $\mathrm{BaO}$ & 0.0 & $<0.005$ & $0.0^{(\mathrm{c})}$ & 0.0 & 0.0191 & 0.03 & 0.03 & 0.0302 \\
\hline $\mathrm{CaO}$ & 1.99 & 2.02 & $1.8387^{(e)}$ & 1.8413 & 2.0095 & 1.97 & $1.7941^{(c)}$ & 1.8073 \\
\hline $\mathrm{CdO}$ & 0.0 & $<0.008$ & $0.0^{(c)}$ & 0.0 & 0.004 & $<0.008$ & $0.004^{(c)}$ & 0.0040 \\
\hline $\mathrm{Co}_{2} \mathrm{O}_{3}$ & 0.0 & $<0.033$ & $0.0^{(c)}$ & 0.0 & 0.0003 & $<0.033$ & $0.0003^{(c)}$ & 0.0003 \\
\hline $\mathrm{Cr}_{2} \mathrm{O}_{3}$ & 0.009 & 0.04 & 0.04 & 0.0401 & 0.0029 & 0.03 & 0.03 & 0.0302 \\
\hline $\mathrm{Cs}_{2} \mathrm{O}$ & 0.0012 & $N M$ & $0.0012^{(\mathrm{c})}$ & 0.0012 & 0.0 & 0.0 & 0.0 & 0.0 \\
\hline $\mathrm{CuO}$ & 0.0 & $<0.015$ & $0.0^{(\mathrm{c})}$ & 0.0 & 0.0021 & $<0.015$ & $0.0021^{(c)}$ & 0.0021 \\
\hline $\mathrm{Fe}_{2} \mathrm{O}_{3}$ & 5.54 & 5.05 & 5.05 & 5.0574 & 7.018 & 6.40 & 6.40 & 6.4471 \\
\hline $\mathrm{K}_{2} \mathrm{O}$ & 2.58 & 3.07 & 3.07 & 3.0745 & 0.1418 & $<1.138$ & $0.1418^{(\mathrm{c})}$ & 0.1248 \\
\hline $\mathrm{MgO}$ & 1.48 & 1.56 & 1.56 & 1.5623 & 2.0117 & 2.11 & 2.11 & 2.1255 \\
\hline $\mathrm{MoO}_{3}$ & 0.0 & 0.0 & 0.0 & 0.0 & 0.0031 & $<0.035$ & $0.0031^{(\mathrm{c})}$ & 0.0031 \\
\hline $\mathrm{Na}_{2} \mathrm{O}$ & 20.0 & 17.66 & $20.0^{(\mathrm{d})}$ & 20.0291 & 20.0 & 18.33 & $20.0^{(\mathrm{d})}$ & 20.1473 \\
\hline $\mathrm{NiO}$ & 0.0 & 0.0 & 0.0 & 0.0 & 0.0351 & 0.05 & 0.05 & 0.0504 \\
\hline $\mathrm{P}_{2} \mathrm{O}_{5}$ & 0.0699 & 0.15 & 0.15 & 0.1502 & 0.0153 & $<0.108$ & $0.0153^{(c)}$ & 0.0154 \\
\hline $\mathrm{PbO}$ & 0.0 & $<0.050$ & $0.0^{(\mathrm{c})}$ & 0.0 & 0.0038 & $<0.051$ & $0.0038^{(\mathrm{c})}$ & 0.0038 \\
\hline $\mathrm{SO}_{3}$ & 0.2139 & $\mathrm{NM}$ & $0.2139^{(c)}$ & 0.2142 & 0.1267 & NM & $0.1267^{(c)}$ & 0.1276 \\
\hline $\mathrm{Sb}_{2} \mathrm{O}_{3}$ & 0.0 & 0.0 & 0.0 & 0.0 & 0.0 & 0.0 & 0.0 & 0.0 \\
\hline $\mathrm{SiO}_{2}$ & 44.05 & 42.16 & $44.05^{(\mathrm{d})}$ & 44.1141 & 44.7841 & 42.80 & $44.7841^{(\mathrm{d})}$ & 45.1139 \\
\hline $\mathrm{SrO}^{\circ}$ & 0.0 & 0.0024 & $0.0029^{(e)}$ & 0.0029 & 0.0013 & 0.0041 & $0.0049^{(e)}$ & 0.0050 \\
\hline$\overline{\mathrm{TiO}_{2}}$ & 1.9939 & 1.72 & $1.8698^{(e)}$ & 1.8725 & 2.0039 & 1.87 & $2.0332^{(c)}$ & 2.0482 \\
\hline $\mathrm{WO}_{3}$ & 0.0 & $<1.181$ & $0.0^{(c)}$ & 0.0 & 0.0115 & $<1.190$ & $0.0115^{(\mathrm{c})}$ & 0.0116 \\
\hline $\mathrm{ZnO}$ & 2.95 & 2.83 & 2.83 & 2.8341 & 2.9949 & 2.91 . & 2.91 & 2.9314 \\
\hline $\mathrm{ZrO}_{2}$ & 2.99 & 2.56 & $3.1963^{(e)}$ & 3.2010 & 3.0097 & 2.72 & $3.3988^{(e)}$ & 3.4239 \\
\hline $\mathrm{Br}$ & 0.0 & $\mathrm{NM}$ & $0.0^{(c)}$ & 0.0 & 0.0784 & $\overline{N M}$ & $0.0784^{(\mathrm{c})}$ & 0.0790 \\
\hline $\mathrm{Cl}$ & 0.0784 & NM & $0.0784^{(\mathrm{c})}$ & 0.0785 & 0.0784 & NM & $0.0784^{(\mathrm{c})}$ & 0.0790 \\
\hline $\mathrm{F}$ & 0.0 & NM & $0.0^{(\mathrm{c})}$ & 0.0 & 0.4701 & NM & $0.4701^{(c)}$ & 0.4736 \\
\hline Unknown & 0.2637 & NM & $0.2637^{(\mathrm{c})}$ & 0.2641 & 0.0 & NM & $0.0^{(c)}$ & 0.0 \\
\hline Total & 100.0000 & 94.3 & 99.8546 & $100.0000^{(t)}$ & 100.0001 & 93.85 & 99.2689 & $100.0000^{(t)}$ \\
\hline \multicolumn{9}{|c|}{$\begin{array}{l}\text { (a) See text for description of how adjusted values were determined. } \\
\text { (b) Adjusted values normalized to total } 100 \text { wt\%. - } \\
\text { (c) Values less than detection limits or not measured (NM) values were adjusted to target values. } \\
\text { (d) Set to target value as best available estimate of actual value. } \\
\text { (e) Bias correction based on ARG-1 applied to measured value. } \\
\text { (f) Total is } 100.0000 \text { prior to rounding entries to four decimal places. } \\
\text { <x.xx = indicates that the analyte is below the detection limit, detection limit value is provided for those analytes. }\end{array}$} \\
\hline
\end{tabular}


Per the RPP-WTP project LAW glass Task Specification, the concentration of the waste sodium oxide shall be greater than $16 \mathrm{wt} \%$. The target concentration of sodium oxide for both glasses is $20 \mathrm{wt} \%$. The measured wt\% sodium oxide content for the AW-101 and AN-107 glasses are 17.7 and 18.3, respectively. As all of the sodium oxide content for the AW-101 glass originated from the initial tank waste, the measured sodium oxide content of the AW-101 glass exceeds the Task Specification, sodium oxide concentration level of 16 weight percent. Based upon past experience, the measured weight percentage for $\mathrm{Na}_{2} \mathrm{O}$ is almost always lower than its true weight percentage, which provides an even larger margin of passing the Task Specification requirement. The ORP Contract Specification 2, Immobilized Low-Activity Waste, Section 2.2.2.2, Waste Loading, states: "The loading of waste sodium from Envelope $\mathrm{A}$ in the ILAW glass shall be greater than 14 weight percent based on $\mathrm{Na}_{2} \mathrm{O}$. The loading of waste sodium from Envelope B in the ILAW glass shall be greater than 5.0 weight percent based on $\mathrm{Na}_{2} \mathrm{O}$. The loading of waste sodium from Envelope $\mathrm{C}$ in the $\mathrm{ILAW}$ glass shall be greater than 10 weight percent based on $\mathrm{Na}_{2} \mathrm{O}$." Therefore, additionally, the AW-101 (Envelope A) glass easily meets the ORP contract specification for waste sodium loading. However, not all of the sodium oxide content for the AN-107 glass originated from the initial tank waste. Therefore, the amount of sodium from the original, as-received AN-107 waste in needed to allow the determination of the waste loading of the AN-107 glass.

The sodium concentration in the as-received AN-107 waste was $9.26 \mathrm{M}$. The as-received waste (1.57-L) was combined with 0.16-L of decanted supernatant $(9.0 \mathrm{M} \mathrm{Na})$ to give $1.73-\mathrm{L}$ of waste with a sodium concentration of $9.2 \mathrm{M}$. The diluted feed was prepared by adding $0.13-\mathrm{L}$ of $19 \mathrm{M} \mathrm{NaOH}$ and $0.44-\mathrm{L}$ of $0.1 \mathrm{M} \mathrm{NaOH}$ to the $1.73-\mathrm{L}$ of waste. The AN-107 diluted feed has a calculated sodium concentration of $8.1 \mathrm{M}$. The diluted feed was $75 \mathrm{vol} \%$ as-received waste. The AN-107 diluted feed was characterized as two individual components, supernatant and centrifuged solids (Urie et al. 1999B). The data.from each component was used to calculate the starting composition of the diluted feed. The data from the individual samples were averaged, and the density was used for the supernatant, along with the percent centrifuged solids data to calculate the initial composition of the diluted feed. The calculated composition of the starting AN-107 diluted feed is shown in Table 2.1 contained in report number PNWD-3035 (Hallen et al 2000). The sodium concentration reported for the supernatant fraction, 7.5M, appears much lower than expected 8.1M. However, the analyses conducted on the treated waste samples, reported in Section 3.0 of this report, also suggest the sodium concentration reported in Table 2.1, report number PNWD-3035 (Hallen et al 2000), is too low. The sodium concentration of the diluted feed must be close to the calculated sodium concentration of $8.1 \mathrm{M}$. So the Diluted feed is $75 \mathrm{vol} \%$ as-received waste. Calculation of sodium in the original waste compared to the amount in the final Sr/TRU treated supernatant shows that $86.4 \%$ of the sodium in the diluted feed was from the original waste; however, the waste could not be treated at this high a concentration so an additional dilution/caustic adjustment was completed before the addition of the $\mathrm{Sr}$ and sodium permanganate solutions were added to complete the $\mathrm{Sr} / \mathrm{TRU}$ precipitation process. The Sr/TRU removal process was demonstrated on 1.4-L of the diluted feed and 0.4-L was saved for future studies. Stock solutions of the reagents $\left(\mathrm{NaOH}, \mathrm{Sr}\left(\mathrm{NO}_{3}\right)_{2}\right.$, and $\mathrm{NaMnO}_{4}$ ) were prepared outside the hot cells for addition to the waste. Sodium hydroxide solution, $3.52 \mathrm{M}$, was added to adjust the sodium and hydroxide concentrations. The strontium solution was made up as the nitrate salt in $1 \mathrm{M}$ concentration. The experiment used $1 \mathrm{M}$ sodium permanganate. The data show that the final treated waste contained $75 \mathrm{vol} \%$ of the diluted feed. The amount of original waste sodium in the Sr/TRU treated waste now takes into account this final dilution factor, i.e. $91.66 \%$.

Therefore, the final sodium concentration in the Sr/TRU treated supernatant from the original waste is 79.2\%. The other sodium is from the $\mathrm{NaOH}$ used for caustic adjustment and a small amount, $1 \%$, from the sodium permanganate. One must be careful using this concentration data as an additional dilution of $25 \%$ was done to facilitate filtering tests, but this did not change the ratio, or amount of sodium in the waste that was from the original, as-received AN-107 waste. 
As $79.2 \%$ of the sodium oxide content for the AN-107 glass originated from the initial tank waste, for the AN-107 glass to exceed the Task Specification target, sodium oxide concentration level of 16 weight percent the wt\% sodium oxide content of the glass would need to be $20 \mathrm{wt} \%$ which is the target glass concentration. Again, based upon past experience, the measured weight percentage for $\mathrm{Na}_{2} \mathrm{O}$ wt $\%$ values are almost always lower than its true weight percentage and we previously discussed the validity of using the target $\mathrm{Na}_{2} \mathrm{O}$ value as the true glass value. Therefore, the amount of sodium from the original, as-received AN-107 waste is determined to meet the Task Specification for the waste loading of the AN-107 glass. And, per the ORP Contract Specification 2.2.2.2, “...The loading of waste sodium from Envelope $\mathrm{C}$ in the $\mathrm{LAW}$ glass shall be greater than 10 weight percent based on $\mathrm{Na}_{2} \mathrm{O}$." therefore, the AN-107 (Envelope C) glass easily meets the ORP contract specification for waste sodium loading.

The waste or additive loading fraction in the glass can be calculated from the dilution (decrease in concentration) of the element oxide concentrations contained either in the waste or in the glass forming additives in the final glass. The calculation is particularly simple when the diluted element oxide is contained in only one of the two components. For this calculation, the concentration of the element oxide in the glass is divided by the concentration of the element oxide in either the waste component or the additive component. As the AW-101 glass had no chemical additions made to it through the various unit operations these calculations can be readily used. For the AW-101 glass, the boron oxide level in the glass has a normalized value of $9.43 \mathrm{wt} \%$ and its concentration as part of the additives was $13.15 \mathrm{wt} \%$ and their ratio is 0.7171 . Again for AW-101, using an element oxide contributed only by the waste such as potassium oxide, the ratio is found to be 0.3109 . Table 4.3 summarizes these calculations for the AW-101 glass. Note that the dilution factors for the additive dilution and the waste dilution theoretically will add up to 1.00. The average factors and their sum, based on the measured oxide values for the AW-101 glass is $0.7312+0.2864=1.0176$. The results indicate that the waste fraction for the AW-101 glass is near or exceeds the target value of $26.15 \%$.

Table 4.3. Waste Loading/Dilution factors for LAW Waste Glass AW-101

\begin{tabular}{|c|c|c|c|c|c|}
\hline \multicolumn{6}{|c|}{ AW-101 } \\
\hline \multirow[b]{2}{*}{ Oxide } & Waste & Additives & Glass & Waste Dilution & Additive dilution \\
\hline & wt\% oxide & wt\% oxide & $\begin{array}{l}\text { Normalized } \\
\text { wt\% oxide }\end{array}$ & (Glass/Waste) & (Glass/Additive) \\
\hline $\mathrm{B}_{2} \mathrm{O}_{3}$ & & 13.15 & 9.43 & & 0.7171 \\
\hline $\mathrm{CaO}$ & & 2.70 & 2.02 & & 0.7481 \\
\hline $\mathrm{Fe}_{2} \mathrm{O}_{3}$ & & 7.50 & 5.06 & & 0.6747 \\
\hline $\mathrm{K}_{2} \mathrm{O}$ & 9.876 & & 3.07 & 0.3109 & \\
\hline $\mathrm{MgO}$ & & 2.00 & 1.56 & & 0.7800 \\
\hline $\mathrm{Na}_{2} \mathrm{O}$ & 76.477 & & 20.029 & 0.2619 & \\
\hline $\mathrm{SiO}_{2}$ & & 59.65 & 44.11 & & 0.7394 \\
\hline $\mathrm{TiO}_{2}$ & & 2.70 & 1.87 & & 0.6926 \\
\hline $\mathrm{ZnO}$ & & $4: 00$ & 2.83 & & 0.7075 \\
\hline $\mathrm{ZrO}_{2}$ & & 4.05 & 3.20 & & 0.7901 \\
\hline \multicolumn{4}{|c|}{$\begin{array}{l}\text { Average Dilution of Waste and Additive } \\
\text { Components }\end{array}$} & $\begin{array}{c}0.2864 \\
\text { (target } 0.2615 \text { ) }\end{array}$ & $\begin{array}{c}0.7312 \text { (target } \\
0.7385 \text { ) } \\
\end{array}$ \\
\hline
\end{tabular}

A straightforward calculation of the original waste loading fraction in the $\mathrm{AN}-107$ glass (Table 4.4) cannot be calculated from the dilution (decrease in concentration) of the element oxide concentrations. This is because a number of element concentrations were changed by chemical additions needed to facilitate the Sr/TRU and sulfate precipitation processing performed on this waste prior to being incorporated in the waste glass. Therefore, the waste loading has been computed on the basis of the processed waste composition as derived from the data given in Table 3.2. As before, only elements were used which were found in significant quantities in either the additives or the processed waste but not both. 
The only waste dilution factor based on more than one significant digit is that for sodium, which gives a value that is likely statistically equal to the target loading for the waste of $21.4 \%$. The other element (Ni) is present in both the waste and the waste glass in small quantities limiting the precision of the dilution factor of this oxide. In addition, the dilution of the additive elements, $79.7 \%$, indicates that the waste loading is at the target level.

Table 4.4. Waste Loading/Dilution factors for LAW Waste Glass AN-107

\begin{tabular}{|c|c|c|c|c|c|}
\hline \multicolumn{6}{|c|}{ AN-107 } \\
\hline \multirow[b]{2}{*}{ Oxide } & Processed Waste & Additives & Glass & Waste Dilution & Additive dilution \\
\hline & wt\% oxide & wt\% oxide & $\begin{array}{l}\text { Normalized } \\
\text { wt\% oxide }\end{array}$ & (Glass/ Waste) & (Glass/Additive) \\
\hline $\mathrm{Al}_{2} \mathrm{O}_{3}$ & & 7.64 & 6.31 & & 0.8259 \\
\hline $\mathrm{B}_{2} \mathrm{O}_{3}$ & & 11.38 & 8.58 & & 0.7487 \\
\hline & & & & & \\
\hline $\mathrm{CaO}$ & & 2.31 & 1.81 & & 0.7835 \\
\hline $\mathrm{Fe}_{2} \mathrm{O}_{3}$ & & 8.93 & 6.45 & & 0.7223 \\
\hline $\mathrm{MgO}$ & & 2.56 & 2.13 & & 0.8320 \\
\hline $\mathrm{Na}_{2} \mathrm{O}$ & 93.3814 & & 20.15 & 0.2158 & \\
\hline $\mathrm{NiO}$ & 0.1639 & & 0.05 & 0.3051 & \\
\hline $\mathrm{SiO}_{2}$ & & 56.99 & 45.11 & & 0.7915 \\
\hline $\mathrm{TiO}_{2}$ & & 2.55 & 2.05 & & 0.8039 \\
\hline $\mathrm{ZnO}$ & & 3.81 & 2.93 & & 0.7690 \\
\hline $\mathrm{ZrO}_{2}$ & & 3.83 & 3.42 & & 0.8930 \\
\hline \multicolumn{4}{|c|}{ Average Dilution of Waste and Additive Components } & $\begin{array}{c}0.2604 \text { (target } \\
0.214) \\
\end{array}$ & $\begin{array}{c}0.7966 \text { (target } \\
0.786 \text { ) }\end{array}$ \\
\hline
\end{tabular}

Summarizing, the waste loading was calculated from the dilution factor (decrease in concentration) of elements contained in either the waste or the glass forming additives. The results indicate that the waste fraction of each glass is near their target, i.e. $26.15 \%$ for AW-101 (measured $28.64 \%$ based on waste dilution and $26.88 \%$ based on additive dilution) and $21.4 \%$ for AN-107 (measured $26.04 \%$ based on waste dilution and $20.34 \%$ based on additive dilution). The measured glass to target composition percent difference comparison of the oxides is small and the calculated waste loading values are very close to or exceed the target. Both support the conclusion that the actual waste loading in each glass met or exceeded the target waste loading.

\subsubsection{Radiochemical Composition}

Samples of powdered waste glass AW-101 (sample ID: AW-101-QC-1) and AN-107 (sample ID: AN-107-QC-1) were analyzed for gamma emitters, ${ }^{90} \mathrm{Sr}, \mathrm{Pu}$, and $\mathrm{Am} / \mathrm{Cm}$. Table 4.5 and Appendix A list measured analyte activities in the original material in units of $\mu \mathrm{Ci} /$ gram. The reported errors $(1-\sigma)$ represent the total propagated error including counting, dilution, yield, and calibration errors, as appropriate. Laboratory and process blank values given with each analysis are the best indicators of the method detection limits, taking into account the actual sample sizes and counting times used for each analysis.

Table 4.5 provides radiochemical data from the Envelope A (AW-101) and C (AN-107) glasses and comparisons with compositional predictions from the waste. The first column of data provides radionuclide estimates based on sample analysis of the pretreated wastes. The second column of data provides analyzed radionuclide values from the actual waste glasses produced by vitrification of the waste. Percent recoveries in the glass are calculated and presented in the last column. 
Table 4.5. Radiochemical Composition of AW-101 and AN-107 Glasses

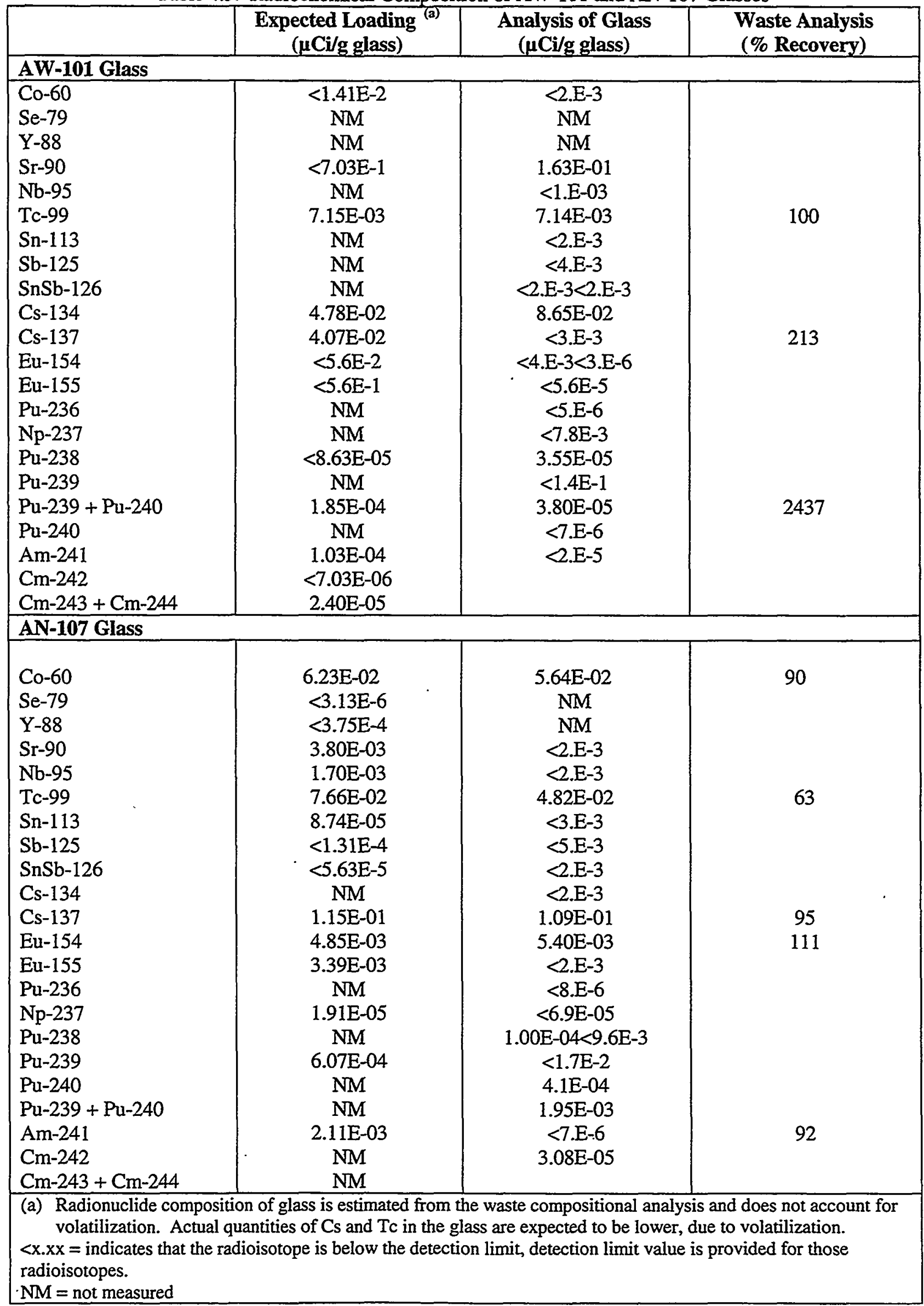


All of the fused samples directly gamma counted showed ${ }^{137} \mathrm{Cs}$. The AN-107 samples also showed significant activities of ${ }^{60} \mathrm{Co}$ and ${ }^{154} \mathrm{Eu}$. The duplicate results for both samples are in good agreement with relative percent difference (RPD) values $<5 \%$. Other requested analytes including ${ }^{51} \mathrm{Cr}$, ${ }^{59} \mathrm{Fe},{ }^{95} \mathrm{Nb},{ }^{103} \mathrm{Ru},{ }^{113} \mathrm{Sn}$, and ${ }^{152} \mathrm{Eu}$ were not detected in any of the samples. The detection limits for the AW-101 samples in units of $\mu \mathrm{Ci} / \mathrm{g}$ glass are: ${ }^{51} \mathrm{Cr}<1 . \mathrm{E}-2,{ }^{59} \mathrm{Fe}<2 . \mathrm{E}-3,{ }^{95} \mathrm{Nb}<1 . \mathrm{E}-3,{ }^{103} \mathrm{Ru}<2 . \mathrm{E}-3,{ }^{113} \mathrm{Sn}$ $<2$.E-3, and ${ }^{152} \mathrm{Eu}<5$.E-3. The detection limits for the AN-107 samples in units of $\mu \mathrm{Ci} / \mathrm{g}$ glass are: ${ }^{51} \mathrm{Cr}$ $<2 . \mathrm{E}-2,{ }^{59} \mathrm{Fe}<4 . \mathrm{E}-3,{ }^{95} \mathrm{Nb}<2 . \mathrm{E}-3,{ }^{103} \mathrm{Ru}<2 . \mathrm{E}-3,{ }^{113} \mathrm{Sn}<2 . \mathrm{E}-3$, and ${ }^{152} \mathrm{Eu}<7 . \mathrm{E}-3$. No gamma activity was detected in the preparation blank.

Radiochemical yields for $\mathrm{Am} / \mathrm{Cm}$ were depressed, probably due in part to the high salt content. Yields for $\mathrm{Pu}$ were within the expected range of $>80 \%$. For sample $\mathrm{AW}-101$, only ${ }^{239+240} \mathrm{Pu}$ and ${ }^{241} \mathrm{Am}$ were detected weakly. No ${ }^{238} \mathrm{Pu}$ or $\mathrm{Cm}$ were detected and the detection limits are listed. For sample AN-107, ${ }^{239+240} \mathrm{Pu},{ }^{238} \mathrm{Pu},{ }^{241} \mathrm{Am}$, and ${ }^{243+244} \mathrm{Cm}$ were detected. The duplicate results are in good agreement except for the high RPD value of $36 \%$ for ${ }^{238} \mathrm{Pu}$ for sample AN107, where the 1-sigma measurement uncertainties were $10-13 \%$. The calculated mean difference (MD) value is 1.14 indicating that the results are in statistical agreement. Neither $\mathrm{Pu}, \mathrm{Am}$ nor $\mathrm{Cm}$ were detected in the preparation blank. Although very weak, ${ }^{241}$ Am activity was seen in the laboratory blank representing about $20 \%$ of the AW-101 sample activity. The LCS and matrix spikes for $\mathrm{Pu}$ and $\mathrm{Am} / \mathrm{Cm}$ resulted in $95 \%$ to $107 \%$ yield-corrected recoveries. This indicates the chemistry and analyses were not biased.

${ }^{90} \mathrm{Sr}$ was detected in sample AW-101 and the duplicate results are in good agreement (4\% RPD). However, ${ }^{90} \mathrm{Sr}$ could not be detected in sample AN-107 and the detection limits are listed. Strontium-90 was not found in the preparation blank or the laboratory blank. The LCS and matrix spike recoveries were $94 \%$ and $86 \%$, respectively, within the control limits established by the SBMS QA exhibit.

Table 4.5 provides radiochemical data from the Envelope A (AW-101) and C (AN-107) glasses and comparisons with compositional predictions from the waste. The first column of data provides radionuclide estimates based on sample analysis of the pretreated wastes. The second column of data provides analyzed radionuclide values from the actual waste glasses produced by vitrification of the waste. Percent recoveries in the glass are calculated from the ratio of the analytical values in the glass to the expected values based on the analyses of the waste components and the fraction of each waste in the final glass feed batch and presented in the last column. However, it should be noted that the AW-101 radiochemical analytical error in the "Expected Loading" column of Table 4.5 is much greater than the actual glass analysis data as the radiochemical data supplied by the Cs IX and Tc IX tasks only included ${ }^{99} \mathrm{Tc},{ }^{134} \mathrm{Cs}$, and ${ }^{137} \mathrm{Cs}$. The other radionuclide data came from the AW-101 "Diluted Feed" report (Urie et al., 1999b) using a dilution factor of $0.71(4.59 \mathrm{M} \mathrm{Na}$ divided by $6.46 \mathrm{M} \mathrm{Na}$ ) to account for the unit operations, i.e. Cs IX and Tc IX, after analysis of the "Diluted Feed". ${ }^{99} \mathrm{Tc}$ recoveries indicate 0 to approximately $40 \%$ volatilization from the melt in the AW-101 and AN-107 glasses respectively and are typical for this element in oxidizing environments such as crucible melts. ${ }^{137} \mathrm{Cs}$ recoveries indicate approximately $5 \%$ volatilization in the $\mathrm{AN}-107$ glass with an erroneous increase in ${ }^{137} \mathrm{Cs}$ for the AW-101 glass. Again, the AW-101 percent recovery value is believed to be an artifact due to the high uncertainty associated with the "Expected Loading" value. It is assumed that if the final AW-101 Tc IX effluent, which was vitrified, had been analyzed for the same suite of radioisotopes as the AN-107 pretreated waste that was vitrified, the percent recovery would have been much closer to unity. Analytical uncertainties of the gamma energy analysis values are $2-3 \%$ due to the gamma counting and do not contribute to the large variance in percent recovery. As for the apparent increase in ${ }^{154} \mathrm{Eu}$ in the AN-107 glass, the analytical uncertainty is $20 \%$ at the 1-sigma confidence level. This uncertainty is much larger than the apparent over recovery of ${ }^{154} \mathrm{Eu}$ and should not be misconstrued. Lastly, the apparent under recovery in the AW-101 glass for ${ }^{239+240} \mathrm{Pu}$ and ${ }^{241} \mathrm{Am}$ cannot be attributed to analytical uncertainties as they are about $17 \%$ at the 1-sigma confidence level for AW-101 glass values. The uncertainties are only $7 \%$ for both ${ }^{241} \mathrm{Am}$ and ${ }^{239+240} \mathrm{Pu}$ glass analysis values for AN-107. Again, the low percent recovery for plutonium and 
americium in the AW-101 glass is almost certainly due to the high uncertainty associated with the "Expected Loading" value, as these refractory elements should not volatilize during glass production. In any case, as will be shown below, both the "Estimated Glass Analysis" and the "Measured Glass Analysis" data show that the glasses easily meet all contract specification limits in spite of the disagreement on percent recovery numbers.

One of the primary success objectives for this work was that for the ILAW glasses, "The concentrations of ${ }^{137} \mathrm{Cs},{ }^{90} \mathrm{Sr},{ }^{99} \mathrm{Tc}$ and transuranic (TRU) radionuclides shall be less than $3 \mathrm{Ci} / \mathrm{m}^{3}, 20$ $\mathrm{Ci} / \mathrm{m}^{3}, 0.1 \mathrm{Ci} / \mathrm{m}^{3}$ and $100 \mathrm{nCi} / \mathrm{g}$, respectively." Table 4.6 below summarizes the radiochemical data from this work so that this glass data is directly comparable with these success criteria. The amount of each of these radionuclides was determined by multiplying the weight of a cubic meter of glass by the measured and estimated (based on sample analysis of the pretreated wastes) concentration of the radionuclide per gram. The criteria for ${ }^{90} \mathrm{Sr}$ and ${ }^{137} \mathrm{Cs}$ are met by any method of calculation in both glasses. In spite of the disagreement on the percent recovery of ${ }^{137} \mathrm{Cs}$ for $\mathrm{AW}-101$, the ${ }^{137} \mathrm{Cs}$ level is one order of magnitude lower than the contract specification limit. AW-101 also passes for ${ }^{99} \mathrm{Tc}$ and transuranic (TRU) radioisotopes. AN-107 passes for (TRU) radioisotopes and fails for ${ }^{99} \mathrm{Tc}$. The failure of AN-107 for ${ }^{99} \mathrm{Tc}$ was not unexpected because the pretreatment process for removing ${ }^{99} \mathrm{Tc}$ selectively removes the pertechnetate anion from LAW solutions and the AN-107 waste only contains approximately 15 to $20 \%$ of its ${ }^{99} \mathrm{Tc}$ as the pertechnetate anion (Blanchard et al. 2000). However, the ORP Contract Specification 2.2.2.8, states: "The average concentrations shall be calculated by summing the actual inventories of each of the above radionuclides in the packages that have been presented to date for acceptance and dividing by the total volume of waste in these packages. The Contractor shall remove on average a minimum of $80 \%$ of the ${ }^{99} \mathrm{Tc}$ present in the feed." therefore, it is believed that the RPP-WTP will be able to meet or exceed the contract ${ }^{99} \mathrm{Tc}$ ILAW glass content requirements by decontaminating the Envelope $\mathrm{A}$ and $\mathrm{B}$ wastes to a greater extent than needed to meet the contract ILAW requirements so that on average the ${ }^{99} \mathrm{Tc}$ concentration in the combined ILAW glasses produced, i.e. Envelope A, B, and C waste glasses, will be less than or equal to the contract ILAW glass limit.

Table 4.6. Contract Success Criteria Determination: Radionuclide Glass Content of the ILAW Glass Product

\begin{tabular}{|c|c|c|c|c|c|}
\hline \multirow[b]{3}{*}{ Radionuclide } & \multicolumn{5}{|c|}{ Radionuclide Concentration in Glass $\left(\mathrm{Ci} / \mathrm{m}^{3}\right)$} \\
\hline & \multirow[b]{2}{*}{ Contract Limit } & \multicolumn{2}{|c|}{ Estimated Glass Analysis } & \multicolumn{2}{|c|}{ Measured Glass Analysis } \\
\hline & & $\mathrm{AW}-101^{(\mathrm{a})}$ & $\mathrm{AN}-107^{(\mathrm{b})}$ & $\mathrm{AW}-101^{(\mathrm{a})}$ & AN-107 ${ }^{(\mathrm{b})}$ \\
\hline Sr-90 & 20 & $0.75^{(\mathrm{c})}$ & 0.012 & 0.435 & 0.005 \\
\hline Tc-99 & 0.1 & 0.023 & 0.206 & 0.019 & 0.129 \\
\hline Cs-137 & 3 & 0.133 & 0.308 & 0.231 & 0.292 \\
\hline TRU & $100 \mathrm{nCi} / \mathrm{g}$ & $<0.436 \mathrm{nCi} / \mathrm{g}$ & $2.88 \mathrm{nCi} / \mathrm{g}$ & $<0.16 \mathrm{nCi} / \mathrm{g}$ & $<2.6 \mathrm{nCi} / \mathrm{g}$ \\
\hline \multicolumn{6}{|c|}{$\begin{array}{l}\text { (a) = assumes the AW-101 LAW glass density to be } 2.668 \mathrm{~g} / \mathrm{cm}^{3} \text { which is the measured density of the simulant } \\
\text { LAWA } 88 \text { glass, reporting temperature of } 20^{\circ} \mathrm{C} \text { per ASTM D854-83; density corrected to } 25^{\circ} \mathrm{C} \text { would be less than } \\
0.005 \mathrm{~g} / \mathrm{cm}^{3} \text { lower than this number. Data supplied by I. Muller of VSL on June } 22,2000 \text {. } \\
\text { (b) = assumes the AN-107 LAW glass density to be } 2.677 \mathrm{~g} / \mathrm{cm}^{3} \text { which is the measured density of the simulant } \\
\text { LAWC15 glass, reporting temperature of } 20^{\circ} \mathrm{C} \text { per ASTM D854-83; density corrected to } 25^{\circ} \mathrm{C} \text { would be less than } \\
0.005 \mathrm{~g} / \mathrm{cm}^{3} \text { lower than this number. Data supplied by I. Muller of VSL on June } 22,2000 \text {. } \\
\text { (c) = assumes the AW-101 LAW glass has approximately the same Sr-90 loading as the Envelope A glass produced } \\
\text { by Ferrara et al., 1998a, 1998b. } \\
\text { TRU = transuranics }\end{array}$} \\
\hline
\end{tabular}




\subsection{Crystalline and Non-Crystalline Phase Determination}

\section{Crystallization Evaluation of AW-101 and AN-107 Heat Treated LAW Glass Samples}

The samples were examined with transmitting light microscope at magnifications up to $250 \mathrm{x}$. No crystals were observed in the samples in any mode of examination including polarized light though numerous bubbles were present in all samples. Very occasional irregular opaque particles $(10-30 \mu \mathrm{m})$ were observed but not identified. See Appendix B for detailed powder XRD plots and SEM micrographs.

$\mathrm{XRD}$ was used to analyze the samples for crystallinity. Initial XRD scans showed amorphous patterns (see Figure 4.7), with a few sharp peaks superimposed. These peaks indicated the presence of a crystalline phase at about 2 volume percent. If a crystalline phase is truly present, it should have been observed optically. The observed peaks indicate a mineral with a large "d" spacing such as a clay or mica mineral. None of these are expected to form these glasses under the heat treatment conditions. This suggested contamination of the samples, which was further investigated.

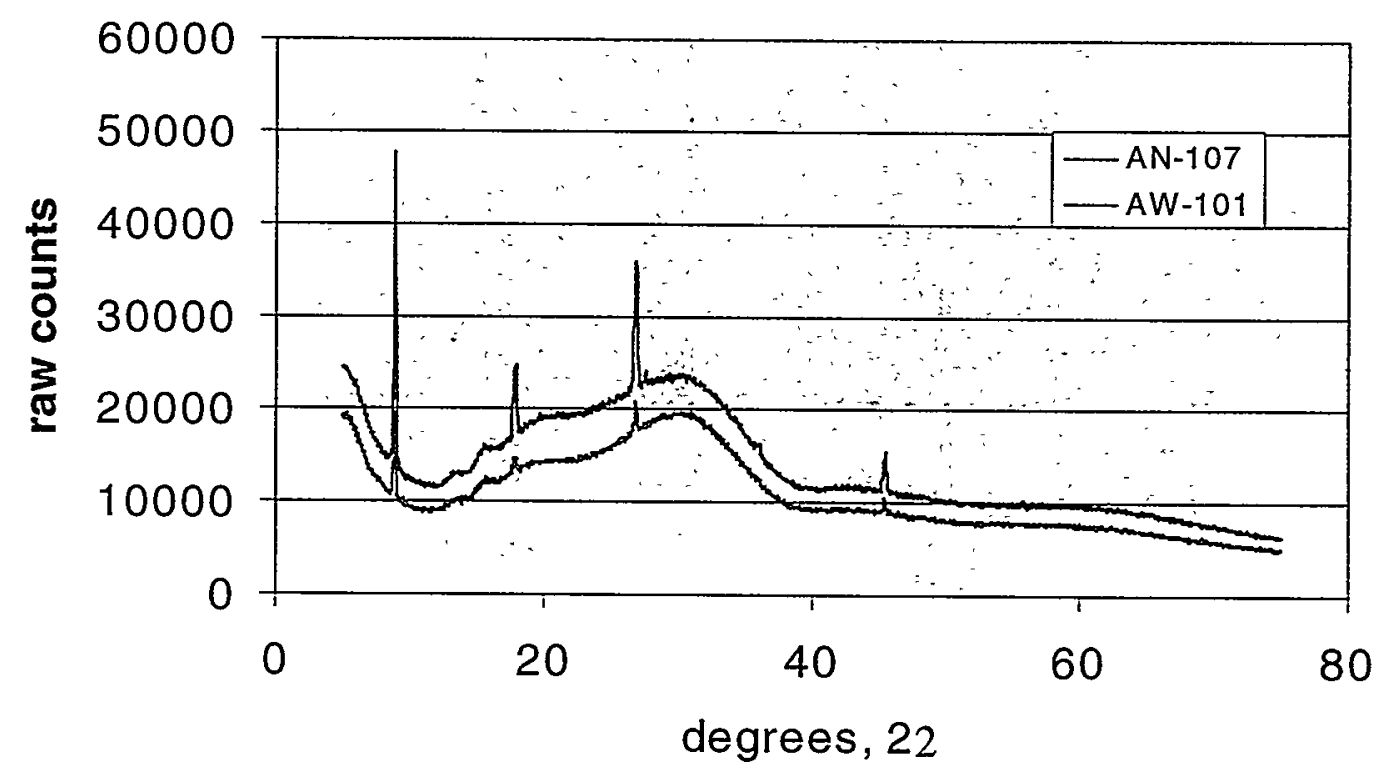

Figure 4.7. XRD Diffraction Profiles for Glasșes AW-101 and AN-107 Showing General Amorphous Character with Superimposed Peaks Indicating a Contaminating Crystalline Phase Present in the Powder Sample as SEM and Optical Microscopy Results Showed no Crystalline Phases Present in Either Glass. 


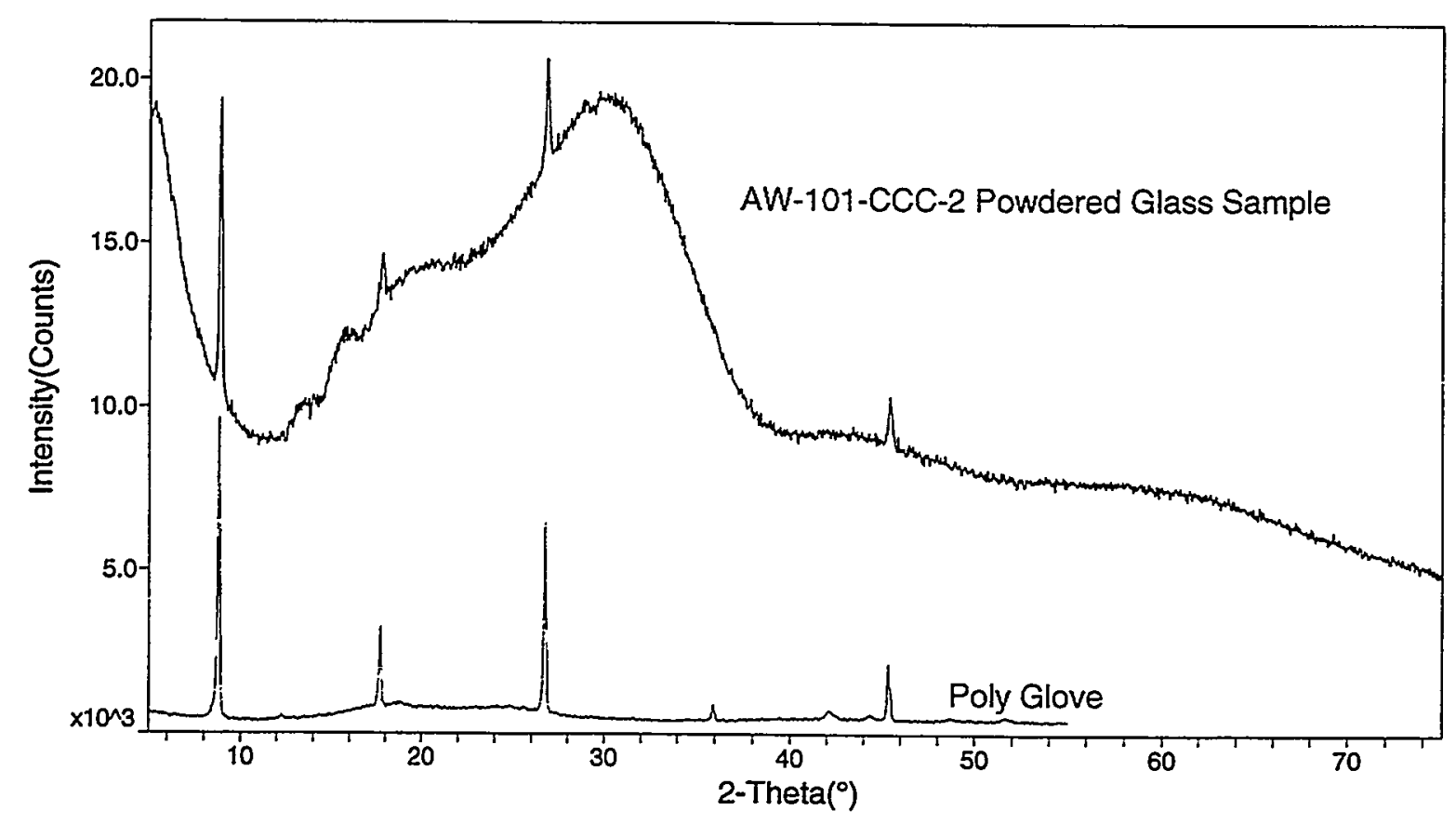

Figure 4.8. XRD Diffraction Profiles for Glass AW-101 Showing General Amorphous Character with Superimposed Peaks Indicating a Crystalline Phase Present in the XRD Powder Sample Compared with the XRD Peaks Observed for a Section of the Poly Glove Material. The position of the peaks are identical indicating that the material 'dusting' the gloves is the material contaminating the glass powder.

$\mathrm{XRD}$ analysis of the protective gloves used during preparation of the initial glass powder samples was performed to determine if the observed contamination was from the mineral powder phase applied by the glove manufacturer to facilitate insertion of ones hands. Figure 4.8 shows the XRD pattern of the 'powdered' poly glove material below the initial XRD scan of the AW-101 glass heat treated to mimic the ILAW canister centerline cooling curve. The position of the 'contamination' peaks is identical indicating that the mineral material used to 'dust' the poly gloves is the same material contaminating the glass powder samples. To confirm this observation, a new sample of AW-101 glass, heat treated to mimic the ILAW canister centerline cooling curve, was prepared using different protective gloves that did not use any type of 'powder'. Figure 4.9 shows the new XRD pattern of the heat treated AW-101 glass powder. This XRD pattern shows only broad amorphous peaks indicating that the heat treated glass is completely amorphous consistent with the optical microscopy and SEM results. 


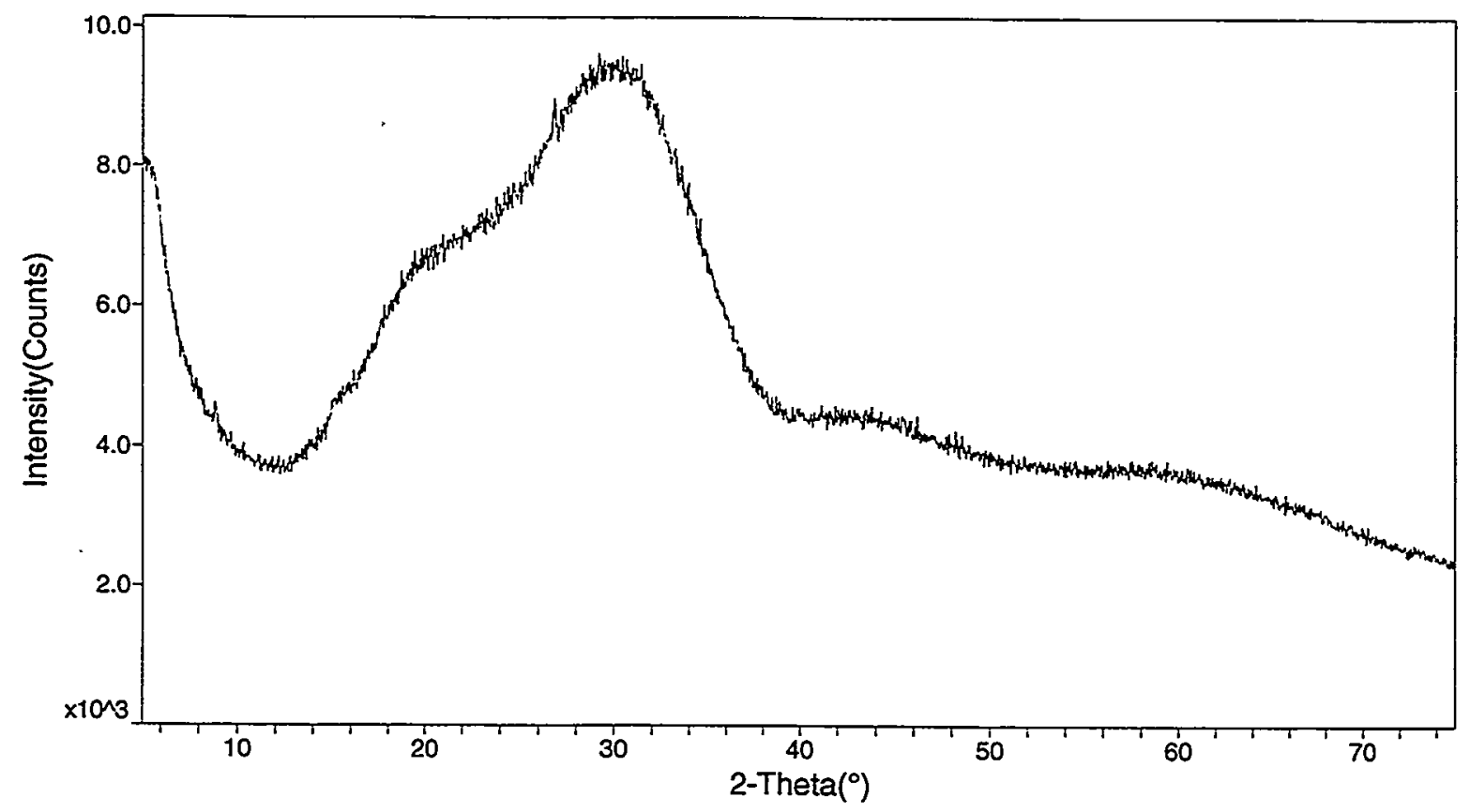

Figure 4.9. XRD Diffraction Profile for the Heat Treated AW-101 Glass Showing General Amorphous Character with out the Superimposed Peaks that Indicated a Crystalline Phase Present in the Initial Glass Powder Sample. The lack of sharp XRD peaks indicates that the glass is completely amorphous consistent with optical and SEM evaluations.

Each glass sample was examined using SEM at magnifications up to $20,000 x$. No crystallites were detected in any of the AW-101 and AN-107 LAW glass samples. Contamination particles, e.g. 'dust', are found on the surface of the glass samples, but no separate phases were found in the glasses. Therefore, no crystals were observed in the glass samples as determined by optical microscopy, SEM, and XRD evaluations.

\section{Non-Crystalline Chemical Homogeneity of AW-101 and AN-107 Heat Treated LAW Glass Samples}

SEM-EDS analyses were performed of various regions of the polished section of each centerline cooled sample. These regions were arranged both vertically and horizontally. The size region scanned for each analysis ranged from less than one square micron to as much as 1600 square microns. The reason for scanning different sized areas was to see if liquid-liquid phase separation might be occurring. Unfortunately the glasses are susceptible to alkali volatilization when heated by the SEM electron beam. Figure 4.8 below shows how the measured sodium level decreases with decreasing analytical area. At the largest area measured the sodium values are about $5 \%$ low.

To make a judgment about the affect of the sodium volatilization on the resulting SEM-EDS analysis of the glasses, several analyses from the AN-107 glass sample were recalculated assuming the original amount of sodium remained in the glass. To do this, the target composition of AN-107 was recalculated to $100 \%$ based just on the 10 elements reported for the SEM-EDS analyses. This is the 
AN-107 target calculated and shown in Table 4.7. The columns headed with "Meas." are SEM-EDS analyses. The columns headed by "Norm." are columns containing the SEM-EDS analyses renormalized to $100 \%$ where the sodium oxide content has been increased to the sodium oxide target value for AN-107 (normalized to the same ten elements). Also two different sized analytical areas (1 and $4 \mu \mathrm{m}^{2}$ ) are included in the evaluation and the different areas result in about the same re-normalized numbers. This adjustment process over compensates for some elements such as calcium and iron, but the overall adjustment is good. It is concluded that the SEM-EDS survey did not observe any phase separation or glass heterogeneity due to poor mixing. 


\section{Sodium Volatilization from $\mathrm{AN}-107$}

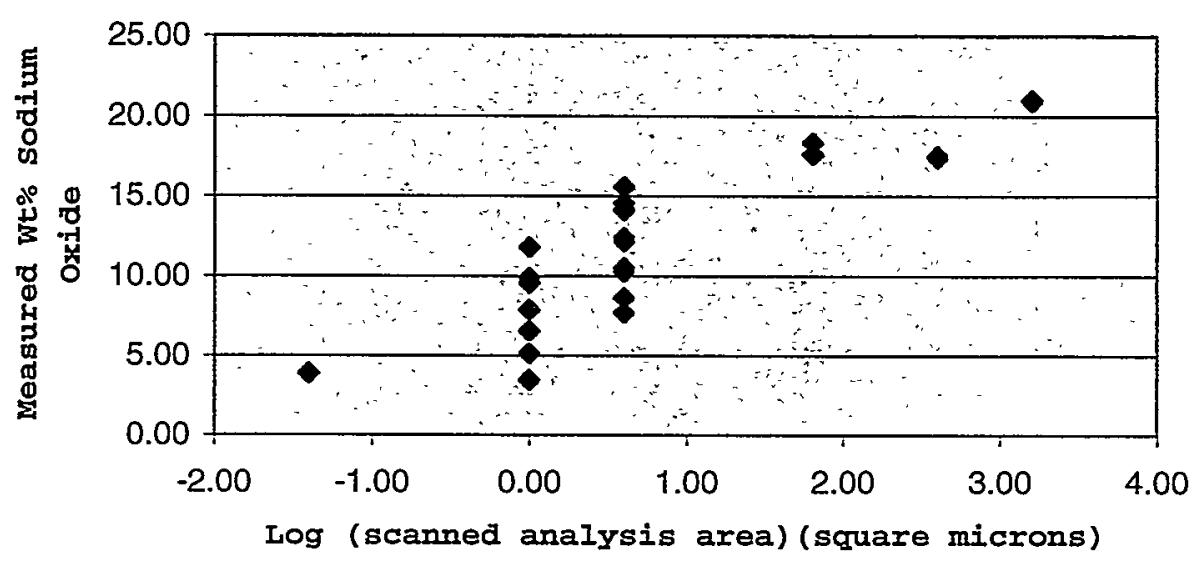

Figure 4.10. Sodium Volatilization Believed to be Due to Electron Beam Heating of the Glass. The heating intensity of the beam would be inversely proportional to the area being analyzed.

Table 4.7. AN-107 Glass 'As Measured' and 'Normalized' Values Compared to the AN-107 Re-normalized Target Values. All Values Have Been Re-normalized to $100 \%$ Using Only the Ten Oxides Listed Below.

\begin{tabular}{|c|c|c|c|c|c|c|c|c|c|}
\hline \multirow[b]{4}{*}{ Oxides } & \multicolumn{9}{|c|}{ Weight Percent Oxide } \\
\hline & \multirow{3}{*}{$\begin{array}{l}\text { AN-107 } \\
\text { Target }^{(\mathrm{a})}\end{array}$} & \multicolumn{4}{|c|}{ Area 1, EDS Beam Spot Size } & \multicolumn{4}{|c|}{ Area 2, EDS Beam Spot Size } \\
\hline & & \multicolumn{2}{|c|}{$1 \mu \mathrm{m}^{2}$} & \multicolumn{2}{|c|}{$4 \mu \mathrm{m}^{2}$} & \multicolumn{2}{|c|}{$1 \mu \mathrm{m}^{2}$} & \multicolumn{2}{|c|}{$4 \mu \mathrm{m}^{2}$} \\
\hline & & Meas. & Norm. & Meas. & Norm. & Meas. & Norm. & Meas. & Norm. \\
\hline $\mathrm{Na}_{2} \mathrm{O}$ & 22.17 & 9.53 & 22.17 & 15.52 & 22.17 & 7.82 & 22.17 & 10.42 & 22.17 \\
\hline $\mathrm{MgO}$ & 2.23 & 2.69 & 2.32 & 2.47 & 2.27 & 2.65 & 2.23 & 2.61 & 2.27 \\
\hline $\mathrm{Al}_{2} \mathrm{O}_{3}$ & 6.91 & 8.48 & 7.29 & 7.88 & 7.26 & 8.31 & 7.01 & 8.29 & 7.20 \\
\hline $\mathrm{SiO}_{2}$ & 49.65 & 58.08 & 49.97 & 54.43 & 50.15 & 59.42 & 50.17 & 57.72 & 50.15 \\
\hline $\mathrm{K}_{2} \mathrm{O}$ & 0.16 & 0.18 & 0.15 & 0.17 & 0.16 & 0.13 & 0.11 & 0.20 & 0.18 \\
\hline $\mathrm{CaO}$ & 2.23 & 2.40 & 2.06 & 2.25 & 2.07 & 2.53 & 2.14 & 2.40 & 2.08 \\
\hline $\mathrm{TiO}_{2}$ & 2.22 & 2.59 & 2.23 & 2.39 & 2.20 & 2.64 & 2.23 & 2.50 & 2.18 \\
\hline $\mathrm{Fe}_{2} \mathrm{O}_{3}$ & 7.78 & 7.93 & 6.82 & 7.49 & 6.90 & 8.60 & 7.26 & 8.07 & 7.01 \\
\hline $\mathrm{ZnO}$ & 3.32 & 3.90 & 3.35 & 3.45 & 3.18 & 3.87 & 3.27 & 3.80 & 3.30 \\
\hline $\mathrm{ZrO}_{2}$ & 3.34 & 4.23 & 3.64 & 3.94 & 3.63 & 4.04 & 3.41 & 3.97 & 3.45 \\
\hline Total & 100 & 100 & 100 & 100 & 100 & 100 & 100 & 100 & 100 \\
\hline$=\mathrm{AN}-1$ & $\operatorname{arget} c$ & ion $\mathrm{r}$ & $\begin{array}{l}\text { malize } \\
\text { alue. }\end{array}$ & 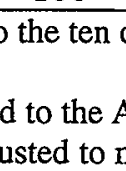 & 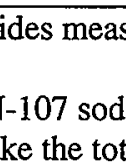 & d by $s$ & EDS. & 22.1 & and \\
\hline
\end{tabular}




\subsection{Release Rate, Modified Product Consistency Testing}

The ultimate objective for immobilization of the low activity waste is to incorporate and convert the radioactive and hazardous components into a solid glassy waste form that will resist their release to the environment in a Hanford near-surface burial ground. This resistance of the waste form to release deleterious environmental components is defined by measuring its chemical durability, i.e. the resistance of the glass to react with the aqueous environment expected in the glass disposal site. However, to mimic the mean temperature, amount and frequency of available ground waster, etc. expected in the near-surface repository would require a great amount of testing time to be able to detect glass dissolution. Therefore, an accelerated chemical durability test, the Product Consistency Test (PCT), is employed to gauge the ILAW glass chemical durability. The PCT was run at 40 and $90^{\circ} \mathrm{C}$, using glass samples given a slow cool down heat treatment which simulates the cooling profile for glass at the center line of a canister been filled with a waste glass and allowed to cool to ambient temperature, to determine the normalized release of sodium, silicon, and boron. The low-activity test reference material (LRM) standard glass was included in these tests to provide a reliable baseline of results by which to judge the quality of the PCT results for the AW-101 and AN-107 glasses.

After the glass particles were cleaned of adhering fines, the crushed glass (a minimum of $1 \mathrm{~g}$ ) was tested per ASTM C1285-97 "Standard Test Methods for Determining Chemical Durability of Nuclear, Hazardous, and Mixed Waste Glasses: The Product Consistency Test (PCT)." For testing the crushed glass (a minimum of $1 \mathrm{~g}$ ) was placed in a Type $304 \mathrm{~L}$ stainless steel vessel ( $22 \mathrm{~mL}$ volume) into which an amount of ASTM Type I water, equal to $10 \mathrm{~cm}^{3}$ per gram of glass, was added. The vessel was sealed and placed into a constant temperature device at 40 or $90 \pm 2{ }^{\circ} \mathrm{C}$. After 7 days, the vessel was cooled to ambient temperature. The $\mathrm{pH}$ was measured on an aliquot of the leachate and the temperature of the aliquot at the time of the $\mathrm{pH}$ measurement was recorded. The remaining leachate was filtered to remove suspended solids and sent for analysis. Analyses of boron, alkali metal, and silicon concentrations were performed, which were then used as a measure of the extent of glass corrosion. The concentrations of elements (C) are normalized to glass composition and glass surface area (S) to solution volume (V) according to:

$$
r_{i}=\frac{C_{i}}{f_{i}(S / V)}
$$

where $r_{i}, C_{i}$, and $f_{i}$ are the $i^{\text {th }}$ element normalized release, concentration in solution, and mass fraction in glass, respectively.

All tests were run without serious deviation from the procedure described above except for the temperature profile for the $40^{\circ} \mathrm{C}$ test. During the first 17 hours the temperature drifted upward to about $46^{\circ} \mathrm{C}$ before the operator was able to bring the temperature down to $40^{\circ} \mathrm{C}$ and get the furnace to control at $40^{\circ} \mathrm{C}$ for the remainder of the test. Since the LRM glass was included in the test, its behavior relative to its expected behavior at $40^{\circ} \mathrm{C}$ could be compared to see if there was significant deviation due to the initial temperature excursion. 
Table 4.8 compares the "measured" PCT leachate concentration and pH with the "round robin" PCT results for the LRM glass as reported by Ebert and Wolf. 1999. This comparison provides an evaluation of how accurately the test followed the ASTM procedure and whether or not any deviation had a significant impact on the results. For instance, since all of the "measured" $40^{\circ} \mathrm{C} \mathrm{PCT}$ results agree within the $95 \%$ confidence interval with the "round robin" PCT results, it is assumed that an early $6^{\circ} \mathrm{C}$ temperature excursion did not seriously affect the $40^{\circ} \mathrm{C}$ PCT results. At $90^{\circ} \mathrm{C}$ the leachate composition values for the LRM glass all fall within the $95 \%$ confidence interval and the temperature is known to have been well controlled, so even though the final pH was about 0.27 units low, the data are believed to be good.

Tables 4.9 and 4.10 give the average release rates found for glasses AW-101, AN-107, and LRM at $40^{\circ} \mathrm{C}$ and $90^{\circ} \mathrm{C}$. Data for glasses LAWA23R, LAWA88 (simulant AW-101 glass), and LAWC15 (simulant AN-107 glass) provided by VSL at $90^{\circ} \mathrm{C}$ is included in Table 10 for comparison. For PCT-A, the $\mathrm{S} / \mathrm{V}$ was assumed to be $2000 \mathrm{~m}^{-1}$ based on assumptions on the size and shape distribution of the ground glass and verified through considerable surface area measurements (ASTM 1998). Normalized releases of $\mathrm{Na}$, Si, and $\mathrm{B}$ were calculated using Equation 1 and are based on a seven-day test period. As is readily observed, all of the glasses easily meet the ORP contract requirement from Specification 2 , Section 2.2.2.17.2, which requires that the normalized mass loss of the LAW waste glasses produced be $<2 \mathrm{~g} / \mathrm{m}^{2}$. 
Table 4.8. Comparison of $40^{\circ} \mathrm{C} \mathrm{PCT}$ and $90^{\circ} \mathrm{C}$ PCT Results from the Low-Activity Test Reference Material (LRM) Glass Round Robin (Ebert and Wolf. 1999) with the Equivalent Values Found for the $40^{\circ} \mathrm{C}$ and $90^{\circ} \mathrm{C}$ PCT Tests Described in this Report.

\begin{tabular}{|c|c|c|c|c|}
\hline & \multicolumn{2}{|c|}{ LRM at $40^{\circ} \mathrm{C}$} & \multicolumn{2}{|c|}{ LRM at $90^{\circ} \mathrm{C}$} \\
\hline Element & $\begin{array}{c}\text { Reported }^{(\mathrm{a})} \\
(\mathrm{mg} / \mathbf{L})\end{array}$ & $\begin{array}{c}\text { Measured } \\
(\mathrm{mg} / \mathrm{L})\end{array}$ & $\begin{array}{c}\text { Reported }^{(\mathbf{a})} \\
(\mathrm{mg} / \mathrm{L})\end{array}$ & $\begin{array}{l}\text { Measured } \\
(\mathrm{mg} / \mathrm{L})\end{array}$ \\
\hline [B] & $2.30 \pm 1.25$ & $1.11-1.13$ & $26.7 \pm 7.2$ & $24.6-24.8$ \\
\hline$[\mathrm{Na}]$ & $19.7 \pm 7.3$ & $19.2-19.5$ & $160 \pm 13$ & $149-150$ \\
\hline$[\mathrm{Si}]$ & $13.7 \pm 4.2$ & $12.1-12.2$ & $82.0 \pm 12.7$ & $83.1-83.7$ \\
\hline Final pH & $9.86 \pm 0.96$ & $8.93-8.97$ & $10.92 \pm 0.43$ & $10.19-10.22$ \\
\hline
\end{tabular}

Table 4.9. Average 7-Day $40^{\circ} \mathrm{C}$ PCT Normalized Mass Loss Data Radioactive LAW Glasses from this Study

\begin{tabular}{|c|c|c|c|}
\hline \multicolumn{4}{|c|}{ Average 7-DAY $40^{\circ} \mathrm{C}$ PCT Normalized Mass Loss $\left(\mathrm{g} / \mathrm{m}^{2}\right)$} \\
\hline \multirow[b]{2}{*}{ Glass } & \multicolumn{3}{|c|}{ Element } \\
\hline & $\mathbf{B}$ & $\mathbf{N a}$ & $\mathbf{S i}$ \\
\hline AW-101 (leachate $\mathrm{pH}$ range $=9.08-9.17$ ) & 0.0481 & 0.0877 & 0.0330 \\
\hline AN-107 (leachate $\mathrm{pH}$ range $=9.00-9.04)$ & 0.0373 & 0.0708 & 0.0267 \\
\hline LRM & 0.0230 & 0.0653 & 0.0240 \\
\hline
\end{tabular}

Table 4.10. Comparison of Average 7-Day $90^{\circ} \mathrm{C}$ PCT Normalized Mass Loss Data Between VSL Non-radioactive Simulant Glasses and Actual Radioactive LAW Glass Counterparts from this Study. LAWA23R and LRM Data is Provided for Comparison Purposes.

\begin{tabular}{|c|c|c|c|}
\hline \multicolumn{4}{|c|}{ Average 7-DAY $90^{\circ} \mathrm{C}$ PCT Normalized Mass Loss $\left(\mathrm{g} / \mathrm{m}^{2}\right)$} \\
\hline \multirow[b]{2}{*}{ Glass } & \multicolumn{3}{|c|}{ Element } \\
\hline & B & $\mathbf{N a}$ & Si \\
\hline LAWA23R $^{(a)}$ & 0.503 & 0.669 & 0.217 \\
\hline LRM & 0.506 & 0.504 & 0.165 \\
\hline LAWA88 (simulant AW-101 glass) & 0.434 & 0.426 & 0.171 \\
\hline $\mathrm{AW}-101$ (leachate $\mathrm{pH}$ range $=10.27-10.33$ ) & 0.569 & 0.589 & 0.196 \\
\hline LAWC15 (simulant AN-107 glass) & 0.329 & 0.335 & 0.161 \\
\hline AN-107 (leachate $\mathrm{pH}$ range $=10.02-10.05$ ) & 0.354 & 0.422 & 0.191 \\
\hline \multicolumn{4}{|c|}{$\begin{array}{l}\text { Note: ORP contract requirement from Specification } 2 \text {, Section } 2.2 .2 .17 .2 \text { requires that the normalized mass loss of } \\
\text { the LAW waste glasses produced be }<2 \mathrm{~g} / \mathrm{m}^{2} \text {. } \\
\text { (a) = PCT data provided by VSL; data is from testing completed from March through June 1999, all triplicate } \\
\text { sampling in accordance with ASTM C1285-97. }\end{array}$} \\
\hline
\end{tabular}




\subsection{Conclusions}

The primary objective for vitrifying the LAW samples was to demonstrate the RPP-WTP projects ability to satisfy the ILAW product ORP contract requirements concerning, chemical and radionuclide reporting, waste loading, identification and quantification of crystalline and non-crystalline phases, and waste form leachability. Two pretreated tank supernates, low-activity wastes (241-AW-101 and 241-AN-107) along with a process simulant (termed the Process Blank) were prepared as melter feeds for vitrification. The analyzed compositions of the pretreated AW-101 and AN-107 wastes were used by Catholic University of America's (CUA) Vitreous State Laboratory (VSL) to calculate the target glass composition. The two supernate tank samples, i.e. 241-AW-101 and 241-AN-107, referred to as AW-101 and AN-107, were processed through pretreatment chemical separation processes, and the decontaminated supernates were converted to low-activity waste (LAW) glass after addition of glass former additives.

The measured wt\% sodium oxide content for the AW-101 and AN-107 glasses are 17.7 and 18.3, respectively. As all of the sodium oxide content for the AW-101 glass originated from the initial tank waste, the AW-101 glass exceeds the Task Specification, sodium oxide concentration level of 16 weight percent easily considering only the measured $w t \%$ sodium oxide content. Based upon past experience, the measured weight percentage for $\mathrm{Na}_{2} \mathrm{O}$ are almost always lower than its true weight percentage, which provides an even larger margin of passing the Task Specification requirement. Note that as discussed in Section 4.1.2, $\mathrm{Na}_{2} \mathrm{O}$ and $\mathrm{SiO}_{2}$ analyzed by ICP-AES are almost always lower than their true weight percentage because of analytical difficulties associated with these elements. However, not all of the sodium oxide content for the AN-107 glass originated from the initial tank waste. As $79.2 \%$ of the sodium oxide content for the AN-107 glass originated from the initial tank waste, for the AN-107 glass to exceed the contract, sodium oxide concentration level of 16 weight percent the wt\% sodium oxide content of the glass would need to be $20 \mathrm{wt} \%$ which is the target concentration. Again, based upon past experience, the measured weight percentage for $\mathrm{Na}_{2} \mathrm{O}$ wt\% values are almost always lower than its true weight percentage. For this reason, the target $\mathrm{Na}_{2} \mathrm{O}$ value is used as the true weight percent oxide value for the ILAW glasses. Therefore, the original, as-received AN-107 waste is determined to meet the Task Specification for waste loading of the AN-107 glass. The ORP Contract Specification 2, Immobilized Low-Activity Waste, Section 2.2.2.2, Waste Loading, states: "The loading of waste sodium from Envelope $\mathrm{A}$ in the ILAW glass shall be greater than 14 weight percent based on $\mathrm{Na}_{2} \mathrm{O}$. The loading of waste sodium from Envelope $B$ in the ILAW glass shall be greater than 5.0 weight percent based on $\mathrm{Na}_{2} \mathrm{O}$. The loading of waste sodium from Envelope $\mathrm{C}$ in the $\mathrm{ILAW}$ glass shall be greater than 10 weight percent based on $\mathrm{Na}_{2} \mathrm{O}$." Therefore, additionally, both the $\mathrm{AW}-101$ (Envelope $\mathrm{A}$ ) and $\mathrm{AN}-107$ (Envelope C) glasses easily meet the ORP contract specifications for waste sodium loading.

The waste loading was calculated from the dilution factor (decrease in concentration) of elements contained in either the waste or the glass forming additives. The results indicate that the waste fraction of each glass is near their target, i.e. $26.15 \%$ for AW-101 (28.64\% based on waste dilution and $26.88 \%$ based on additive dilution) and $21.4 \%$ for AN-107 (26.04\% based on waste dilution and $20.34 \%$ based on additive dilution). The measured glass to target composition percent difference comparison of the oxides is small and the calculated waste loading values are very close to or exceed the target. Both support the conclusion that the actual waste loading in each glass met and exceeded the target waste loading.

To demonstrate that the glass product, radionuclide compositional limits were met a radionuclide glass compositional estimate based on sample analysis of the pretreated wastes was completed for both the AW-101 and AN-107 glasses as volatilization of radionuclides may occur during vitrification in crucible melts. ${ }^{90} \mathrm{Sr},{ }^{99} \mathrm{Tc},{ }^{137} \mathrm{Cs}$, and transuranic (TRU) radionuclide values were checked to make sure 
the glass product met or exceeded the contract success criteria. The estimated glass composition concentrations for ${ }^{90} \mathrm{Sr}$ passed the contract success criteria for both glasses. The estimated glass composition concentrations for ${ }^{99} \mathrm{Tc}$ passed the contract criteria for the AW-101 glass. The estimated glass composition concentrations for ${ }^{99} \mathrm{Tc}$ did not pass the contract criteria for the AN-107 glass. However, Blanchard et al. 1999 have previously shown that an Envelope A waste (e.g. AW-101) can be ${ }^{99} \mathrm{Tc}$ ion exchange decontaminated to a level much below the contract ILAW glass limit. This would allow a sufficient amount of ${ }^{99} \mathrm{Tc}$ to be removed from the AW-101 and AN-107 wastes so that the average ${ }^{99} \mathrm{Tc}$ concentration in the IIAW glass produced would meet or exceed the contract specification. The estimated glass composition concentrations for ${ }^{137} \mathrm{Cs}$ passed the contract success criteria for the AW-101 and AN-107 glasses. Is in spite of the disagreement on the percent recovery of ${ }^{137} \mathrm{Cs}$ for $\mathrm{AW}-101$, the ${ }^{137} \mathrm{Cs}$ level is one order of magnitude lower than the contract specification limit. And finally, the estimated glass composition concentration analysis for the transuranic (TRU) radionuclides shows that both glasses pass the contract criteria.

Identification and quantification of crystalline and non-crystalline phases were completed by using $x$-ray diffraction (XRD), optical microscopy, and scanning electron microscopy (SEM) on samples given a slow cool down heat treatment which simulated the calculated cooling profile for glass at the centerline of a LAW canister during filling. No crystals were observed in the samples during both SEM and optical examination though bubbles were present in all samples and a few irregularly shaped, opaque particles (10-30 $\mu \mathrm{m})$ were observed but could not be identified. However, initial powder XRD samples used to analyze the glass samples for crystallinity showed broad amorphous patterns with a few sharp 'crystalline' peaks superimposed on the amorphous curve. These crystalline peaks were suggestive of contamination of the ILAW glass powder XRD samples and investigated further. XRD analysis of the protective gloves, used during preparation of the initial powder XRD samples, showed conclusively that the crystalline peaks were due to contamination by the mineral phase applied by the glove manufacturer to facilitate insertion of ones hands. One of the heat treated glass samples, AW-101, was prepared for XRD using different protective gloves and reanalyzed. This XRD pattern showed only broad amorphous peaks indicating that the glass is completely amorphous consistent with the optical and SEM results.

The Product Consistency Test (PCT) was employed to gauge the ILAW glass chemical durability. The PCT was run at 40 and $90^{\circ} \mathrm{C}$, using glass samples given a slow cool down heat treatment which simulates the cooling profile for glass at the center line of a canister being filled with waste glass, to determine the normalized release of sodium, silicon, and boron. The low-activity test reference material (LRM) standard glass was included in these tests to provide a reliable baseline of results by which to judge the quality of the PCT results for the AW-101 and AN-107 glasses. Both the AW-101 and AN-107 glasses and the LRM glass gave a normalized sodium, silicon, and boron release rates of less than $1 \mathrm{~g} / \mathrm{m}^{2}$ for the $90^{\circ} \mathrm{C} \mathrm{PCT}$ test, which is generally considered to indicate a durable glass. The normalized sodium, silicon, and boron $90^{\circ} \mathrm{C} \mathrm{PCT}$ release rates for the AW-101, AN-107, and LRM glasses are: 1) $0.6 \mathrm{~g} / \mathrm{m}^{2}$, $0.2 \mathrm{~g} / \mathrm{m}^{2}$, and $0.6 \mathrm{~g} / \mathrm{m}^{2}$; 2) $0.4 \mathrm{~g} / \mathrm{m}^{2}, 0.2 \mathrm{~g} / \mathrm{m}^{2}$, and $0.4 \mathrm{~g} / \mathrm{m}^{2}$; and 3) $0.5 \mathrm{~g} / \mathrm{m}^{2}, 0.2 \mathrm{~g} / \mathrm{m}^{2}$, and $0.5 \mathrm{~g} / \mathrm{m}^{2}$; respectively. The normalized sodium, silicon, and boron $40^{\circ} \mathrm{C}$ PCT release rates for the AW-101, AN-107, and LRM glasses are: 1) $0.09 \mathrm{~g} / \mathrm{m}^{2}, 0.03 \mathrm{~g} / \mathrm{m}^{2}$, and $0.05 \mathrm{~g} / \mathrm{m}^{2}$; 2) $0.07 \mathrm{~g} / \mathrm{m}^{2}, 0.03 \mathrm{~g} / \mathrm{m}^{2}$, and $0.04 \mathrm{~g} / \mathrm{m}^{2}$; and 3) $0.07 \mathrm{~g} / \mathrm{m}^{2}, 0.02 \mathrm{~g} / \mathrm{m}^{2}$, and $0.02 \mathrm{~g} / \mathrm{m}^{2}$, respectively. More importantly, the normalized release rates of sodium, silicon, and boron from the AW-101 and AN-107 glasses are less than $2.0 \mathrm{~g} / \mathrm{m}^{2}$, the ORP contract criteria.

Finally, the ILAW product testing results from the AW-101 and AN-107 glasses show that in all cases they meet or exceed ORP contract specifications for waste loading, chemical composition documentation, radionuclide concentration limitations, and waste form testing (i.e. chemical durability). 


\subsection{References}

American Society for Testing and Materials, ASTM C1285-97 "Standard Test Methods for Determining Chemical Durability of Nuclear, Hazardous, and Mixed Waste Glasses: The Product Consistency Test (PCT)," West Conshohoken, Pennsylvania.

Arm, Stuart T, BNFL, E-mail to Gary L. Smith, Battelle, dated November 16, 1999, titled "ILAW Cooling Curve", CHG reference number: $015928 \mathrm{C}$.

Blanchard Jr., D. L., D. E. Kurath, and J. R. Bontha. 1999. Small Column Testing of Superlig 639 for - Removal of ${ }^{99}$ Tc from Hanford Tank Waste Envelope A (Tank 241-AW-101). PNWD-3004, Battelle, Pacific Northwest Division, Richland, Washington.

Blanchard Jr., D. L., D. E. Kurath, and B. M. Rapko. 2000. Small Column Testing of Superlig 639 for Removing ${ }^{99}$ Tc from Hanford Tank Waste Envelope C (Tank 241-AN-107). PNWD-3028, Battelle, Pacific . Northwest Division, Richland, Washington.

Brooks, K. P., P. R. Bredt, G. R. Golcar, S. A. Hartley, M. W. Urie, J. M. Tingey, K. G. Rappe, and L. K. Jagoda. 1999. Ultrafiltration and Characterization of AW-101 Supernatant and Entrained Solids. PNWD-3000, Battelle, Pacific Northwest Division, Richland, Washington.

Ebert, W. L. and S. F. Wolf. 1999. Round-Robin Testing of a Reference Glass for Low-Activity Waste Forms. ANL-99/22, Argonne National Laboratory, Argonne, Mlinois.

Ferrara, D. M., C. L. Crawford, B. C. Ha, and N. E. Bibler. 1998a. Vitrification of Three Low-Activity Radioactive Waste Streams from Hanford, in Proceedings of the International Conference on "Decommissioning and Decontamination and on Nuclear and Hazardous Waste Management," pp. 706-713. Spectrum '98 Vol. 1, American Nuclear Society, Inc., La Grange Park, lllinois.

Ferrara, D. M., C. L. Crawford, B. C. Ha, N. E. Bibler and A. S. Choi. 1998b. Vitrification of Four Radioactive Hanford Waste Samples (U). SRTC-BNFL-023, Rev. 2. Savannah River Technology Center, Aiken, South Carolina.

Fiskum, S. K., D. E. Kurath, and B. M. Rapko. 2000. Development and Demonstration of a Sulfate Precipitation Process for Hanford Waste Tank 241-AN-107. BNFL-RPT-029, PNWD-3050 (to be published), Battelle, Pacific Northwest Division, Richland, Washington.

Hallen, R. T., P. R. Bredt, K. P. Brooks, and L. K. Jagoda. 2000. Combined Entrained Solids and Sr/TRU் Removal from AN-107 Diluted Feed. BNFL-RPT-027, PNWD-3035 (to be published), Battelle, Pacific Northwest Division, Richland, Washington.

Kim, D. S., P. R. Hrma, S. E. Palmer, and D. E. Smith. 1995. "Effect of $\mathrm{B}_{2} \mathrm{O}_{3}, \mathrm{CaO}$, and $\mathrm{Al}_{2} \mathrm{O}_{3}$ on the Chemical Durability of Silicate Glasses for Hanford Low-Level Waste Immobilization," in Proceedings of the International Symposium on "Environmental Issues and Waste Management Technologies in the Ceramic and Nuclear Industries," pp. 531-538. Ceramic Transactions, Vol. 61, The American Ceramic Society, Westerville, Ohio.

Kurath, D. E., D. L. Blanchard, and J. R. Bontha. 2000a. Small Column Ion Exchange Testing of Superlig 644 for Removal of ${ }^{137}$ Cs from Hanford Tank Waste Envelope C (Tank 241-AW-101), PNWD-3001, Battelle, Pacific Northwest Division, Richland, Washington. 
Kurath, D. E., D. L. Blanchard, and JR Bontha. 2000b. Small Column Ion Exchange Testing of Superlig 644 for Removal of ${ }^{137}$ Cs from Hanford Tank Waste Envelope C (Tank 241-AN-107), PNWD-3039, Battelle, Pacific Northwest Division, Richland, Washington.

PNNL Operating Procedure, PNL-ALO-103, Rev. 1, 1990. "Water Leach of Sludges and Soils," Pacific Northwest National Laboratory, Richland, Washington.

PNNL Operating Procedure, PNL-ALO-114, Rev 1, 1995. "Solubilization of Metals from Solids Using Na2O2 Fusion," Pacific Northwest National Laboratory, Richland, Washington.

PNNL Operating Procedure, PNL-ALO-115, Rev 1, 1995. "Solubilzatioin of Metals from Solids Using KOH-KNO3 Fusion," Pacific Northwest National Laboratory, Richland, Washington.

PNNL Operating Procedure, PNL-ALO-211, Rev. 0, 1991. "Determination of Elements by Inductively Coupled Argon Plasma Atomic Emission Spectrometry," Pacific Northwest National Laboratory, Richland, Washington.

PNNL Operating Procedure, PNL-ALO-212, Rev. 1, 1992. "Determination of Inorganic Anions by Ion Chromatography," Pacific Northwest National Laboratory, Richland, Washington.

PNNL Operating Procedure, PNL-ALO-280, Rev. 1, 1993. "Inductively Coupled Argon Plasma Atomic Emission Spectrometry (ICP/MS) Analysis," Pacific Northwest National Laboratory, Richland, Washington.

PNNL Operating Procedure, PNL-ALO-281, Rev. 1, 1993. "(ICP/MS) Determination of 99Tc," Pacific Northwest National Laboratory, Richland, Washington.

PNNL Operating Procedure, PNL-ALO-282, Rev. 1, 1996. "Determination of Uranium Concentration/Isotopic Composition Using ICP/MS," Pacific Northwest National Laboratory, Richland, Washington.

PNNL Operating Procedure, PNL-ALO-381, Rev. 1, 1995. "Direct Determination of TC, TOC, and TIC in Radioactive Sludges and Liquids by Hot Persulfate Method," Pacific Northwest National Laboratory, Richland, Washington.

PNNL Operating Procedure, RPG-CMC-408, Rev 0, 1999. "Total Alpha and Beta Analysis," Pacific Northwest National Laboratory, Richland, Washington.

PNNL Operating Procedure, PNL-ALO-417, Rev 2. 1996. "Separation of U, Am/Cm, and Pu and Actinide Screen by Extraction Chromatography," Pacific Northwest National Laboratory, Richland, Washington.

PNNL Operating Procedure, PNL-ALO-422, Rev 0, 1992. "Solution Analysis: Alpha Spectrometry," Pacific Northwest National Laboratory, Richland, Washington.

PNNL Operating Procedure, PNL-ALO-432, Rev. 0, 1992. "Separation of Technetium by Cation Exchange and Solution Extraction Prior to Measurement by Beta Counting," Pacific Northwest National Laboratory, Richland, Washington. 
PNNL Operating Procedure, PNL-ALO-450, Rev. 1, 1993. "Gamma Energy Analysis (GEA) and Low-Energy Photon Spectrometry (LEPS)," Pacific Northwest National Laboratory, Richland, Washington.

PNNL Operating Procedure, PNL-ALO-476, Rev. 1, 1995. "Strontium Determination Using SR-SPEC," Pacific Northwest National Laboratory, Richland, Washington.

PNNL Operating Procedure, PNL-ALO-496, Rev 1, 1994. "Precipitation Plating of Actinides for High-Resolution Alpha Spectrometry," Pacific Northwest National Laboratory, Richland, Washington.

Smith, G. L. 1993. Characterization of Analytical Reference Glass-1 (ARG-1). PNL-8992, Pacific Northwest National Laboratory, Richland, Washington.

Urie, M. W., J. J. Wagner, L. R. Greenwood, O. T. Farmer, S. K. Fiskum, R. T. Ratner, C. Z. Soderquist. 1999a. Inorganic and Radiochemical Analysis of AW-101 and AN-107 Tank Waste. PNWD-2462,

Battelle, Pacific Northwest Division, Richland, Washington.

Urie, M. W., J. J. Wagner, L. R. Greenwood, O. T. Farmer, S. K. Fiskum, R. T. Ratner, C. Z. Soderquist. 1999b. Inorganic and Radiochemical Analysis of AW-101 and AN-107 "Diluted Feed" Materials.

PNWD-2463, Battelle, Pacific Northwest Division, Richland, Washington. 


\section{Appendix A: LAW Radioactive Glass Analysis Data}


Table A.1. Radioactive AW-101 Glass Chemical Composition Data.

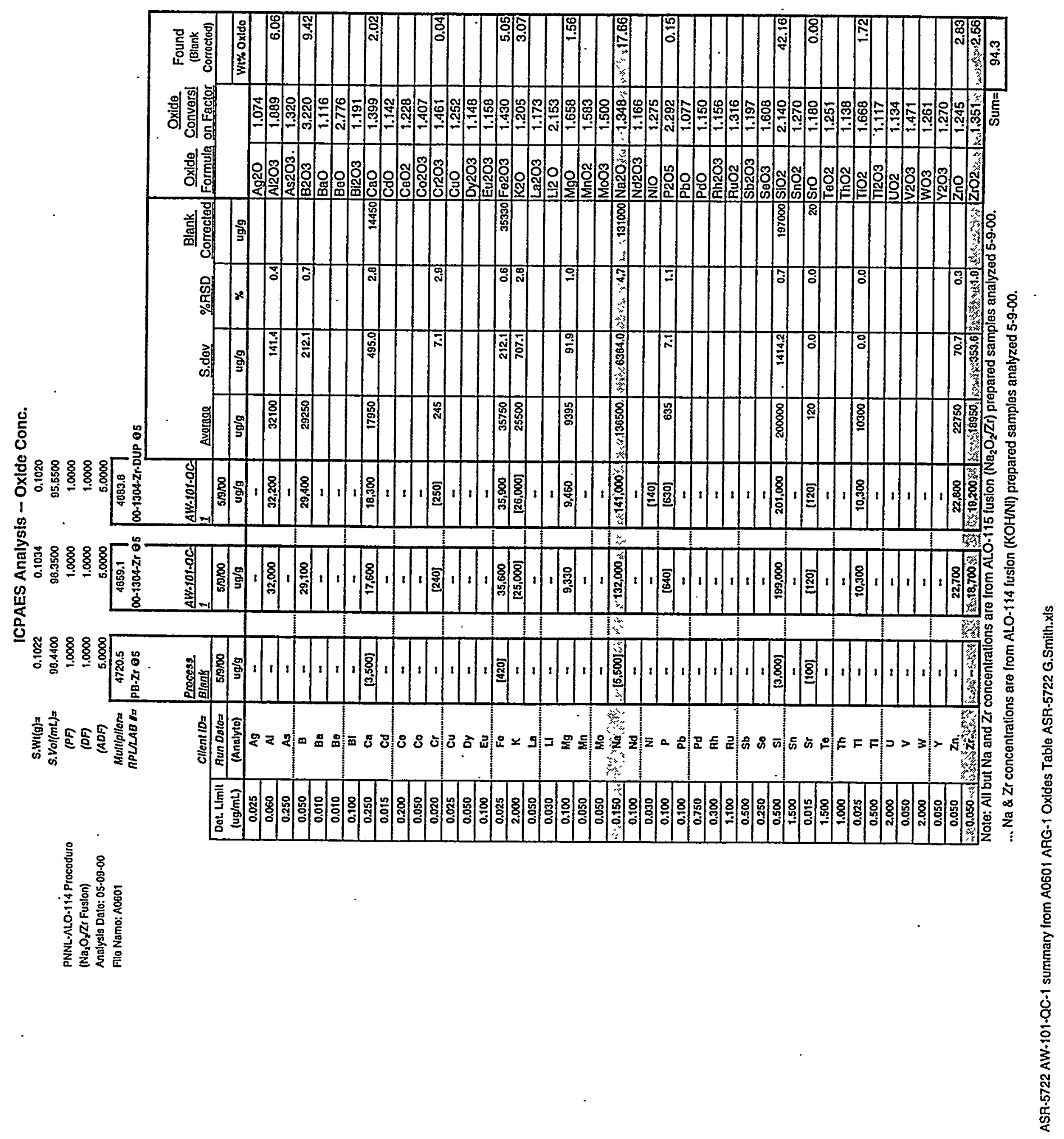


Table A.2. Radioactive AN-107 Glass Chemical Composition Data.

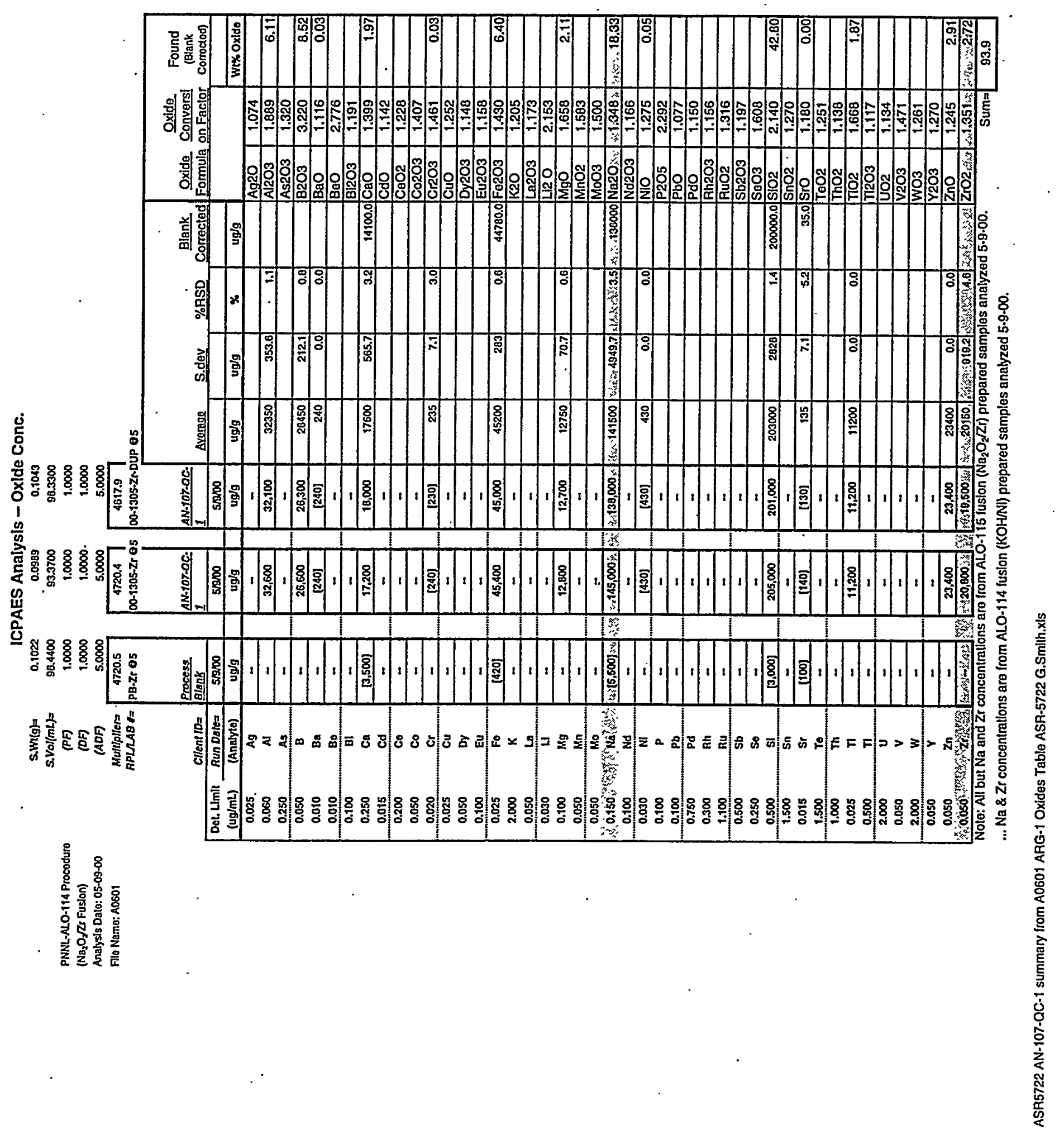




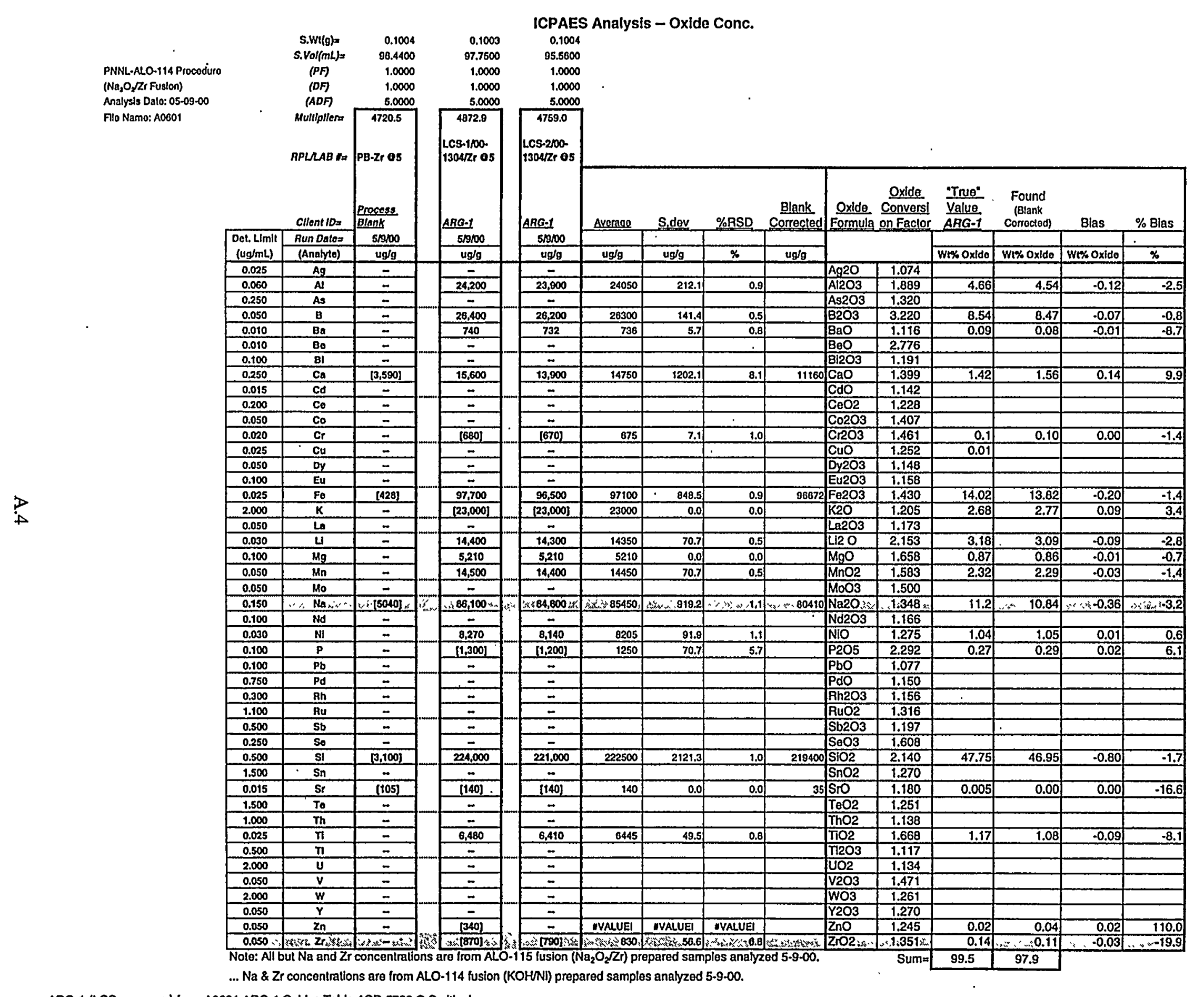


Battelle Pacific Northwest Laboratory

Radiochemical Processing Group-325 Building

'Chemical Measurements Center

\section{Client: G. Smith}

Cognizant Scientist:

Concur :

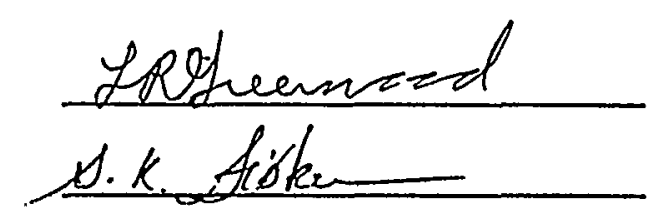

00-1304

$5 / 26 / 2000$

Measured Activities (uCi/g) with 1-sigma error

\begin{tabular}{|c|c|c|c|c|c|c|c|c|c|c|}
\hline \multirow[b]{2}{*}{$\begin{array}{l}\text { ALO ID } \\
\text { Client ID } \\
\end{array}$} & \multirow{2}{*}{$\begin{array}{c}\text { Pu-239+ } \\
\text { Pu-240 } \\
\text { Error \% }\end{array}$} & \multirow[b]{2}{*}{$\begin{array}{l}\text { Pu-238 } \\
\text { Error \% }\end{array}$} & \multirow[b]{2}{*}{$\begin{array}{l}\text { Pu-236 } \\
\text { Error \% }\end{array}$} & \multicolumn{3}{|c|}{$\mathrm{Cm}-243+$} & \multirow[b]{2}{*}{$\begin{array}{c}\text { Sr-90 } \\
\text { Error \% }\end{array}$} & \multicolumn{3}{|c|}{ Gamma Energy Analysis* } \\
\hline & & & & $\begin{array}{l}\text { Am-241 } \\
\text { Error \% } \\
\end{array}$ & $\begin{array}{l}\text { Cmi-244 } \\
\text { Error \% } \\
\end{array}$ & $\begin{array}{l}\text { Cm-242 } \\
\text { Error \% } \\
\end{array}$ & & $\begin{array}{c}\text { Co-60 } \\
\text { Error \% }\end{array}$ & $\begin{array}{l}\text { Cs-137 } \\
\text { Error \% }\end{array}$ & $\begin{array}{l}\text { Eu-154 } \\
\text { Error \% }\end{array}$ \\
\hline $\begin{array}{l}00-1304 P B \\
A W 101-Q C-1\end{array}$ & $<5 . E-6$ & $<2 . E-5$ & $<3 . E-6$ & $<4 . E-6$ & <4.E-6 & $<4 . E-6$ & $<2 . E-3$ & $<1 . E-3$ & $<2 . E-3$ & $<3 . E-3$ \\
\hline $\begin{array}{l}00-1304 \\
\text { AW101-QC-1 }\end{array}$ & $\begin{array}{c}3.29 E-5 \\
17 \%\end{array}$ & $<5$. E-6 & $<2 . E-6$ & $\begin{array}{c}3.80 E-5 \\
17 \%\end{array}$ & $<6 . E-6$ & $<2$.E-6 & $\begin{array}{c}1.59 E-1 \\
4 \%\end{array}$ & $<2 . E-3$ & $\begin{array}{c}8.68 E-2 \\
2 \%\end{array}$ & $<3 . E-3$ \\
\hline $\begin{array}{l}\text { 00-1304 DUP } \\
\text { AW101-QC-1 }\end{array}$ & $\begin{array}{c}3.80 E-5 \\
17 \%\end{array}$ & $<3 . E-6$ & $<3 . E-6$ & $<3 . E-5$ & $<2$.E-5 & $<7 . E-6$ & $\begin{array}{c}1.66 E-1 \\
4 \%\end{array}$ & $<2 . E-3$ & $\begin{array}{c}8.61 E-2 \\
3 \%\end{array}$ & $<3 . E-3$ \\
\hline RPD & $14 \%$ & & & . & & & $4 \%$ & & $1 \%$ & \\
\hline $\begin{array}{l}00-1305 \\
\text { AN107-QC-1 }\end{array}$ & $\begin{array}{c}4.29 E-4 \\
6 \%\end{array}$ & $\begin{array}{c}1.18 E-4 \\
10 \%\end{array}$ & $<3 . E-6$ & $\begin{array}{c}1.88 E-3 \\
7 \%\end{array}$ & $\begin{array}{c}3.08 E-5 \\
36 \%\end{array}$ & $<6 . E-6$ & $<2 . E-3$ & $\begin{array}{c}5.63 E-2 \\
3 \%\end{array}$ & $\begin{array}{c}1.11 E-1 \\
3 \%\end{array}$ & $\begin{array}{c}5.54 E-3 \\
20 \%\end{array}$ \\
\hline $\begin{array}{l}00-1305 \text { DUP } \\
\text { AN107-QC-1 }\end{array}$ & $\begin{array}{c}3.91 E-4 \\
6 \%\end{array}$ & $\begin{array}{c}8.19 E-5 \\
13 \%\end{array}$ & $<8 . E-6$ & $\begin{array}{c}2.01 E-3 \\
7 \%\end{array}$ & $<2 . E-5$ & $<7$. E-6 & $<2 . E-3$ & $\begin{array}{c}5.64 E-2 \\
3 \%\end{array}$ & $\begin{array}{c}1.06 E-1 \\
3 \%\end{array}$ & $\begin{array}{c}5.26 \mathrm{E}-3 \\
20 \%\end{array}$ \\
\hline $\begin{array}{l}\text { RPD } \\
\text { MD }\end{array}$ & $9 \%$ & $\begin{array}{l}36 \% \\
1.14\end{array}$ & & $7 \%$ & & & . & $0 \%$ & $5 \%$ & $5 \%$ \\
\hline Blank Spike & $103 \%$ & & & $96 \%$ & & & $94 \%$ & & & \\
\hline Matrix Spike & $107 \%$ & & & $95 \%$ & & & $86 \%$ & & & \\
\hline Blank & $<4 . E-6$ & $<3 . E-6$ & $<2 . E-6$ & $\begin{array}{c}7.73 E-6 \\
44 \%\end{array}$ & <3.E-6 & $<2$.E-6 & $<2 . E-3$ & & & \\
\hline
\end{tabular}

Date: $5 / 26 / 00$

Date: $5 / 26 / 00$

*Note: Gamma energy analysis did not detect any activity for Cr-51, Fe-59, Nb-95, Ru-103, Sn-113, or Eu-152. 
Table A.5. Radioactive AW-101 and AN-107 Glass Radiochemical Composition Data: GEA Detection Limits.

Battelle Pacific Northwest Laboratory

Radiochemical Processing Group-325 Building

Chemical Measurements Center

Client: G. Smith

Cognizant Scientist:

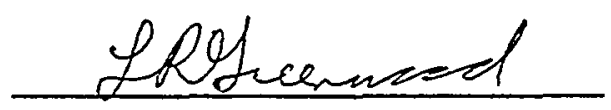

Concur :

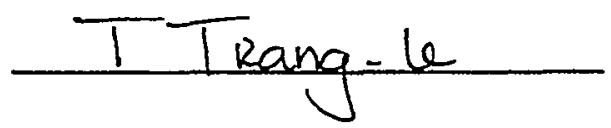

00-1304

$5 / 24 / 00$

Detection Limits for Additional Gamma Emitters Requested in ASR 5772

Measured Activities ( $\mathrm{uCi} / \mathrm{g}$ ) with 1-sigma error

\begin{tabular}{|c|c|c|c|c|c|c|}
\hline \multirow[b]{2}{*}{$\begin{array}{l}\text { ALO ID } \\
\text { Client ID }\end{array}$} & \multicolumn{6}{|c|}{ Gamma Energy Analysis } \\
\hline & $\begin{array}{c}\text { Cr-51 } \\
\text { Error \% }\end{array}$ & $\begin{array}{c}\text { Fe-59 } \\
\text { Error \% }\end{array}$ & $\begin{array}{l}\mathrm{Nb}-95 \\
\text { Error \% }\end{array}$ & $\begin{array}{l}\text { Ru-103 } \\
\text { Error \% }\end{array}$ & $\begin{array}{c}\text { Snln-113 } \\
\text { Error \% }\end{array}$ & $\begin{array}{l}\text { Eu-152 } \\
\text { Error \% }\end{array}$ \\
\hline $\begin{array}{l}00-1304 \text { PB } \\
\text { AW101-QC-1 }\end{array}$ & $<9 . E-3$ & $<2$.E-3 & $<1 . E-3$ & $<1$.E-3 & $<2 . E-3$ & $<5$.E-3 \\
\hline $\begin{array}{l}00-1304 \\
\text { AW101-QC-1 }\end{array}$ & $<1 . E-2$ & $<2$.E-3 & $<1 . E-3$ & $<1 . E-3$ & $<2 . E-3$ & $<5 . E-3$ \\
\hline $\begin{array}{l}\text { 00-1304 DUP } \\
\text { AW101-QC-1 }\end{array}$ & $<1 . E-2$ & $<2 . E-3$ & $<1 . E-3$ & $<2$.E-3 & $<2 . E-3$ & $<5 . E-3$ \\
\hline $\begin{array}{l}00-1305 \\
\text { AN107-QC-1 }\end{array}$ & $<2 . E-2$ & $<4 . E-3$ & $<2 . E-3$ & $<2 . E-3$ & $<3 . E-3$ & $<6$.E-3 \\
\hline $\begin{array}{l}00-1305 \text { DUP } \\
\text { AN107-QC-1 }\end{array}$ & $<2 . E-2$ & $<3 . E-3$ & $<2 . E-3$ & $<2 . E-3$ & $<3 . E-3$ & $<7 . E-3$ \\
\hline
\end{tabular}


Table A.6. Radioactive AW-101 and AN-107 Glass Radiochemical Composition Data: ICP-MS.
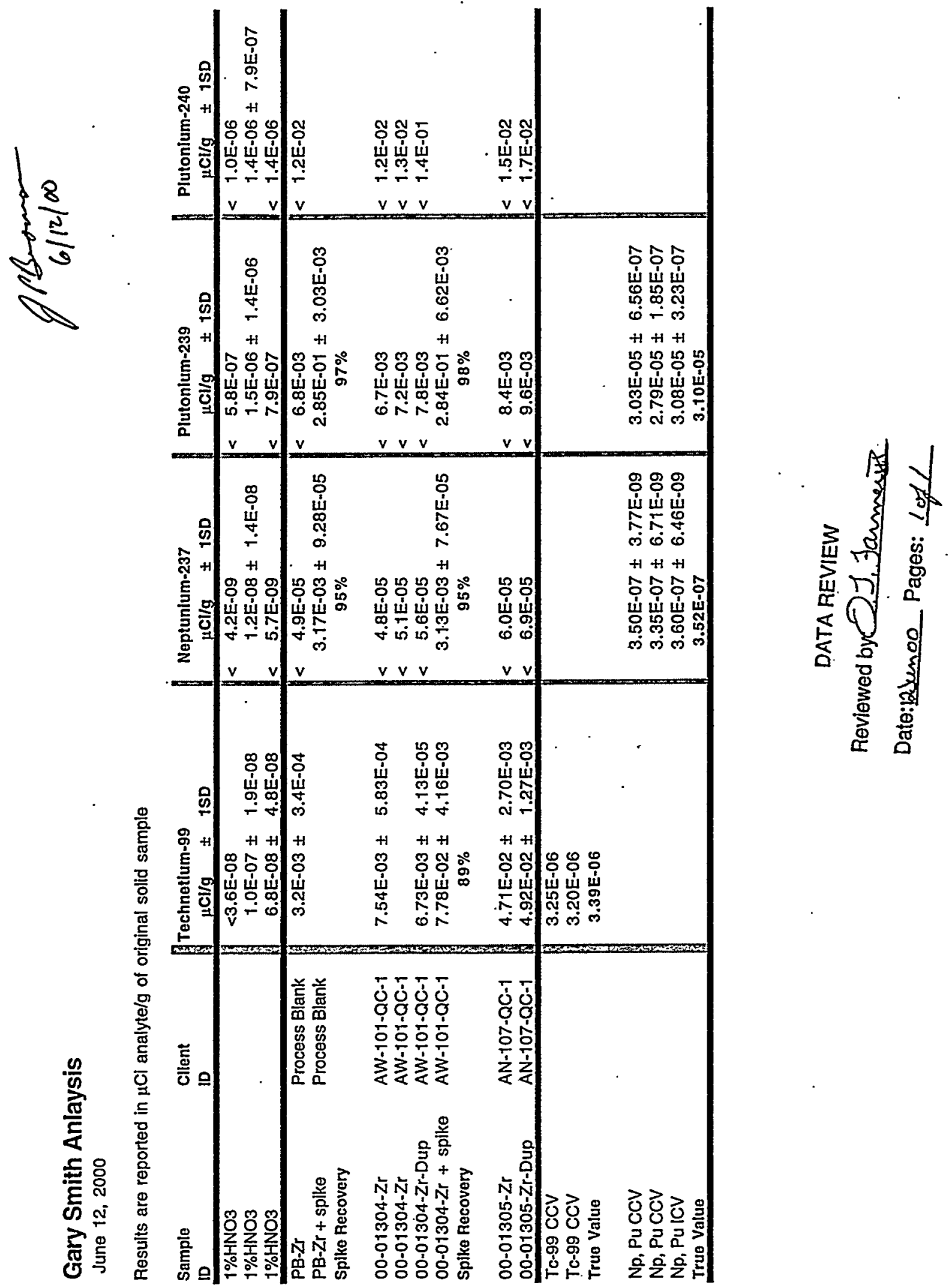


\section{Appendix B: Crystalline and Non-Crystalline Phase Determination Data}




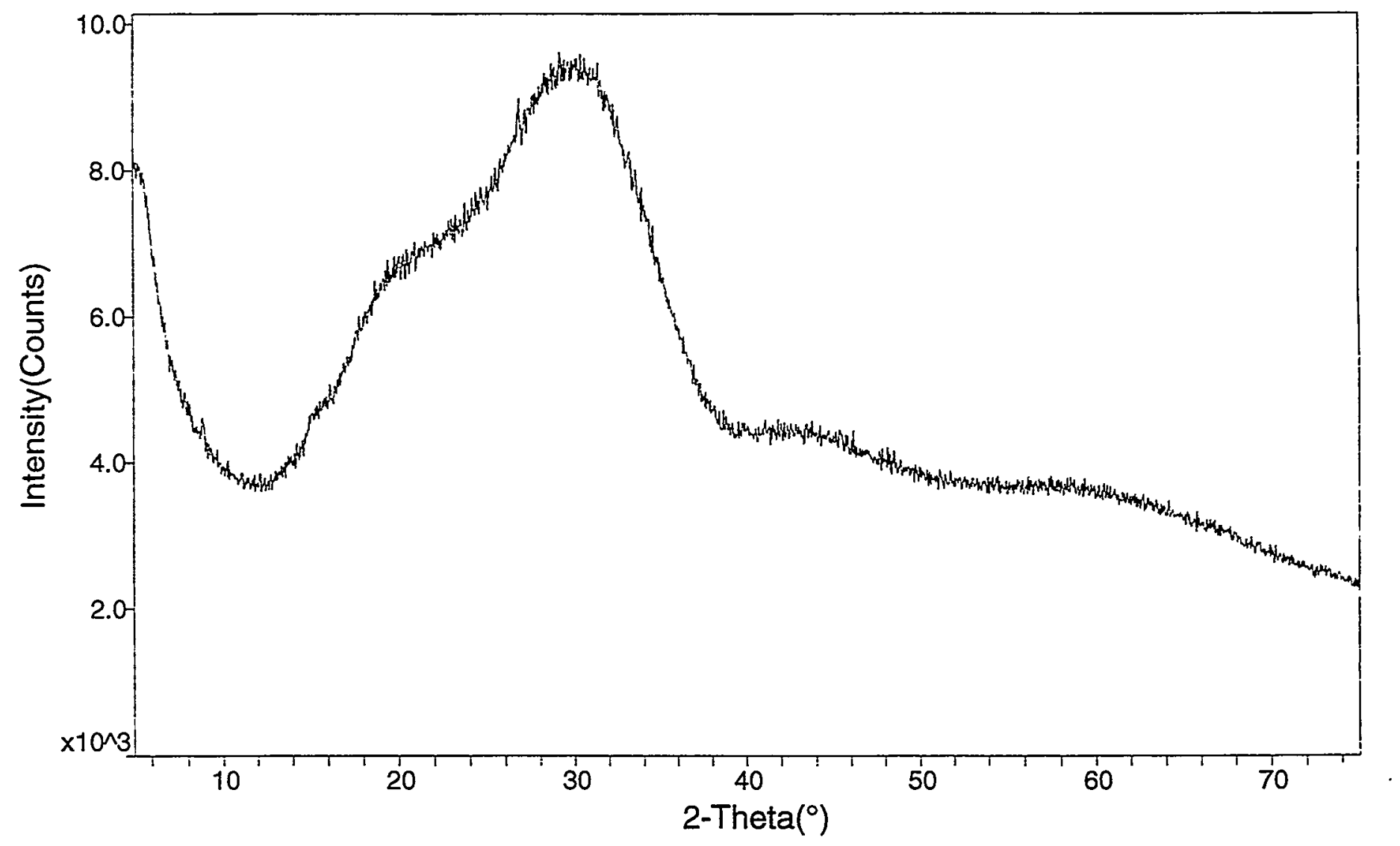

Figure B.1. Radioactive AW-101 Glass Powder X-Ray Diffraction Results for Glass Heated to Simulate the Calculated ILAW Centerline Cooling Curve of a LAW Canister of Glass 2/5 of the Way from the Bottom of the Canister. Note the completely amorphous character of this profile. 


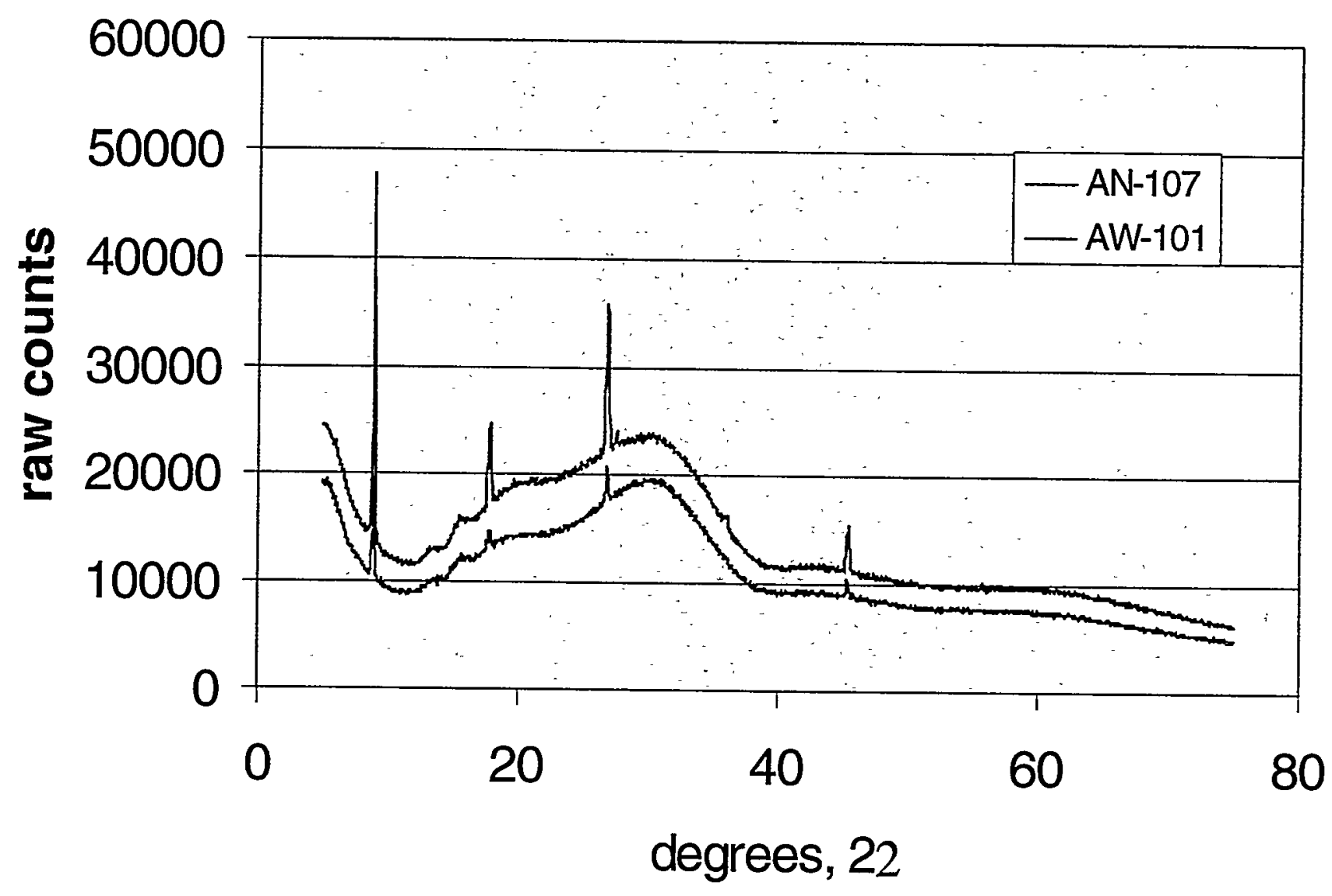

Figure B.2. Radioactive AW-101 and AN-107 Glass Powder X-Ray Diffraction Results for Glass Heated to Simulate the Calculated ILAW Centerline Cooling Curve of a LAW Canister of Glass 2/5 of the Way from the Bottom of the Canister. Note the amorphous character of these profiles with crystal XRD peaks superimposed. These peaks were subsequently found to match peaks from powder on the glove worn when these powder mounts were made up. See Figure B-3. 


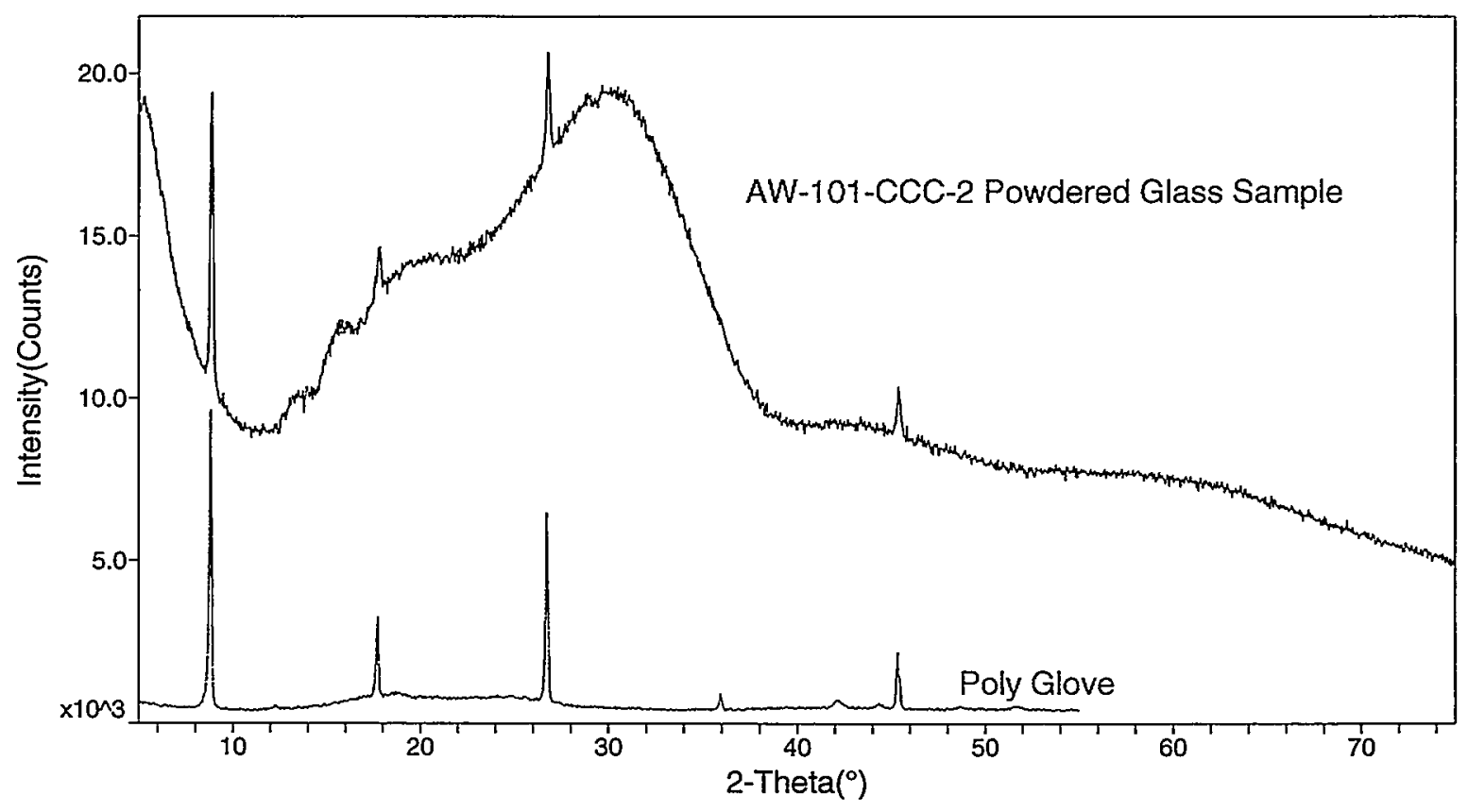

Figure B.3. Radioactive AW-101 Glass Powder X-Ray Diffraction Results for Glass Heated to Simulate the Calculated ILAW Centerline Cooling Curve of a LAW Canister of Glass $2 / 5$ of the Way from the Bottom of the Canister. This initial XRD profile shows crystalline peaks that are identical with the XRD peaks produced by the mineral powder used to dust the gloves. 


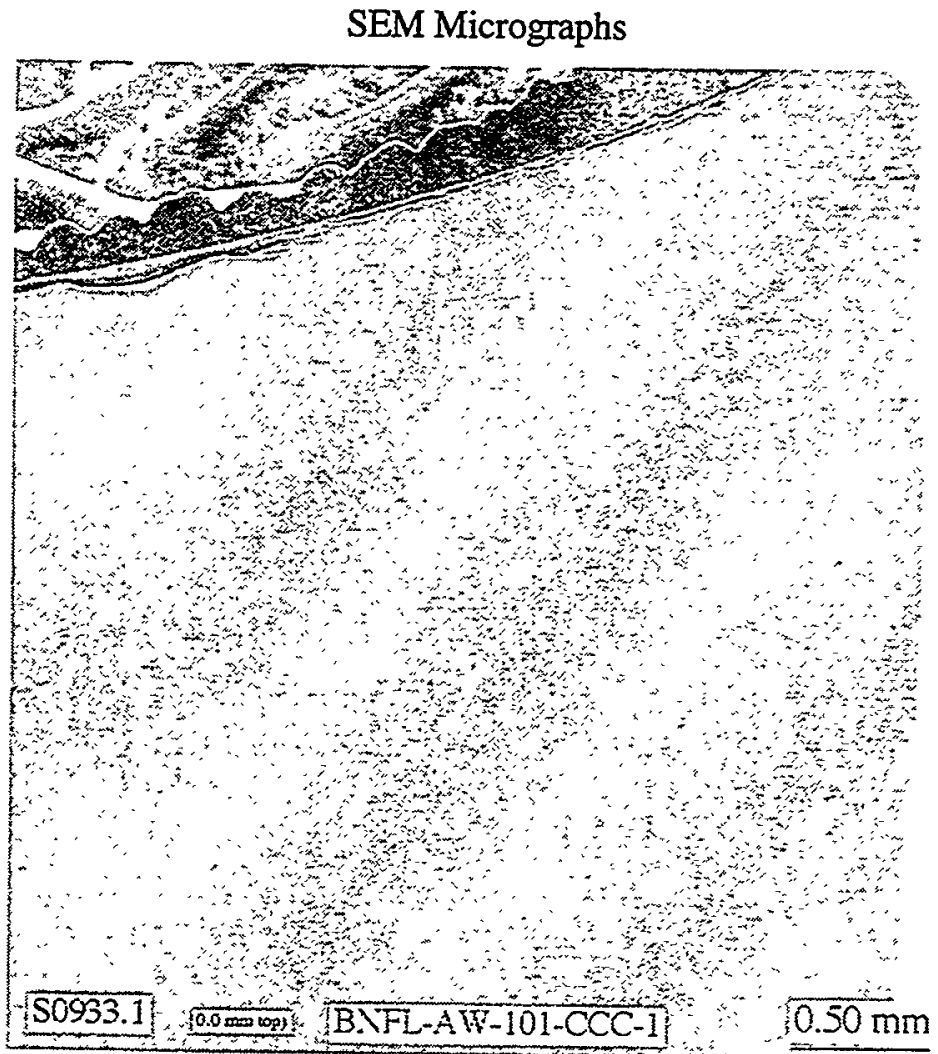

Figure B.4. Radioactive AW-101 Glass SEM Micrograph from a Glass Sample Heated to Simulate the Calculated ILAW Centerline Cooling Curve of a LAW Canister.

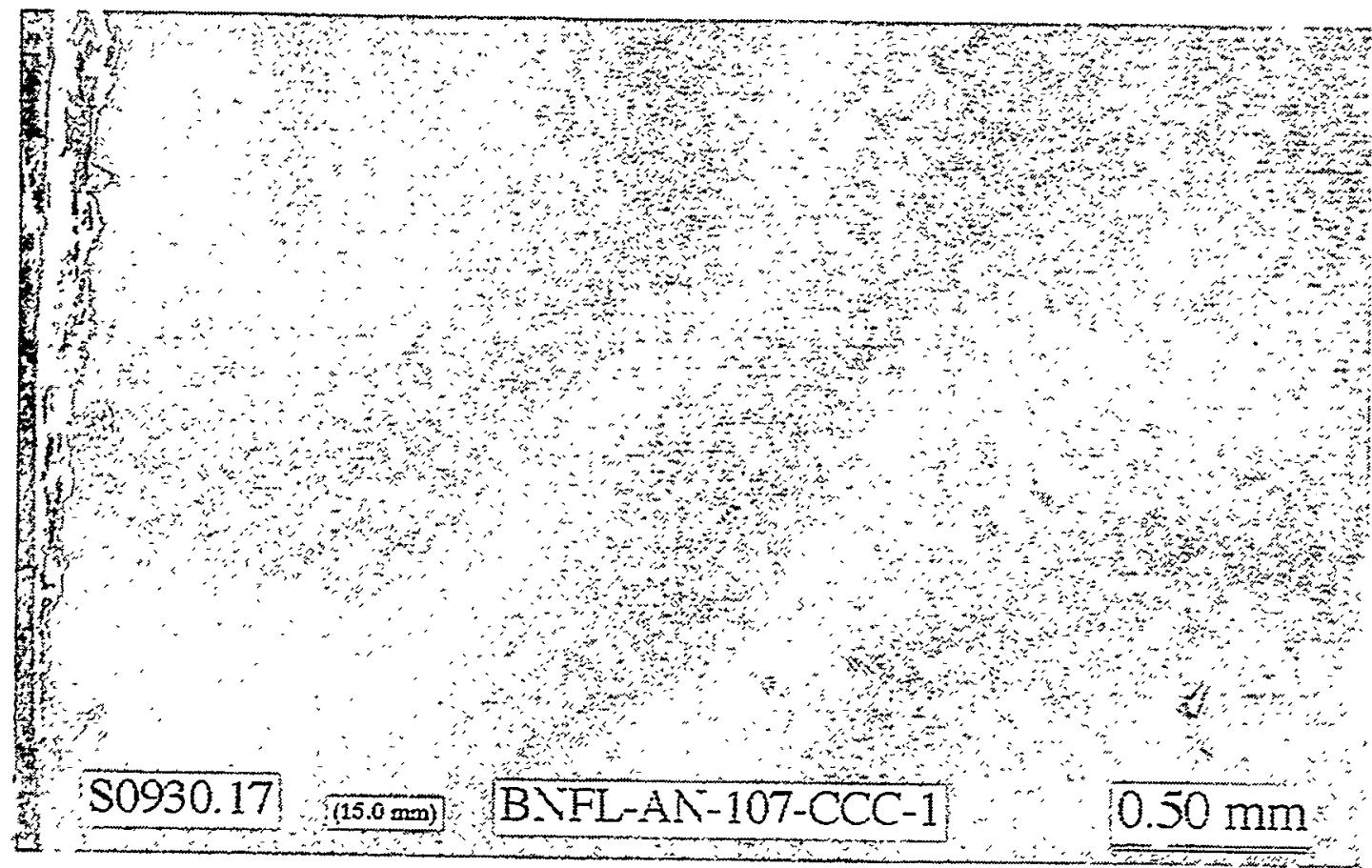

Figure B.5. Radioactive AN-107 Glass SEM Micrograph from a Glass Sample Heated to Simulate the Calculated ILAW Centerline Cooling Curve of a LAW Canister. 


\section{Appendix C: Release Rate, Modified Product Consistency Test (PCT) Data}

C.1 
Table C.1. Product Consistency Testing (PCT) Leachate Analysis Data.

Battelle PNNL/RPG/Inorganic Analysis ... ICPAES Data Report Page 1 of 5

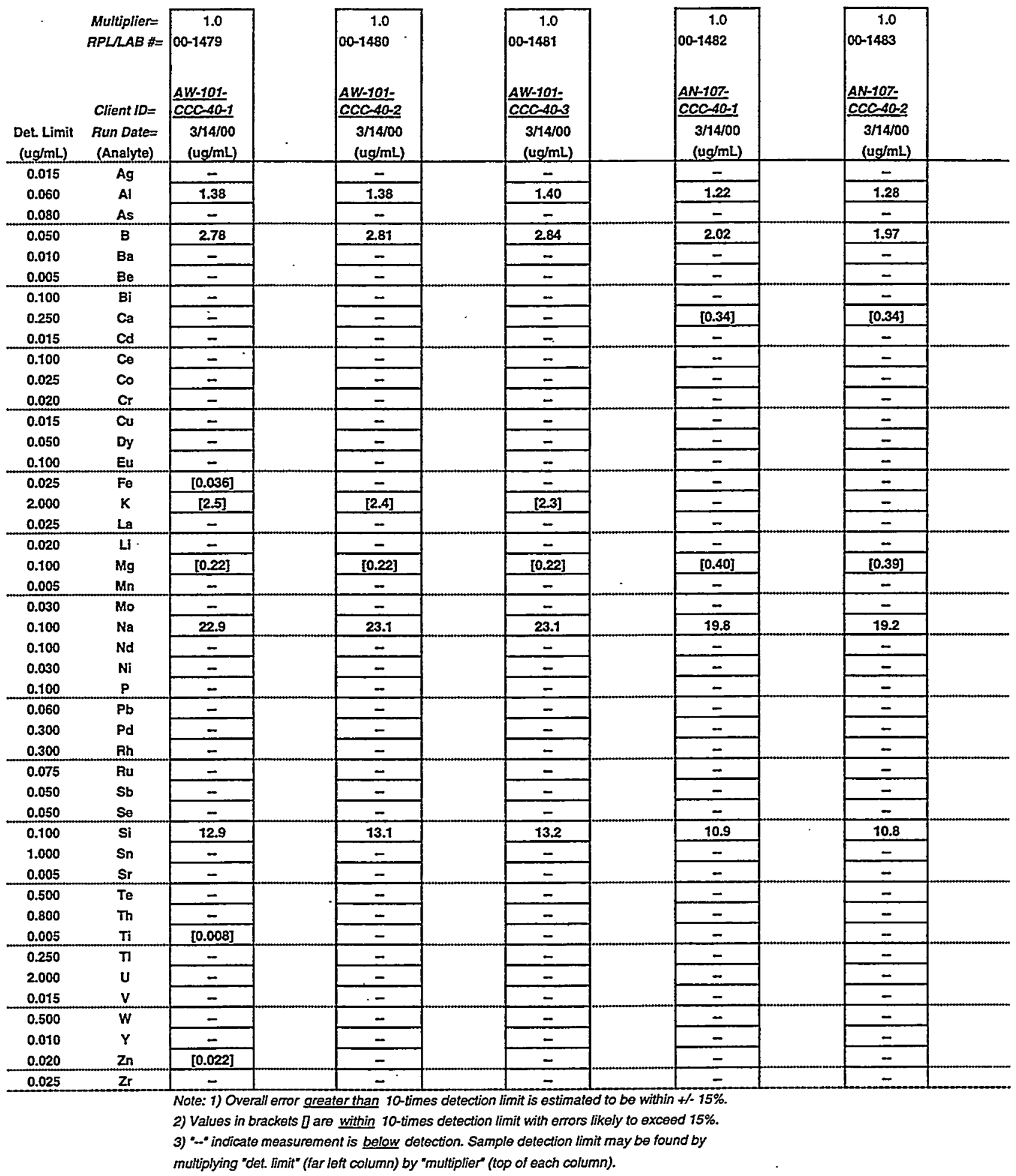


Table C.2. Product Consistency Testing (PCT) Leachate Analysis Data.

Battelle PNNL/RPG/Inorganic Analysis ... ICPAES Data Report Page 2 of 5

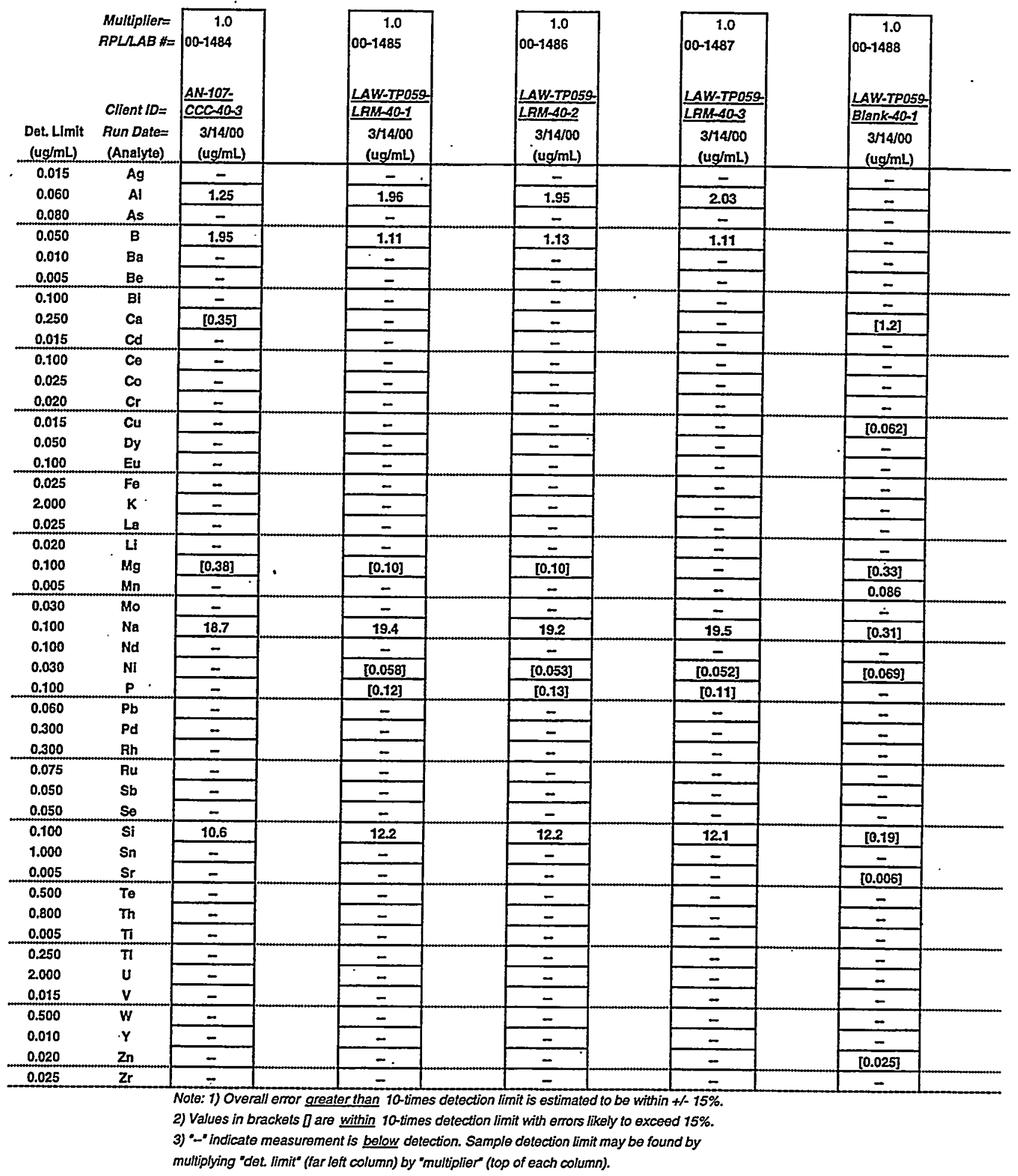


Table C.3. Product Consistency Testing (PCT) Leachate Analysis Data.

\section{Battelle PNNL/RPG/Inorganic Analysis ... ICPAES Data Report Page 3 of 5}

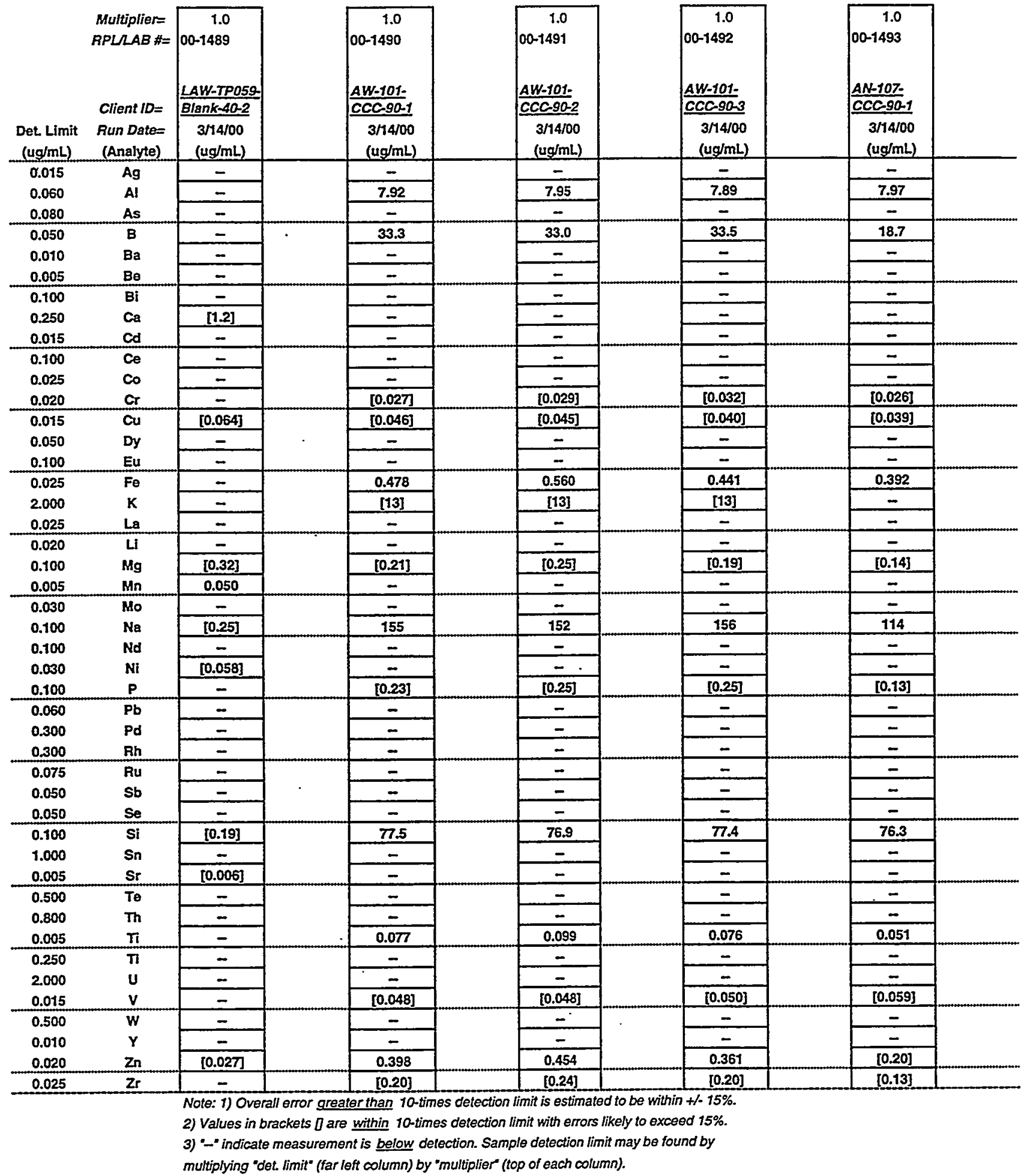


Table C.4. Product Consistency Testing (PCT) Leachate Analysis Data.

Battelle PNNL/RPG/Inorganic Analysis ... ICPAES Data Report Page 4 of 5

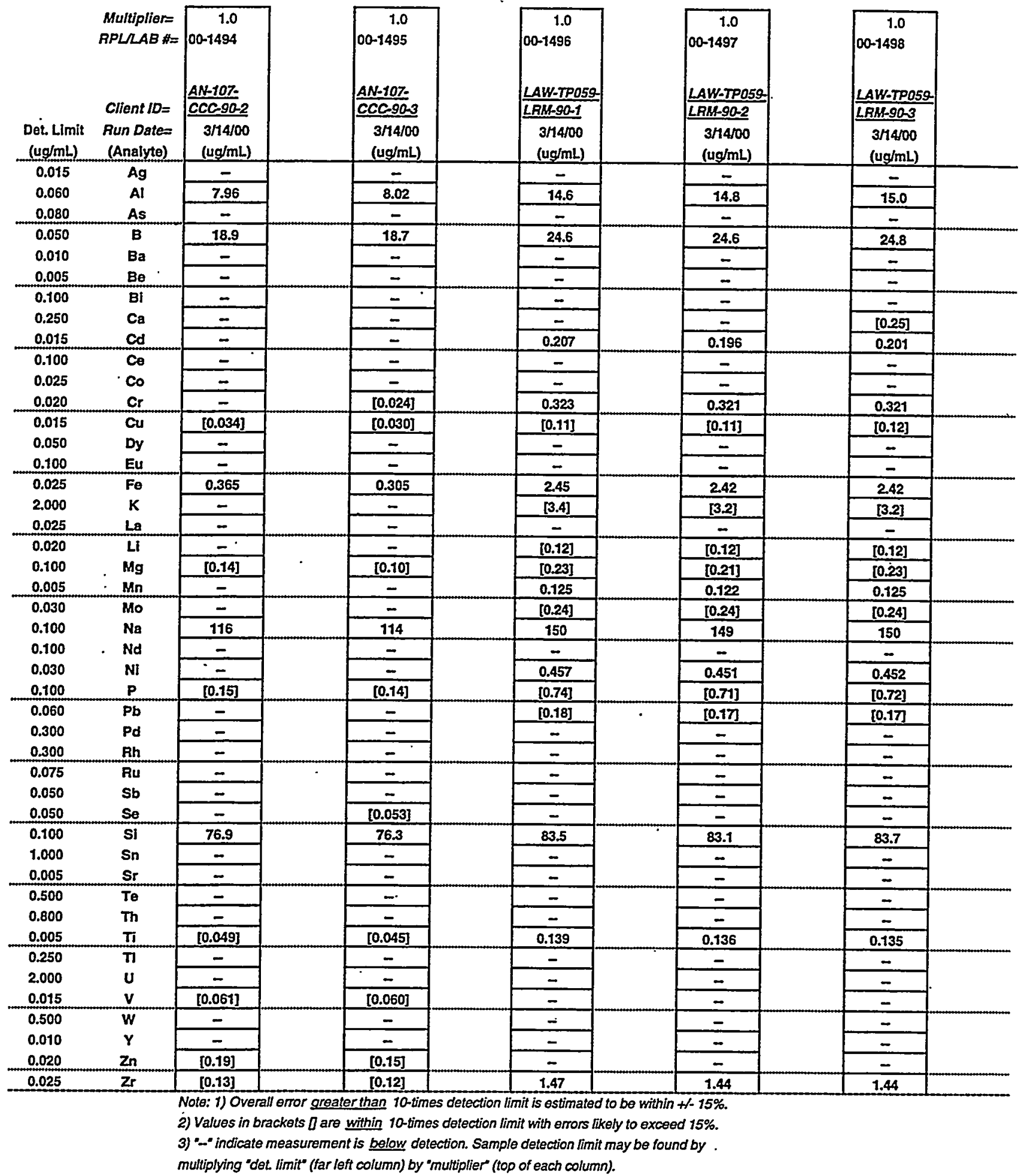


Table C.5. Product Consistency Testing (PCT) Leachate Analysis Data.

Battelle PNNL/RPG/Inorganic Analysis ... ICPAES Data Report Page 5 of 5

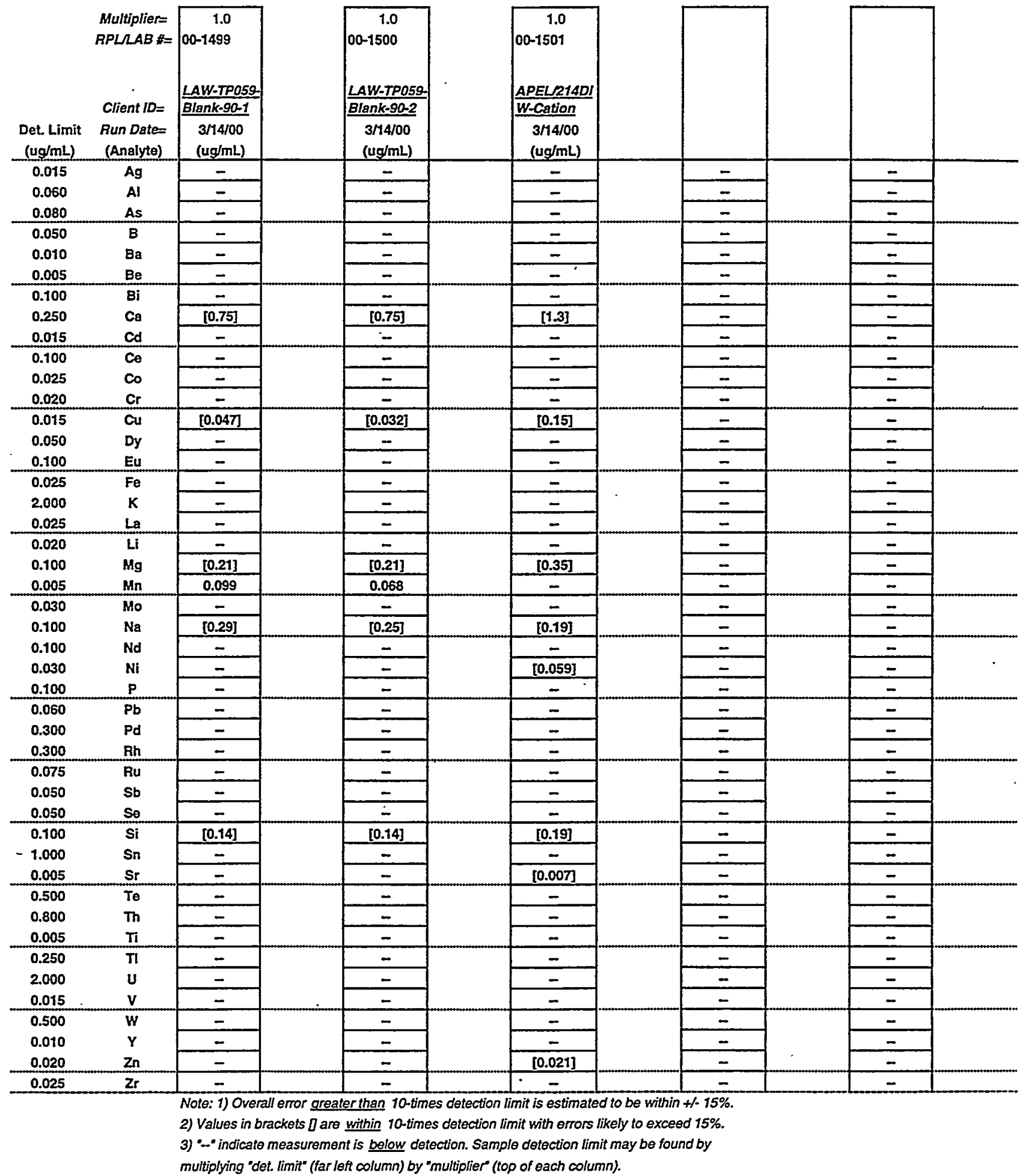


PNNL-13372

WTP-RPT-003, Rev. 0

Distribution

No. of

Copies

OFFSITE

2 DOE/Office of Scientific and Technical Information

1 Harold Sturm

Savannah River Technology Center

PO Box 616, Road 1

Building 773-A, Room A-233

Aiken, SC 29808

1 Paul Townson

BNFL, Inc

3000 George Washington Way

Richland, WA 99352

1 Ed Higginbotham

BNFL; Inc

3000 George Washington Way

Richland, WA 99352
No. of

Copies

ONSITE

$7 \quad$ CH2M Hill Hanford Group, Inc.

S. T. Arm

$\mathrm{H} 4-02$

T. W. Crawford

$\mathrm{H} 4-02$

M. E. Johnson (4)

$\mathrm{H} 4-02$

A. Thompson

$\mathrm{H} 4-02$

15 Pacific Northwest National Laboratory

L. R. Greenwood

P7-22

G. F. Piepel

$\mathrm{K} 5-12$

M. J. Schweiger

K6-24

H. D. Smith

K6-24

G. L. Smith (3)

K6-24

M. W. Urie

P7-22

J. J. Wagner

P7-22

Project Office

P7-28

Technical Report Files (5) K1-06

Distr. 1 